\title{
The role of structures in semiotic systems: Analysis of some ideas of Leonardo da Vinci and the portrait Lady with an Ermine
}

\author{
GEORGIJ YU. SOMOV
}

Postprint $^{*}$ v1.0

\begin{abstract}
* Somov, G. (2008). The role of structures in semiotic systems: Analysis of some ideas of Leonardo da Vinci and the portrait Lady with an Ermine. Semiotica, 2008(172), pp. 411-477. Retrieved 28 Sep. 2017, from doi:10.1515/SEMI.2008.106
\end{abstract}

Abstract

The formation of all sign systems is based on structures. Structures support the functioning of codes and organization of denotations, connotations, and groups of signs of visual art works. Due to codes, structure interrelations are manifested in characteristics, relations, differences-identities, and groups of elements, forming the structure of an art work. This role of structures was examined in the frames of theoretical ideas of antiquity and Renaissance. Its most complete application to the visual art is manifested in the ideas by Leonardo da Vinci. Developed structures organizing sign systems are illustrated by the analysis of Lady with an Ermine.

Keywords: semiotics; structures; connotations; sign systems; Leonardo da

Vinci; Lady with an Ermine.

\section{Introduction}

According to methodological ideas, the structures relate different levels of reality (Russell 2000 [1948]), represent the ways of interrelation and principles of texture. They are manifested in various interrelations (Kröber 1968:13-14; Klaus 1973; Greimas, Courtes 1979:314; Il'in 1972). They appear as conflicting or mutually overbuilding units and are transformed in informational processes (Tyukhtin 1977). Structural trans formations simulate object modifications. This is why they are helpful for the description of different areas and mechanisms of thinking. This role of structures is apparent in the description of identification (Rosenfeld 1969; Shekhter 1967), mechanisms of hypothetical simulation of situation (Piaget 1979), processes of guessing the organization of different objects, processes of productive acts of thinking (Dilthey 1905 [1958]:15; Hjelmslev 1948; Nöth 1998: III 2.1; Voronin et al. 1982), and mechanisms of spatial organization of architectural objects (Barbischev and Somov 1990). The structure of thinking is closely related to the structures of human languages, which was discussed separately 
(Chomsky 1972; Piaget 1979) . Structures are observed as invariants of styles and other cultural processes (Levi-Strauss 1970; Eco 1968). Moreover, there is no doubt that structures are related to the characteristics of informational processes, such as choice, prediction, and statistical expec-Tation, and their display in aesthetic perception (Moles 1966) . Structures imple-mented in thinking, perception, communication, games, and other pro-cesses of the psychic world are hardly perceptible. In connection with this, the reality of structures has been called into question was several times. The explorers were accused of constructing the structures them-selves and then treating them as real objects (Petitot-Cocorda 1985:23-26; Martinet 1962) . However, the structures created by these explorers do not abolish real structures. Many of these real structures are quite apparent (meters of architectural composition, rhythms of music, or pulsation). In semiotic systems, structures are found in codes (Eco 1968:20-27; 1973:171; 1976:9-14), different sign formations, texts, and languages.

\section{Structures, codes, and signs}

In semiotic systems, structures are inseparable from mechanisms. I tried to substantiate this when determining the theoretical objects of semiotics (Somov 2001). Correspondingly, the structures can be examined as the interrelations among interpretants, objects, and representamens, in the terms by C. S. Peirce. This triad corresponds to three groups of fundamental codes: (1) intentional, (2) codes of object character, and (3) organizational (Somov 2006, 2007a). Sign formations of visual art works are realized due to these three groups of fundamental natural codes and their interrelations in cultural codes. This corresponds to a semiotic idea that cultural codes are built over natural ones (Chandler 1994) and, in total, form the culture (Danesi 1999).

Structures of intentional codes (1) represent the interrelations among intentions, representamens, and reactions (Somov 2003). Intentions form fundamental centers of interpretation. This corresponds completely to the idea of organism interpretation (Morris 1971) and understanding of codes as interpreting devices (Deacon et al. 1999: 139). Emotional meanings (danger and security, threat and attractiveness, tension and relaxation, anxiety and rest, etc.) are incarnated in intentional codes. Intentional codes are spread to the sphere of interrelations of communicants (features of aggression or compassion, indifference or interest). Semiotic systems of visual art involve codes of intentionality of different spheres of inter-relations with the natural environment, living beings, other people, and objects. This is why the manifestations of fundamental intentional codes 
are numerous in visual art (emotional characteristics of rest and dynamics, abrupt rhythms, fluttering, sharp, broken, or smooth contours, warm and cold colors, threatening gestures, or caressing motions). In visual art, characteristics of codes (1) are based on structures. Symmetries and rhythms, topological principles, relations of temporal precedence, intervals of dimensions, and numeric values - these and other structures are implemented in characteristics: smooth, broken, closed, sharp, or mild character and direction of movement of depicted objects, directions of movement of color configurations and lines (which can be active, straight, broken, or smooth), secluded contours, mirror symmetries, rhythms, and corresponding characteristics (ascent, descent, turnover, flight, somersaults, smoothness, fluidity, identation, heaviness, lightness, force, weakness, sharpness, mildness, etc.). In the mechanisms of intentional codes, structures and characteristics of this kind mainly form a systems of indices.

Structures of codes of object character (2) represent the relations between objects and representamens. They are manifested, first of all, in the denotation of spatial-temporal relations. In visual art, an important role in revealing mutual disposition and dimensions of real objects be-longs to the structures of dissections, directions, and proportions of de-picted objects and color relations: sharp or gradual transitions from dark to light tones, from warm to cold tints, from bright to dim colors. The structures of these codes are the most apparent in the construction of geometric and aerial perspective. Predominating structures of geometric perspective are those of object articulations and dimensions, intervals of transitions from thick lines of foreground to thinner lines of remote plans. In aerial perspective, these are the structures of color relations (from warm to cold, from contrast to nuance, from dark to light ones, etc.). Identificationforming codes of object character also are based on struc-tures. Identification features rely upon structures, too: closed and open ones, numeric reiterations, symmetries, linear and point ones, and dimen-sional interrelations (Bongard 1967; Shekhter 1967; Rosenfeld 1969). In particular, visual recognition of a person is based on the following characteristics: step rhythms, proportions of figure, head, body, and typical face features. Structures of identification codes make it possible to produce allusions to some objects. I have previously tried to demonstrate that this is the basis of fine connotations (Somov 2005, 2006). The struc-tures of codes of this type mainly form icons (typical objects of reality, sign objects of life and culture).

Structures of organizational codes (3) promote mutual interrelations of different signs. Structures of these codes appear in the feeling of rhythm (e.g., in case of walking, running, sport game), in the sensation of pulses 
and rhythms of any perceived objects. Due to the structures of these codes, sign formations are organized in mutual interrelations. This is apparent in visual art works. Different relations of representamens are or-ganized: allocation of elements, dimension proportions, relations of color, configurations, textures, etc. (Somov 2007b). All elemental relations in visual art are structurally organized (Somov 1975). Structures of codes (3) 'aspire to become' structures and characteristics of codes (1) and (2). As a result, the levels of signs and semantic systems are organized.

Organizing structures of codes (3) are significant for the creation of symbols. These structures are preserved when relations and elements are changed. This corresponds to the idea of mutual replacement and mutual reversibility of symbol systems (Martynov 1966: 142). This is why the structures of codes (3) form, in Peirce's terms, the basis of development of sign systems of symbols. Earlier, I have tried to demonstrate this role of organizing structures in visual art in analyzing The Holy Trinity by A. Rublev (Somov 2007a). The articulations, organizing this icon, form symbols: heavenly world, life, earth; geometric generalization of contours, which is important in the organization of representamens, creates a sign formed in semiotic systems of culture (circle, triangle, square); contrasts of color, configurations, contours, active lines, and centers, being the ways of organization, form symbols of the Bible text.

Due to the action of codes (1), (2), and (3), their structures become interrelated. Typical objects are formed in structure interrelations: characteristics, groups of relations, differences-identities, elements, sign units. Interrelations of these objects are described in different ways in different models of languages and texts. A characteristic is subordinated to a basic structure or forms a beam of structures (realization). For example, a line incarnates the main direction, a group of points incarnates the localiza-tion of discrete formations, symmetric secluded configurations reflect symmetry structures; secluded contours incarnate topological structures (e.g., circular ones). Groups of relations of representamens also incarnate structures. In particular, object size relations (small-larger-large-enormous) incarnates a structure formed by spatial-temporal interval. The golden section is a particular manifestation of this relation. The relations of repetition represent the symmetry. Relations of colors also realize the intervals of their relations, i.e., structures.

Differences-identities relate structures, characteristics, and groups of re-lations in code mechanisms. Codes can be regarded as authentications. Differences-identities realize basic relations: interpretant - representamen (1), representamen - object (2), and representamen - representamen (3). Differences-identities are directed by a managing act (choice or decision). This is why the differences play a fundamental role in the regulation 
models as a whole (Ashby 1956). Occupying a central place in code mechanisms, differences-identities often are regarded as a nucleus of informational process. They are recognized to be language basis (Saussure 1959; Nöth 1998: III 2.1), the major universal of information (Ursul 1971), and invariants of transformations 'reality/thinking/culture' (Quine 1973). In more particular theories, differences-identities appear as facilities of action. For example, in the theory of architects-constructivists, they were regarded as fundamental means of architectural composition (Somov 1986a). As differences-identities are based on real relations and ways of relations, i.e., structures, the descriptions of binary semantic structures (Greimas and Courtes 1979), semantic differentials, and binary structures of semi-otic systems in general (Ivanov 1978; 2008) were developed. In the groups of relations and elements, identities rely upon the structures of relation groups, depending on the degree of their isomorphism. Identity levels appear: absolute identity, analogy, similarity (identity of lines and configurations; analogy of large and small configurations; similarity of forms, etc.).

The general idea can be expressed as following: structures form the foundation of the processes of informational character. And vice versa: each piece of information is structurally organized (Tyukhtin 1977). This fact presupposes the structural character of representamens. Structural organization of representamens makes it possible to actualize different signs. It provides the convincingness of denotations and connotations and the possibility of implementation of metaphors and metonymies. Structural transformations are incarnated in codification. Structures (1) form the ba-sis of indices and emotional meanings. Structures (2) form icons. In par-ticular, the identification proceeds due to the comparison of structures of representamens and stable object types (class characteristics, according to the theory of identification). Structures (3) organize the relations of different levels and promote sign actualization. Hence, it is clear that due to organizing structures, all characteristics and relations (heterogeneities) participate in codes in the compositions of visual art works. Along the lines of codes (1), (2), and (3), the units of visual art works are formed - integral structural formations uniting groups of relations and elements. In particular, the features of motion, anxiety (or statics and rest) form groups of elements, which are included in intentional codes. Typical identificationpromoting characteristics form groups of elements, which strengthen each other and facilitate identification. Common symmetries, meters, rhythms, and proportional systems organize groups of active ele-ments. This enhances an efficient reading of the general harmony of an art work. Relation-organizing, system-structural formations can enter into developed relations with denotations and connotations. A spectator can feel hidden connotations, e.g., subordinating the perception to 
interflowing lines, feeling centers, axes, and focus points, following color patterns of art work.

In general, structural character is quite important in the semiotic system of an artwork. This is why, since the earliest antiquity, the idea of structure has prevailed in creative. In New Time ${ }^{1}$ this idea appeared in a developed form in theoretical concepts and visual art works by Leonardo da Vinci. This is why the heritage of this great philosopher is important for a deeper understanding of structures in semiotic science.

\section{Structures of sign systems in the ideas and works by Leonardo da Vinci}

The ideas of Leonardo developed the ideas from antiquity of a divine order in the universe. This idea was manifested, first of all, in the principle of calacagatia, divine and eternal nature of universals, in the formation of artificial environment of humans advanced by the Pythagorean school. These ideas were implemented by the creators of Greek orders, authors of the Athens necropolis. They were developed in philosophy, in particular, in the doctrine of 'eternal ideas' - abstract universals in the philoso-phy of Platon and his multiple disciples. Ideas of order and structures were developed in the theory of architecture by Vitruvius. He treated reality like its creator. Hence, this or that principle of structure of architec-tural object appeared to him in activity, i.e., a definite sequence of actions (Vitruvius 2004; Zöllner 1991). This combination of an activity approach and the idea of structurality was inherited by L. B. Alberti. In each act of form generation, he saw a mechanism called partitioning (distinguishing) (Alberti 1935). In this mechanism, the choice of structures proceeds (choice of basic spaces, their number and dimensional relations, setting the number of floors, choice of allocation and size of walls, columns, apertures, etc.). This partitioning by Alberti can be regarded as a choice of this or that structure in a definite relation. In the case of this approach, the sequence of architectural form generation can be described in modern terms as a sequence of different structure formations (Somov 1990). The idea of Alberti was similar to the theory of proportions by the mathematician L. Pacioli. He regarded any activity as the organization of relations corresponding to a definite principle — proportion. What Pacioli called proportion can be examined as a group of structures: definite intervals of space and time. Hence, the evolution of ideas of order, proportions, geometrical universals, and numeric values in human thinking had a complicated evolution: from the Pythagoreans to Vitruvius and then to Alberti and Pacioli. The most complete representation of these ideas was the 
concept of visual art advanced and implemented in works by Leonardo da Vinci. Leonardo revered Alberti and was deeply inspired by the ideas of his friend Luca Pacioli (Wallace et al. 1975). Much of what Leonardo searched for in the domain of visual art was the manifestation of a certain general structure concept. His notes represent only a verbal fragment of thinking. The thoughts of Leonardo belonged mainly to the non-verbal world of invention, architectural forming, and visual art. So, it is reasonable to examine this concept comparing statements and art works by Leonardo.

Leonardo spread the idea of structural organization of relations in the manner of Alberti and Pacioli to the sphere of visual art: perception, cognition, and visual communication. In many respects, his visual art continued scientific cognition of the world. In particular, Leonardo saw large potentialities in a direct observation of regularities in natural objects and discovering internal structures of things through their external features. We know these Leonardo's ideas were not understood by Florentine philosophers (Wallace et al. 1975). These philosophers followed Platon's idea of the world of universals, which is inaccessible for a direct observation (Wallace et al. 1975). The possibility of visual cognition of the world hardly can be accepted by modern cognition theories. The understanding of energies, forces, fluxes, and particles is known to be attained in conceptual thinking and modeling in conditional semiotic systems, including mathematical languages. This is why the vision of general regularities in visual perception often appear as a naive realism. However, Leonardo's observations and discoveries support the possibility of a direct visual cognition of the world. In particular, these are his depicted structures of water fluxes: lines corresponding to hydrodynamic turbulences (figure 1). The picture of water turbulence is known to represent a precise model of hydrodynamic flow discovered later (Wallace et al. 1975; Witcombe 2007). Leonardo discovered them by means of direct observation, by generalizing imperceptible movements in structurally organized denotations.

The character of Leonardo's drawings reflects a cognitive element. His drawings represent some generalized models. A developed talent for seeing the general and the abstract in the object of environment led to a specific way of representation. Structures of a real world become the major denotation in many Leonardo's pictures. In his drawings, denoted objects are generalized. Geometrically regular lines generate accurate and regularity-conformable geometric forms. They become an organizing basis. The contours are complemented by strokes reinforcing the denotation of geometric form (according to the strength of tone and direction of stroke lines). This is why Leonardo's drawings are so convincing. Denotations are organized, first of all, in correspondence with the codes of 


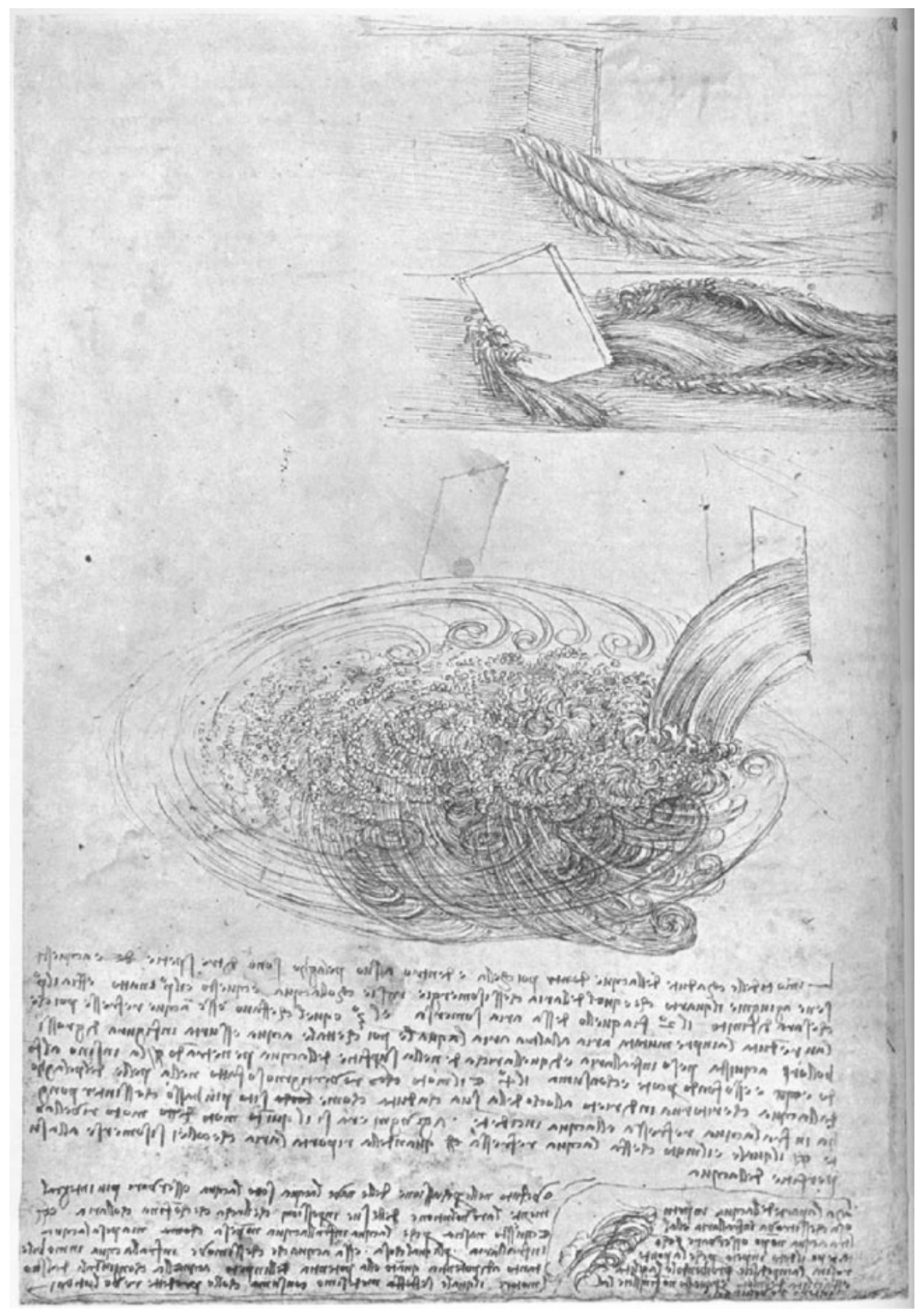

Figure 1. Leonardo, 'Studies of water' (1508-1509, pen and ink on paper, Royal Library, Windsor) 
object character (Somov 2006). Their structures and interrelations have different importance in real perception. In particular, the perception of geometric forms and allocation of objects is more fundamental than that of form surfaces. This is why the structures, interrelations, and elements denoting basic directions of motion and form-governing geometric universals were most significant for Leonardo in different images. As these structures of denotative character are the most substantial, they simultaneously are the basis of realization of intentional codes; directions and geometrical features of forms become organizing and emotional elements. When drawing people, he creates geometrical generalizations of body motions, impulses, energies, and muscular efforts - indices. Hence, these de-notative forms became the sources of emotive meanings and the foundation of metonymies.

In different tasks and means, Leonardo selected definite interrelations and principles of their organization, i.e., structures. His opinions (concerning aerial perspective, depiction of people, their poses, gestures, and clothes, and landscape painting) represent the specification of theoretical ideas of integrate principles of organization of visual information. In particular, when regarding similarities, he used the example of mutual reflections of mirrors, when objects and their parts change the size, corresponding to the distance of reflection. But most important is that they preserve identity (invariant character) (Leonardo 'Codex Atlanticus': ${ }^{2} 138$; Leonardo 1999: 74). Thus, the model of the world appeared, where its infinity contained an infinite number of mirrors, one being smaller than and inside the other (Leonardo 'Codex Atlanticus': 138; Leonardo 1999: 74). According to Leonardo, each object has its own identical images; these images are reflected in visual perception and memorization. This idea corresponds to the models of invariant character of structures.

The central nucleus of structures of sign systems of difference-identity was the key point of Leonardo's ideas of visual art. He regarded differences as the most important artistic facilities: the neighborhood of the ugly and beautiful, large and small, old and young, strong and weak. He aimed at diversifying the samples on this basis (Leonardo 'Treatise on Painting': 3187 by Leonardo 1999: 167). This corresponds to modern ideas treating differences and diversity as a fundament of information production. The means of modeling of object forms, by Leonardo, clearly represent the interrelations of differences and identities as the basis of production of visual information. This phenomenon was especially developed in the denotations and signs of visual level. The treatment of light and shade was important for Leonardo. He paid attention to the efficiency of active fragmentation of forms of depicted objects by shadows, especially to the demonstration of parts of human body. He pointed to 
an efficient principle: a dark part of the body should border a light background, and vice versa (Leonardo 'Treatise on Painting': 759 by Leonardo 1999: 96). According to Leonardo, the shadows on the surface of human body should have tortuous outlines, in accordance with the diversity of shadow-giving body parts and objects, to which the shadows are projected (Leonardo 'Treatise on Painting': 760 by Leonardo 1999: 96).

Earlier, I have tried to demonstrate the differences among denotative, connotative, and organizing forms in visual art (Somov 2007a). Various theoretical statements by Leonardo demonstrate that for him the most significant denotations are those promoting cognition. At the same time, like in any other fine art, denotations, connotations, and organizing elements are integrated in a complex way in the works by Leonardo. A typical feature of this integration in his creative work is the fact that denotations are already organized at the level of denoted objects and that the character of denotations themselves is such that they represent signs with different but quite definite meanings. A specific phenomenon appears: metonymies (meanings of energy, motion, and life pulsation) seem to be built over the denotations of physical world. This appears through the features of internal tension of forms, interlacing of bodies, dynamics of various movements, and contraposition of depicted objects by different characteristic. These features are apparent in the richest and most dynamic works by Leonardo. Powerful dynamics and internal tension of forms is illustrated by his painting St. Jerome in the Wilderness (figure 2). The most complicated sign facilities, which strengthen tension, dynamics, and struggle, can be examined when looking at The Battle of Anghiari (figure 3). The composition is based on spiroid forms of bent human and horse figures. These forms are incarnated in contours, axes, and motion directions of bent forms. A specific spiroid form repeats. It resembles twisted water streams and air-blasts studies by Leonardo. Spiroid dynamic forms of this kind can be seen in sculptural compositions by Michelangelo, while their developed sequels are present in architectural and sculptural works of baroque time. The most outstanding development of this approach was given in the works by Rubens who copied The Battle of Anghiari. In his different works, Rubens repeated typical features of structural organization of this painting. In particular, he drew human figures as spirally bowed, assigning them dynamics in this way. A specific structurality of dynamic forms was developed later in the works by Delacroix. For Leonardo, the dynamics of represented objects, which produces emotional tension, was the way of including an artwork into emotional codes. This was understood properly by his followers.

Generally, artworks demand structural organization in the course of intentional codes. This is the basis forthe formation of emotional meanings. 


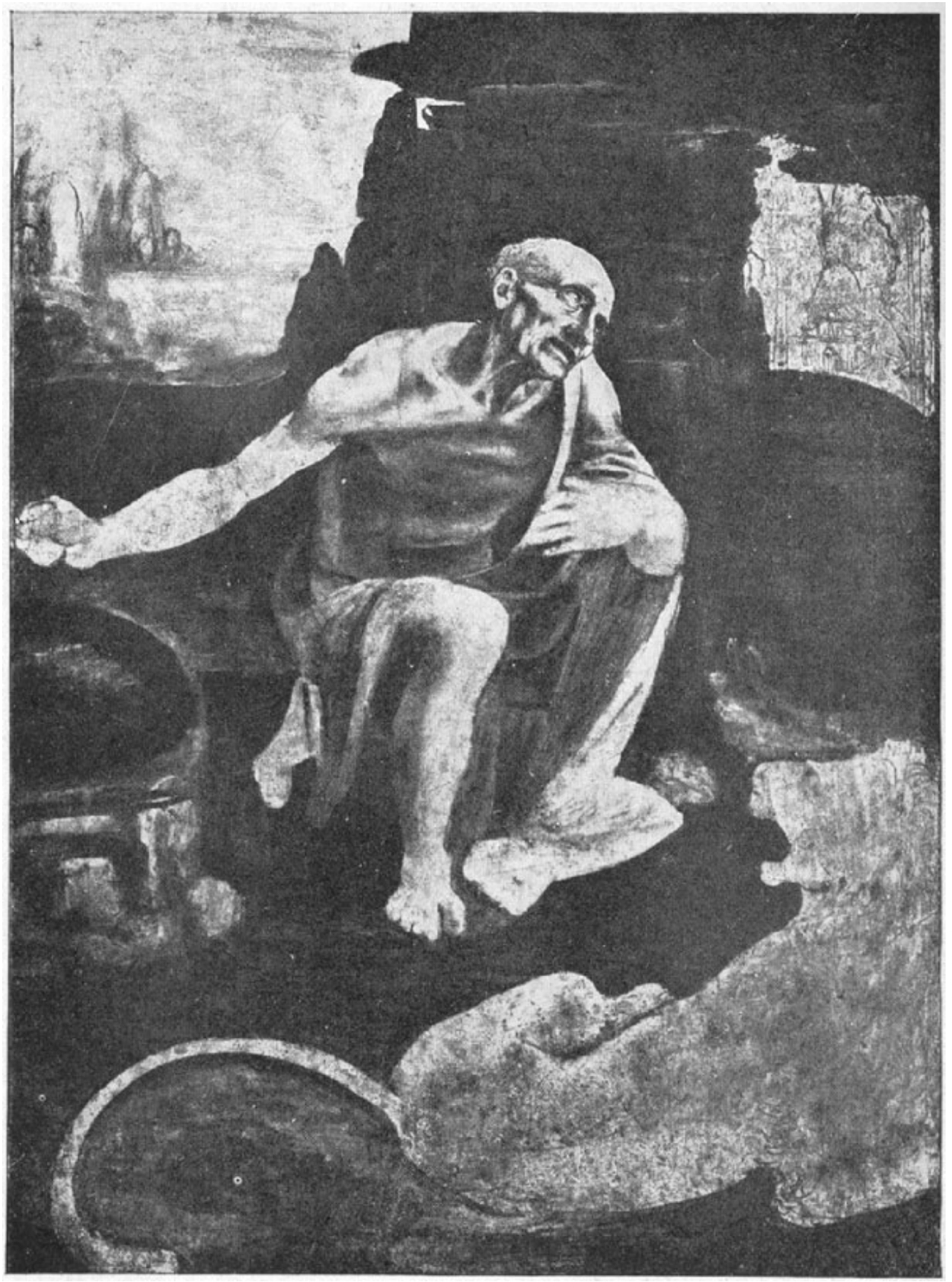

Figure 2. Leonardo, 'St. Jerome in the Wilderness'(1480-82, tempera and oil on panel, $10375 \mathrm{~cm}$, Vaticano, Pinacoteca Apostolica Vaticano, Rome, unfinished painting). The composition of the painting has a dynamic construction. 


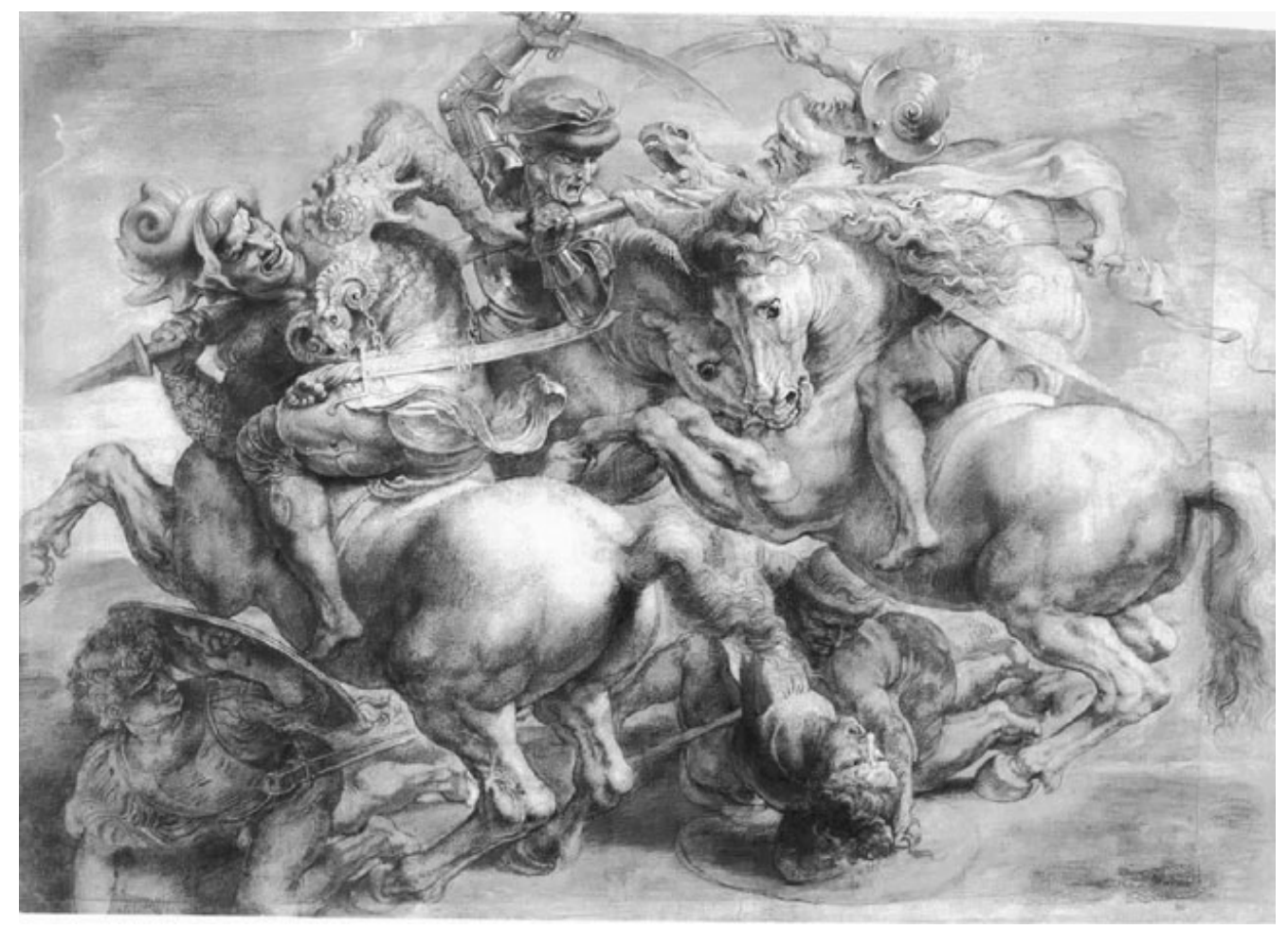

Figure 3. Peter Paul Rubens's copy of 'Struggle around the Standard' from 'The Battle of Anghiari' by Leonardo (1550-1603, black chalk and ink heightened with lead white, overpainted with watercolour, Louvre, Paris, France).

This is why Leonardo pointed to the subordination of an artwork to a definite emotional mood as to one of the principles of visual art (Leonardo 'Treatise on Painting': 286, 384, and 385; Leonardo 1999: 129, 130). This attitude was spread to denotations and connotations: poses, gestures, and motions of people, clothes, and color combinations.

Interrelations between denotations and connotations need the structures of codes (1) and (2) to be interrelated. First of all, this is manifested in the interrelations of movements, poses, gestures, mimicry, and expression of human intentions and emotions. This is why Leonardo paid much attention to human interrelations, their sign representation within systems of indices, and representation of these indices in the features of geometric character, color peculiarities, and contrast combinations of various charActeristics in human image. These problems were related with the methods of people coding in Leonardo's notes: typical forms of nose, eyes, ears, and other face elements with typical features. This approach is a threshold of contemporary models of people identification.

The whole diversity of sign reality of visual art was represented in a systematized way in Leonardo’s concept. Different icons, indices, and 
symbols; denotative, connotative, and organizing forms; types of denotations; sign meanings of denotations - all this and other aspects of semiotic systemity of visual art works were related by an integrated principle in this concept. Its most appropriate determination is the term 'principle of structurality.' Everything was linked by structures and structure-based differences-identities along all lines of an 'interrelation net.' Integrated structures, differences-identities, and identification characteristics essentially were in the center of Leonardo's theoretical ideas of visual art. These ideas were manifested in very different works of the great painter and were materialized in different ways. A well-known masterpiece of visual art Lady with an Ermine (figure 4) is an artwork with multiple and fine manifestations of structures, differences-identities, organizing features, relations of analogies of element groups organized in denotative, connotative, and organizing forms. I think that the analysis of this work will help us to demonstrate clearly the interrelations of aforementioned semiotic objects and especially reveal the fundamental role of structures in semiotic systemity of visual art works.

\section{Structures and signs of the portrait Lady with an ermine}

According to the majority of art historians, this portrait was painted by Leonardo da Vinci, although there are the hypotheses about other authors. In addition, there is a hypothesis postulating that the portrait was painted over after Leonardo and the background was darkened. The sign systems developed in the semiotic approach convince that this is the portrait by Leonardo. The majority of explorers suppose that the young mistress of the Duke of Milan, Cecilia Gallerani, is represented. According to other versions, other favorites of the Duke could have been depicted. Having in mind these versions, in any case, I shall follow the tradition and call the painted lady Cecilia. Some vagueness in the history of the portrait does not prevent us from seeing its context.

The verbal systemity of the context of the picture is the Duchy of Milan, the court of L. Sforza, the Duke himself, and the influential favorite. The Duchy was quite powerful. Its court was one of the most luxurious in Europe, with shining beautiful women, treasures, astrologists, and poets, with splendid celebrations, costumes, and fireworks invented by Leo-nardo himself (Wallace et al. 1975). The Duke was famous for his tena-cious and cruel character and was thus nicknamed Lodovico il Moro. A great importance of the painted beautiful lady objectively relates the por-trait with the duchy, denotes the Duchy of Milan and its court, and sym-bolizes the polish of this court and tenacity of the Duke's power. There is 


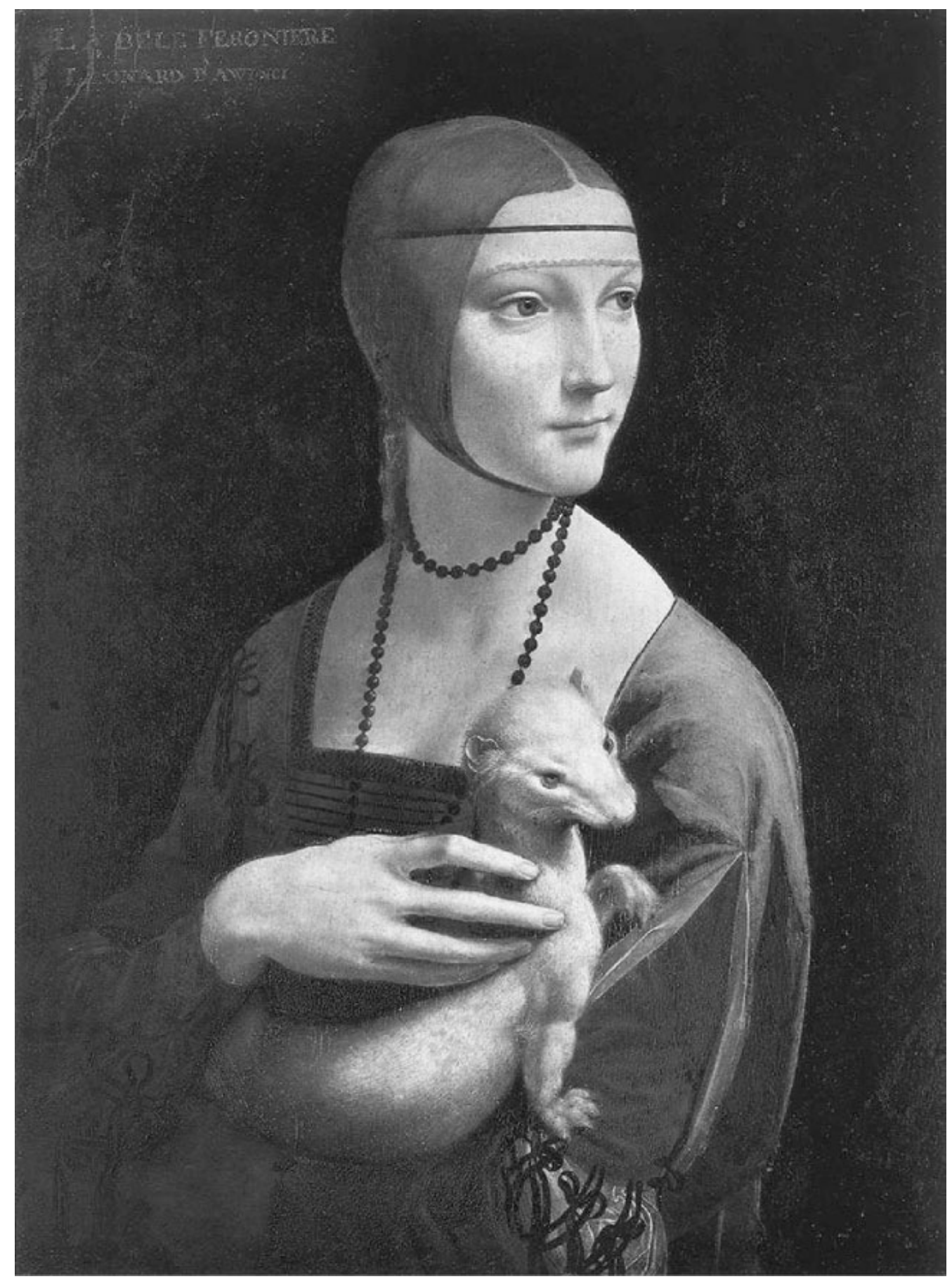

Figure 4. Leonardo, 'Lady with an Ermine'(1483-1490, oil on wood, 53.439 .3 cm, Czartoryski Museum, Krakow) 
the interrelation between the sign system of the portrait and this context. The image of the animal is a sign of this interrelation. The ermine was the symbol of Duchy of Milan. In connection with this, the sign system of the interrelation between the lady and the small animal is the basis of visual sign system of the portrait.

The visual sign system of the portrait relays upon the analogy of the lady and the small animal. This analogy is visible in the similarity of their figures, poses, gestures, parts of body, motions, and character of pattern of both figures. The analogy between the lady and the carnivore beast helps to feel the affity of their tempers.

The lady denotes the Duchy, the luxurity and refined aristocraticism of its court. According to some explorers, the representation of the small beast in the hands of the Duke's favorite, with a patronizing movement of the lady's hand, denotes her supervision over the Duke (Wallace et al. 1975; Zöllner 1991). There is another possible meaning to this gesture. There is the portrait of L. Sforza kicking an ermine. This denotes his attitude to people (Wallace et al. 1975). So, the caressing gesture makes a hint about a fine and capable guidance not only of the Duke, but also of his folk; this tells about a mild and delicate manner of treating subjects.

The organization of denotations is the foundation of the sign systems in the work. The interrelations of figures, heads, and part of bodies of Cecilia and the small beast reinforce their semantic interrelation.

The systemity of basic denotations is activated. The treatment of light and shade reveals the forms and their spatial allocation. This becomes obvious when emphasizing the most important denotations of the portrait: the lady's head, the beast's head, and the holding hand. The contours of woman's head visually are continued by an active line of clothes, beast's snout, and S-shaped contour of its body; the contours of the hand flow into a bent line of the hand (figure 5). The group of similar elements is formed, including elongated and directed configurations with S-shaped extensions. This equity forms a systemity of major denotations and makes it possible to perceive them as integral. The interrelation between the head and hand movement of the woman depicted and beast's figure and snout creates a metaphor.

A significant symbolic role of the ermine and its analogy with the lady demanded a structural organization of denotation representamens. It was necessary to depict the beast as proportionate to lady's figure and head and approach his snout to her face. In connection with this, instead of a small ermine, the artist depicted a rarer animal - a white polecat. This is the deviation from the symbol of the Duchy. However, due to the proportionality, visual and semantic analogies between Cecilia and the beast are produced. This metaphor is developed in the structural organization of 


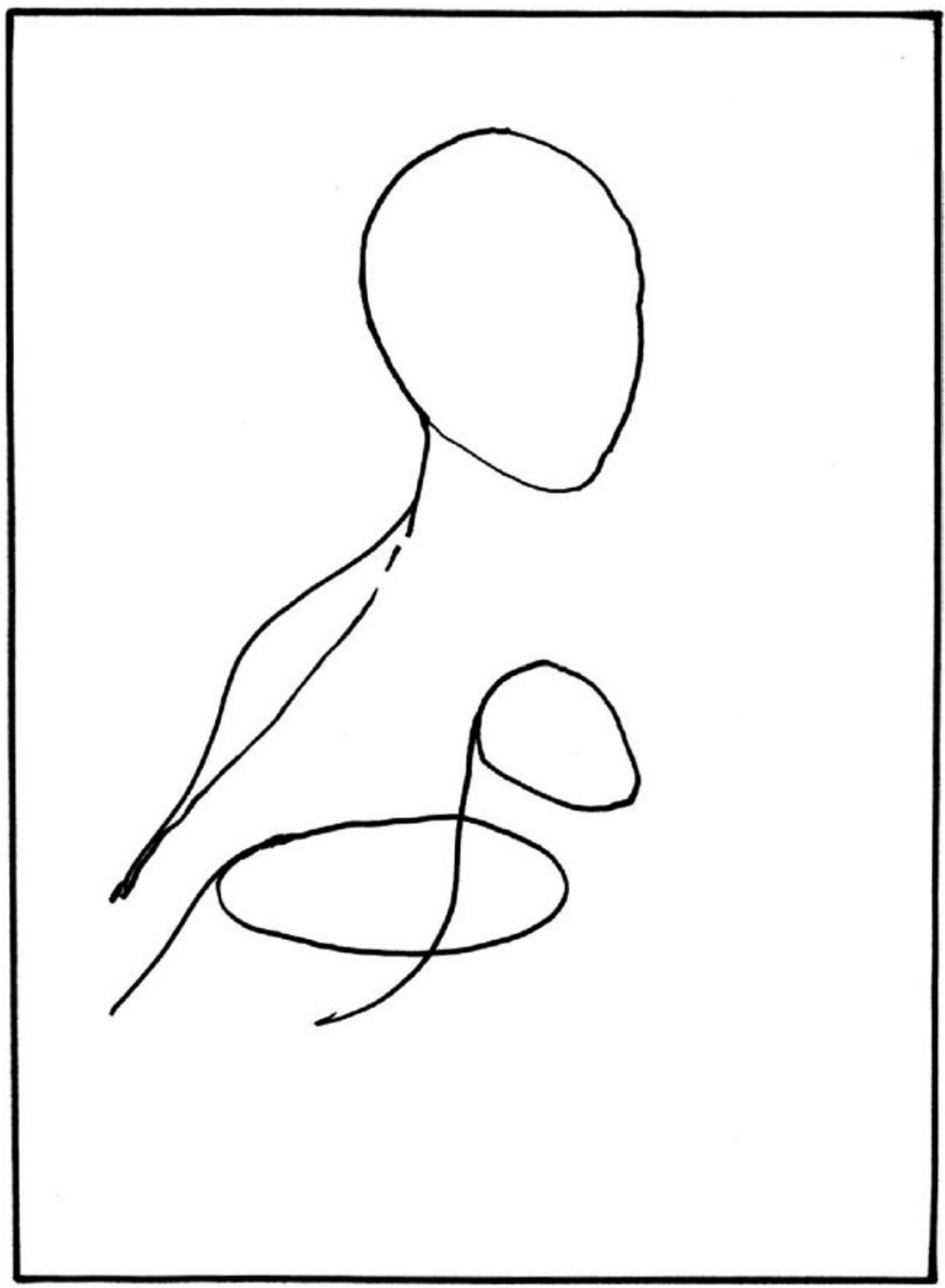

Figure 5. 'Lady with an Ermine.' Representamens of main denotations of the portrait are interrelated by a common structure. This contributes to the formation of a general denotation. A memorable denotative form is created. 
denotations, connotations, and active signals. The uplifted lady's head on a long neck resembles the stretched beast's figure. The analogy also is implemented in the form of hand and general lines of polecat's figure. In general, an integer sign system is formed: straight, raised living beings with a look focused on some goal.

Denotations developing as representamens form symbols. The forms of body parts of the beauty and beast and the elements of clothes are denoted by light and shadow and color relations. This corresponds to Leonardo's aforementioned instructions concerning the representation of clothes and advising to oppose actively the parts of body to clothes. The shades produce a contrast between a light body and a dark color of clothes. Alighted parts emphasize the color contrasts of body and clothes. Where the forms border with each other, deep dark shades sharply sepa-rating these forms are painted. These shades have an indented contour. This systemity of light-and-shade and color produces the meaning of deep space. The diversity in the freaks of relations of light-and-shade and color favors the expression of motion and form vitality. The shades compose an integer meandering form. It resembles the body of a snake (figure 6). This form resembles the emblem of the Duchy of Milan, allocated on castle tower, created in the reign of Visconti, Sforza's predecessor (figure 7). The emblem represents a shield with the serpent, brought by the ancestor of Visconti from the crusade. The serpent makes four large bends. The structure of major shades of the portrait corresponds to this image. Due to this structure, the portrait represents the Duchy of Milan and its main castle. The laces of Cecilia's clothes also have the character of bending lines, which strengthen the connotation of serpentine forms.

In general, denotative forms obtain the character of connotations (energies, vital forces, and pulsations) and become organized by common forms and structures.

Connotations of emotional type are based on structural organization of denotations: basic depicted figures, their poses, movements, and gestures. Leonardo paid special attention to the representation of the emotional status of the depicted event and its participants. According to his known statement, if the subject represents horror, fear, flight, sorrow, weeping and complaint, or enjoyment, pleasure, laughter, and other states, the souls of spectators should set their limbs in motions producing an impres-sion of their personal participation in the event represented by figures in a given subject (Leonardo 'Treatise on Painting': 188; Leonardo 1999: 167). In our case, the representation of figure obtains an emotional meaning. This is achieved by the fact that the figure is painted in turn and motion. The movement directed f rom the lower left part forward and up is supported by configurations and lines: ascending, bending, spiroid, 


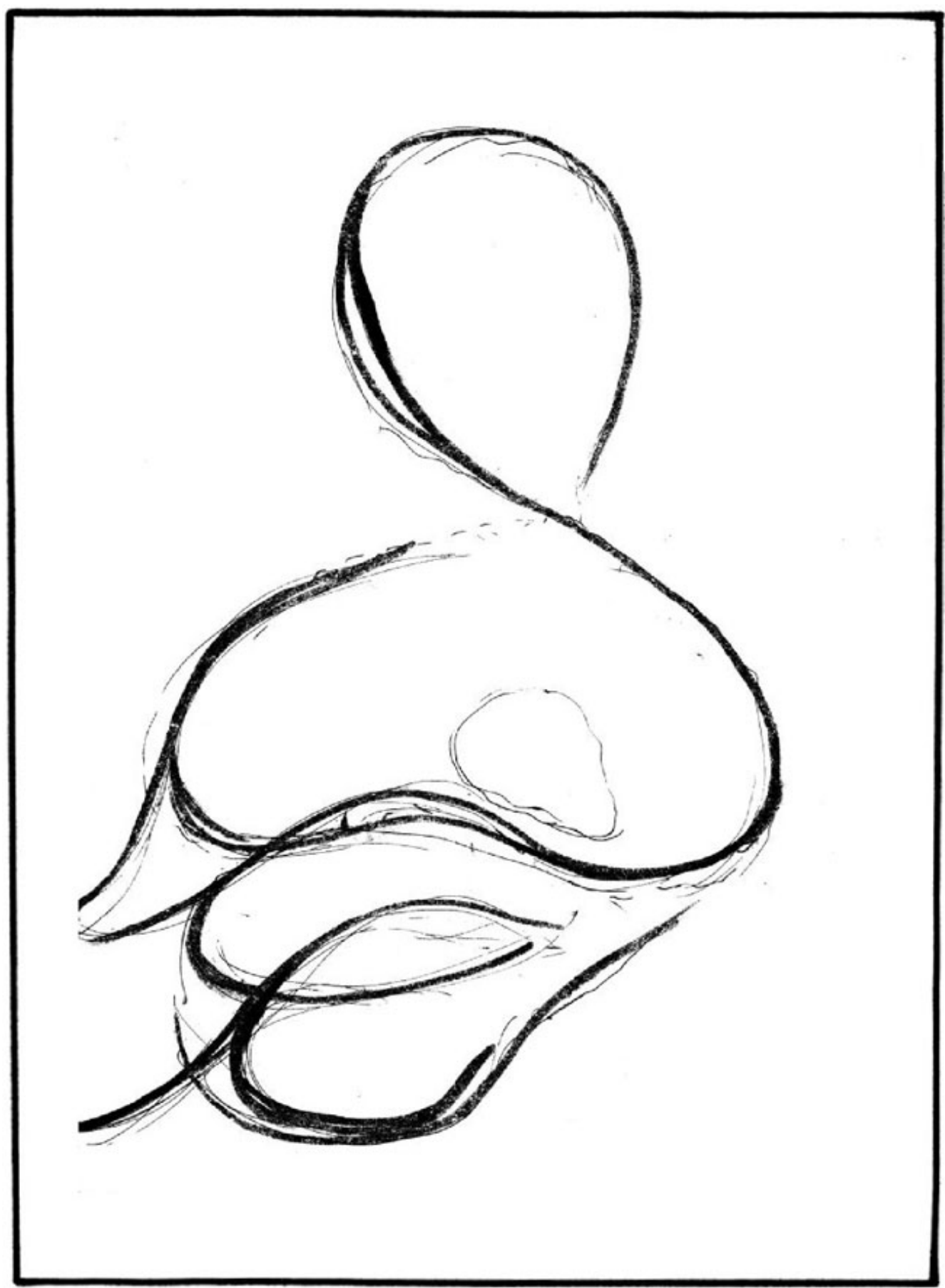

Figure 6. 'Lady with an Ermine.' Organizing denotations functioning as a symbol. Basic shades of denotative form constitute a typical pattern. This pattern is serpentine and resembles the emblem of the Duchy of Milan (see figure 8). 


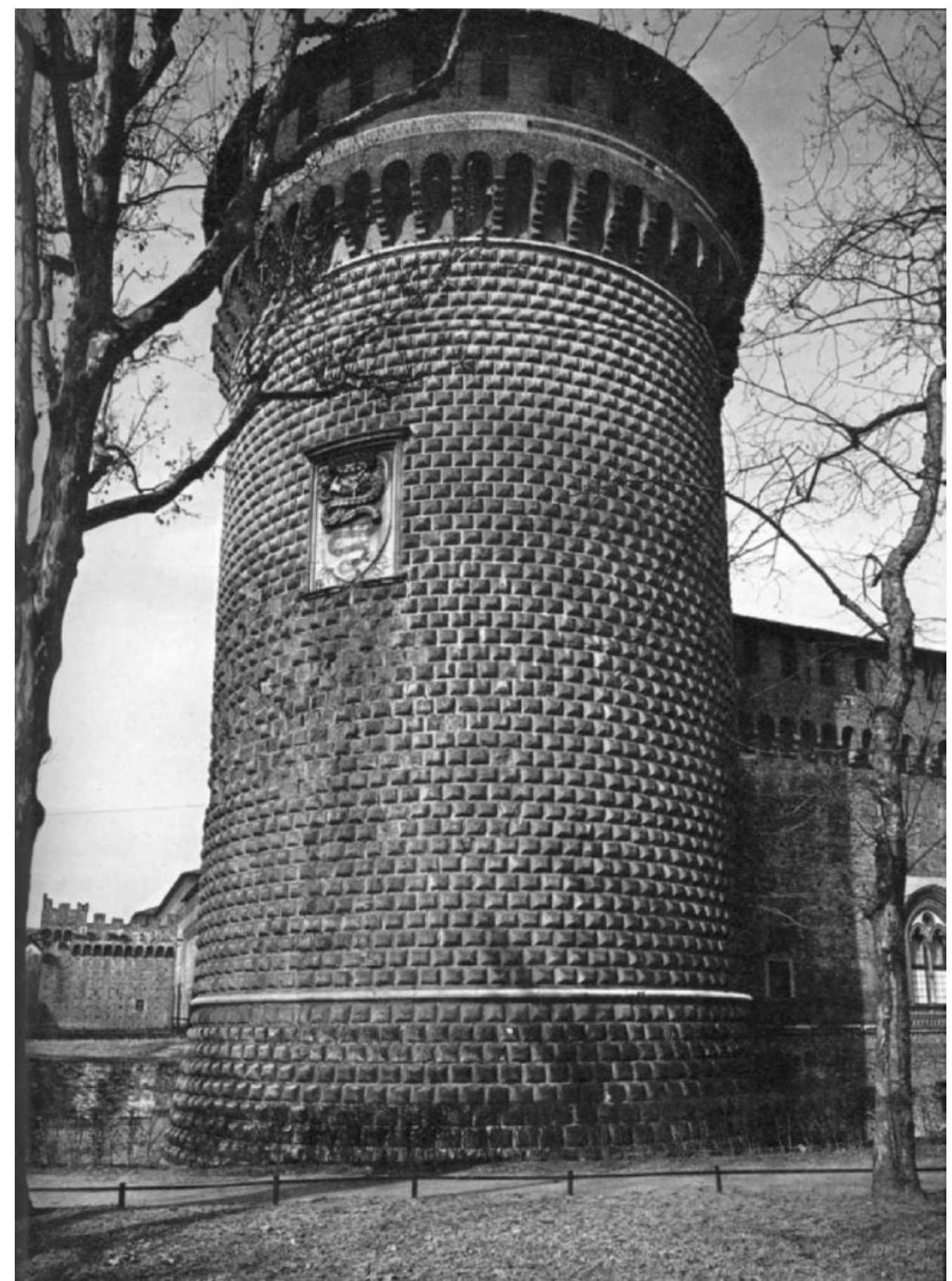

Figure 7. The tower of the castle of the Duke of Milan with the emblem. St. George strikes the serpent. The emblem was created by Sforza's predecessor, Visconti. The image of serpent has a character of horizontally elongated bends. S-shaped horizontally elongated lines are formed. This structure is similar to the structure of shades on the portrait. 
falciform, and sail-shaped configurations (figures 8-11). Active configurations are directed from the lower left part up and forward. These configurations and their rhythms denote splashes and ascents, and resemble sails, comets, or wind turbulence. There connotations are strengthened by the structures of relations of light and shade. They join to the feeling of proud elevation of figures. An integer meaning of vital energy, pride, eminence, and enthusiasm is formed.

Denotative, connotative, and organizing forms obtain different meanings in the artwork. Denotations mainly promote the representation of statics and certitude. Connotations mostly enhance the meanings of dynamics, changeability, and emotion splashes. On this foundation, the interpretants of context are linked in a general meaning: power, rapacity, and vig-ilance of the Duchy of Milan, refinement and luxury of its court, and secret stratagems of court life.

Representamens of denotations create developed system-structural formations. Basic denotations (Cecilia's head, the head and body of the small beast, and the holding hand) are represented in three-dimensional forms and their configurations. These forms are identical (Zöllner 1991). The basic organizing configuration visually highlights the face. This con-figuration has prominent contours in its broad part and concave ones in a narrower part. These configurations become visible when slightly general-izing the contours of the beauty's face, beast's snout, and hand, joining them with the help of cloth pattern (figure 12). The axes of configuration directions are focused in one point. An integer structural formation is produced. The axis crossing Cecilia's and the beast's eyes and the point of hand end is perpendicular to the axis of the hand (figure 13). Lines and configurations organizing basic denotations are formed by the boundaries of their configurations (figure 14). Triangle constructions of Cecilia's and the beast's heads are formed. They are likened to a triangle construction in the lower part of the portrait. The lines of these elements consti-tute an integer system-structural formation.

The representamens of the major denotations are organized by general lines and points (figures 15-18). Active lines flow into each other and are organized in common points (figure 15). Configurations of elements, partitioning the picture along the boundaries of connotative elements, constitute a specific group. They are united in the point of intersection of fragments of different colors (figure 16). Active signals are united by lines in common points (figure 17). Lines and points are subordinated to the structure of inclined lines (figure 18).

Active signals (configurations, contours, and lines) are organized into system-structural formations of a connotative character. In particular, small animal's pad is strengthened by the analogy with the configuration 


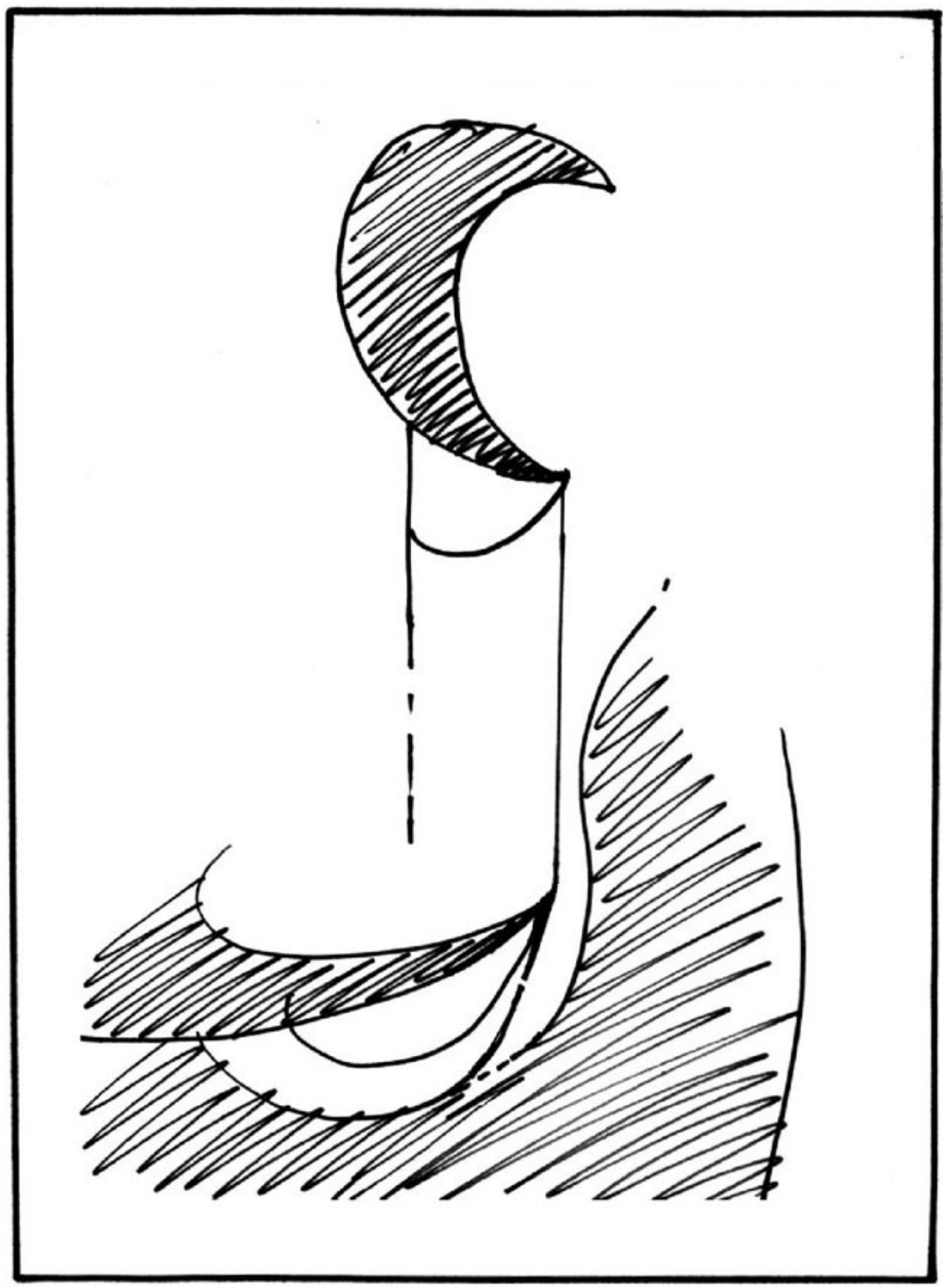

Figure 8. 'Lady with an Ermine.' Organizing connotations of emotional character. The configurations of shades form ascents, denote ascending fluxes and energy motions. 


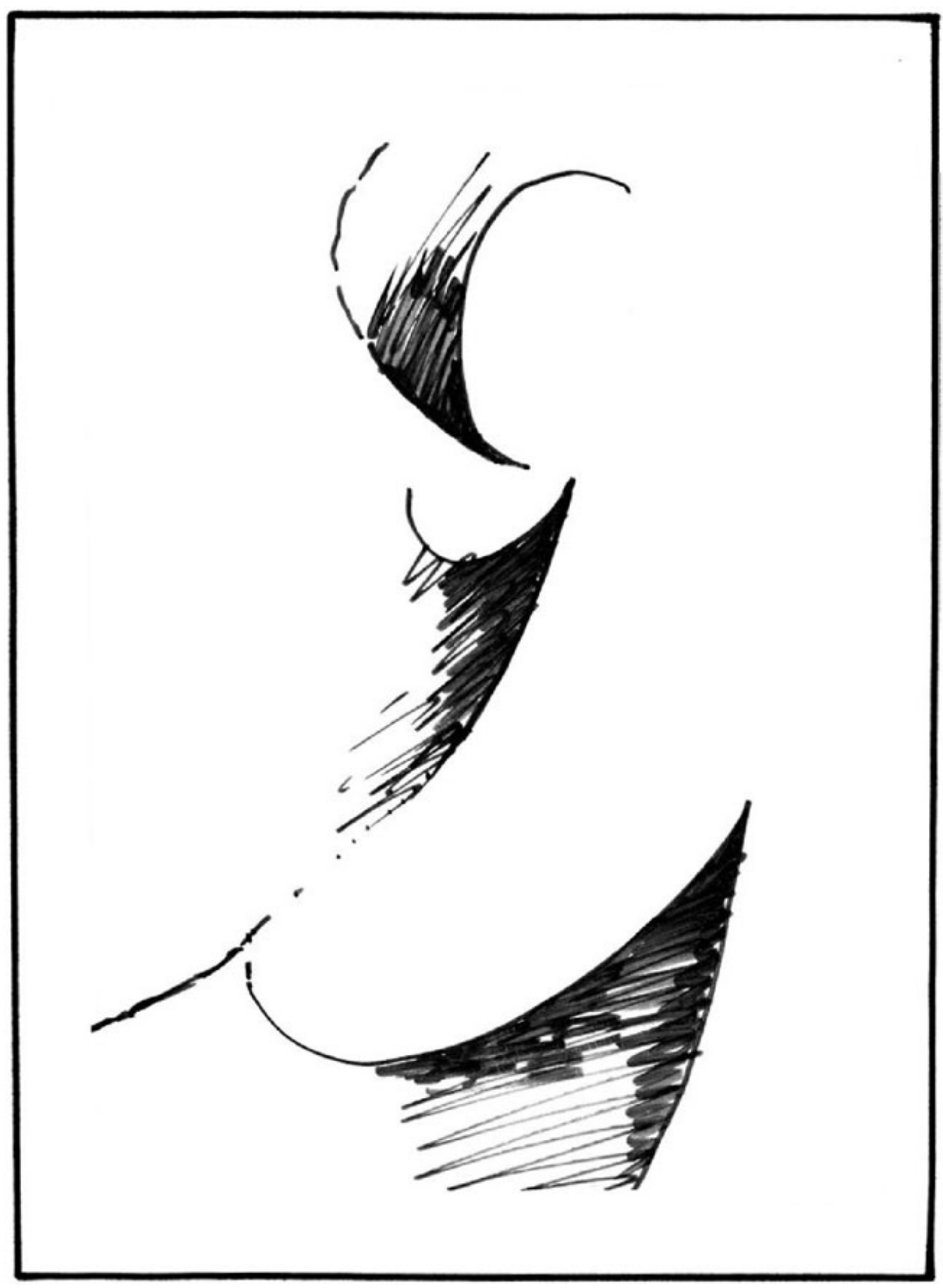

Figure 9. 'Lady with an Ermine.' Organizing connotations of emotional character. Falciform configurations and their active contours resemble comet trajectories. 
The role of structures

23

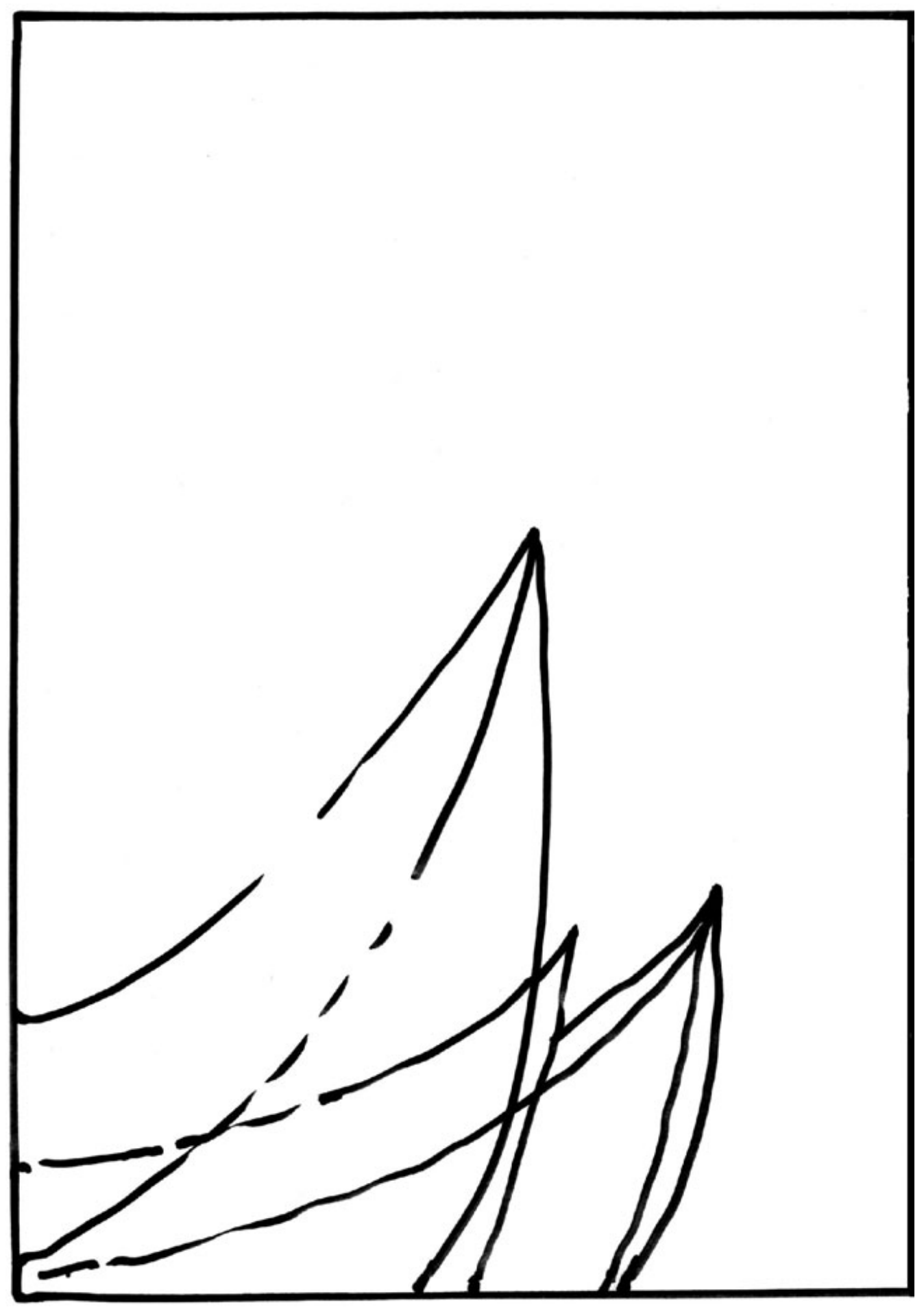

Figure 10. 'Lady with an Ermine.' Organizing connotations of emotional character. Configrations of lines and color masses and their characteristics denote ascents and splashes; contours resemble sails. These features enhance the impression of motion and impulse. 


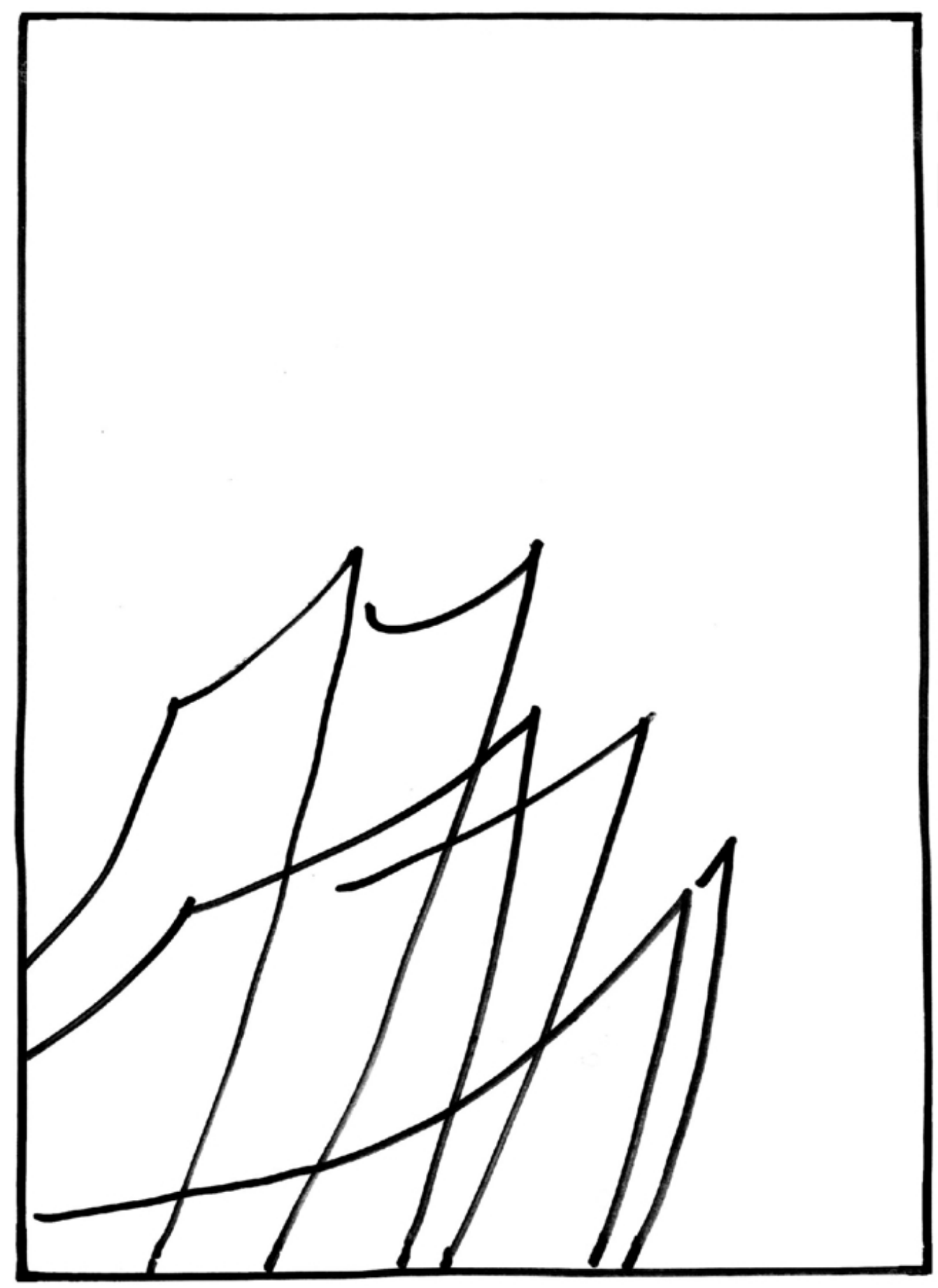

Figure 11. 'Lady with an Ermine.' The organization of connotations of emotional character. Configurations of typical lines and contours. These characteristics denote motion and enhance the feeling of ascent. 


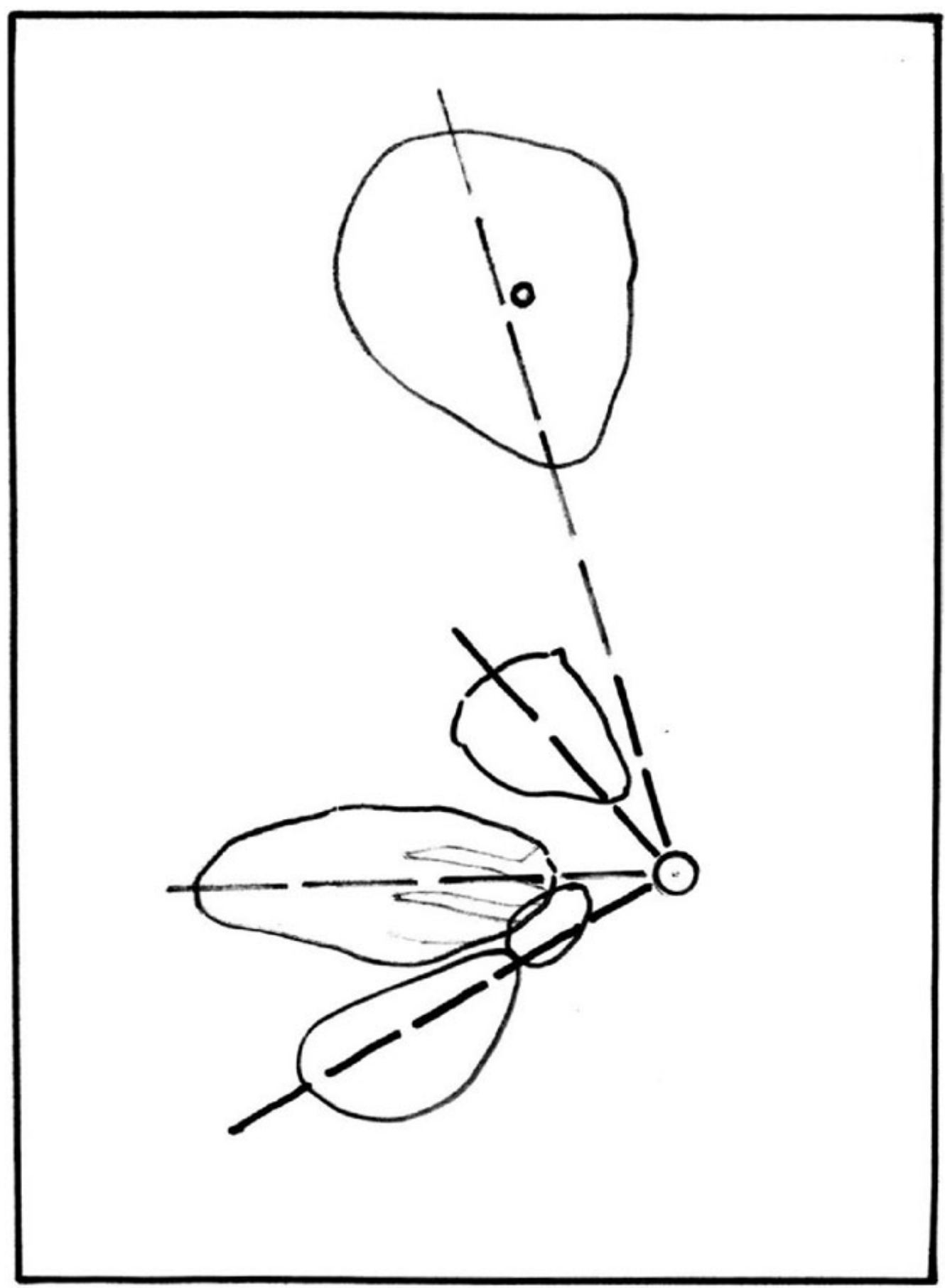

Figure 12. 'Lady with an Ermine.' Representamens of denotations. System-structural formations. Axes of denotation representamens. The convergence of axes in one focus point organizes the representamens of denotations, linking them into a general structure. This provides the formation of a general semantic system of given denotations. 


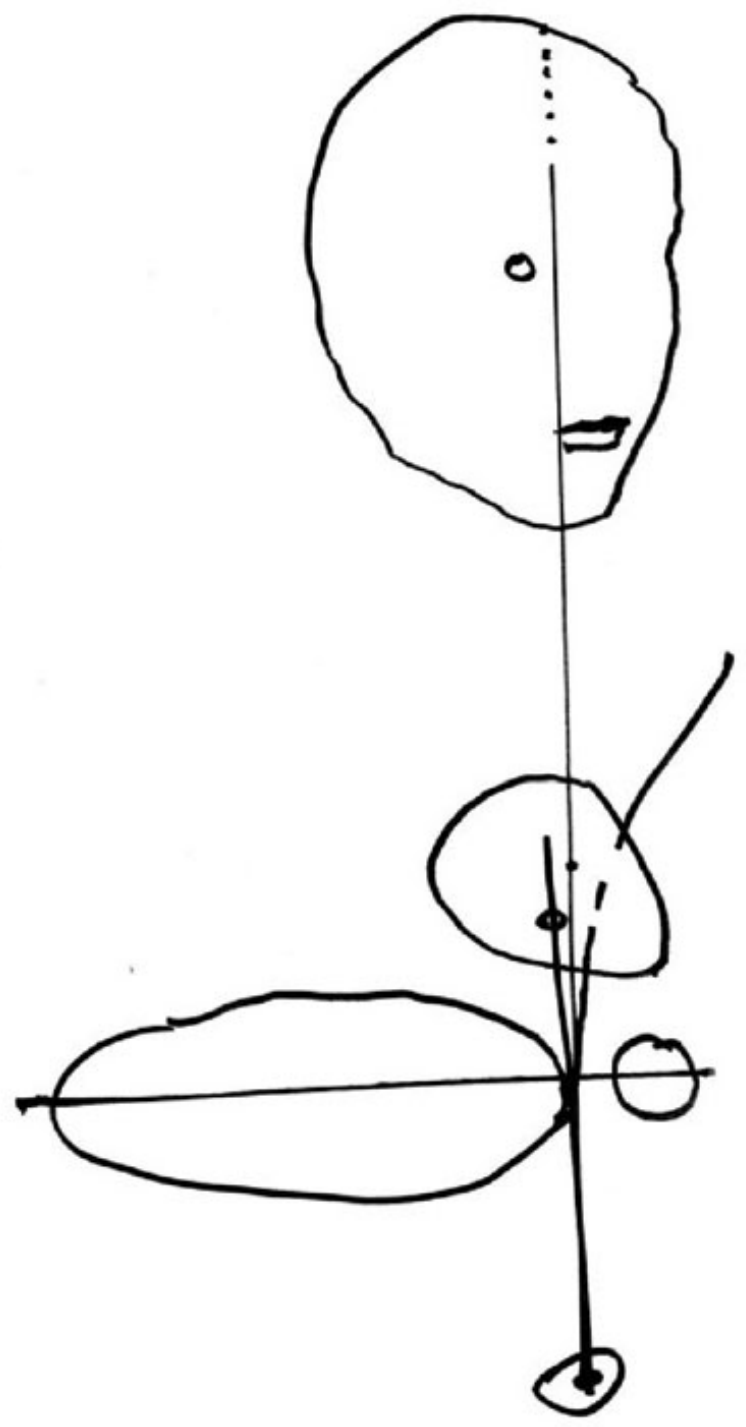

Figure 13. 'Lady with an Ermine.' Representamens of denotations are organized in systemstructural formations. Axes interrelate the representamens of important denotations. The contours of denotations are situated on the axes intersecting at right angles. The structure is formed. Due to this structure, a small pad with claws digging into clothes becomes significant. 


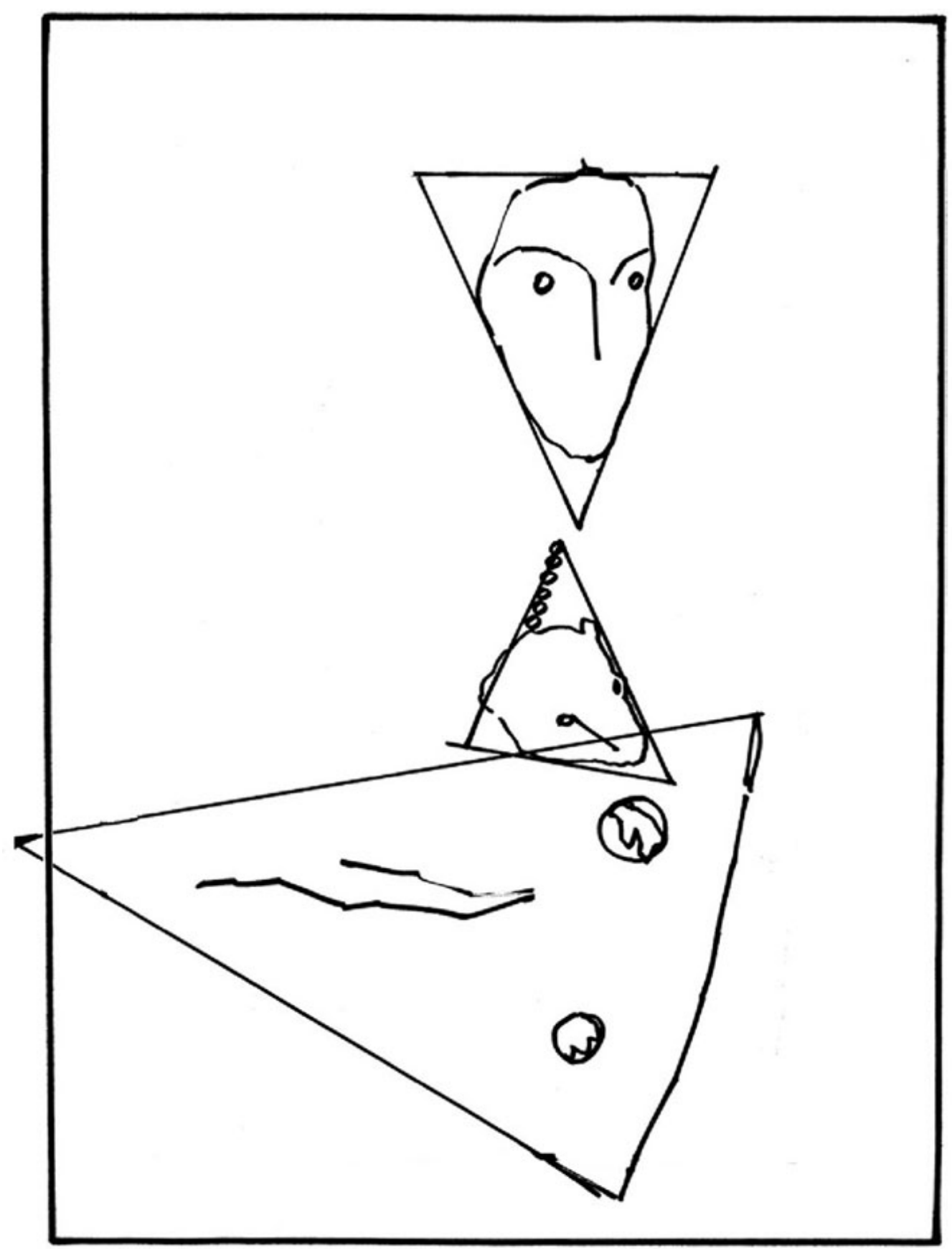

Figure 14. 'Lady with an Ermine.'Representamens of denotations are organized in systemstructural formations. Triangle outlines circumscribe denotation contours. The representamens of two key denotations of lady's face and animal head are inscribed into triangle contours. Triangles are developed in a large configuration organizing the elements of the lower part of the portrait. 


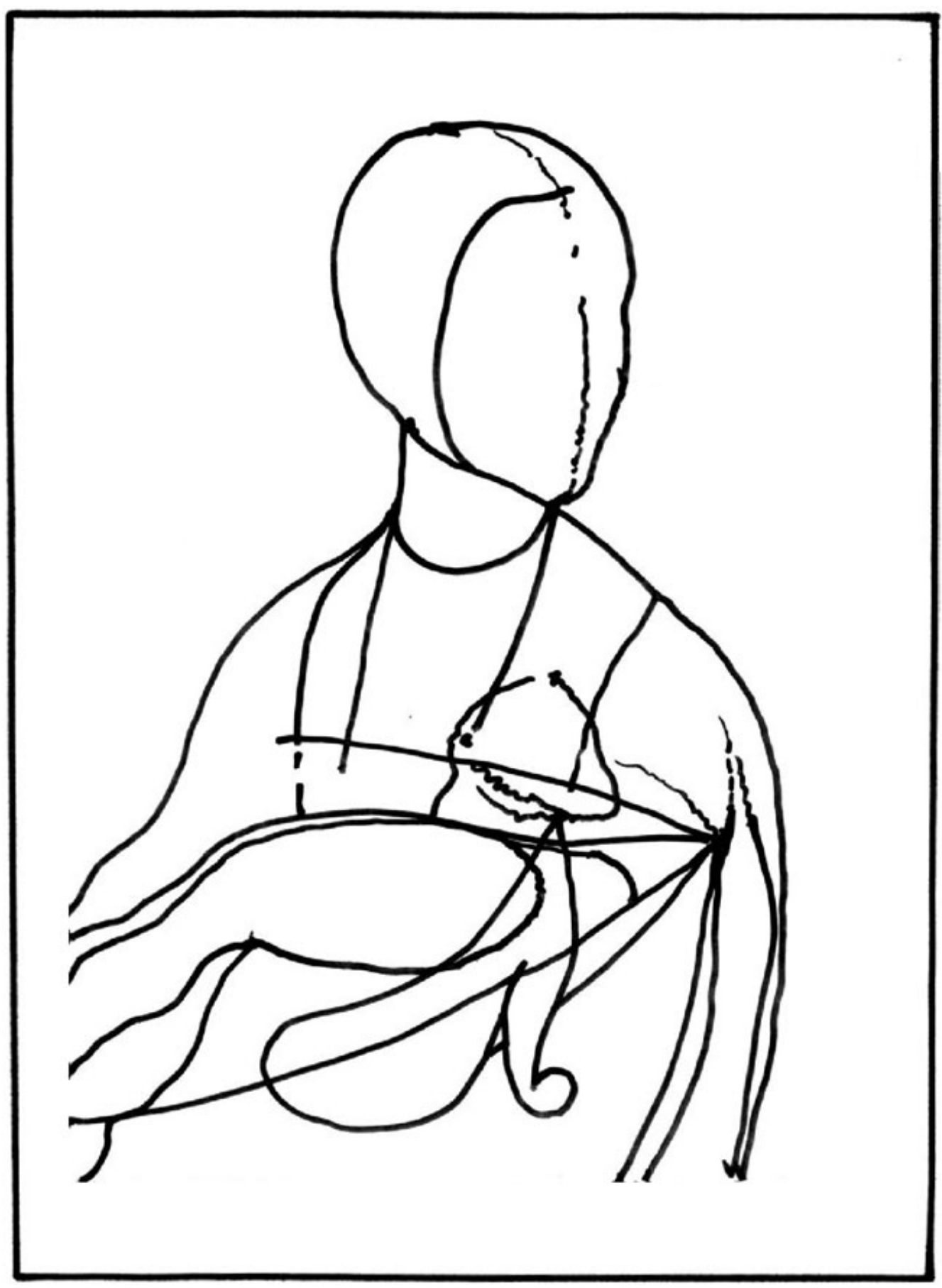

Figure 15. 'Lady with an Ermine.' Representamens of denotations are organized in systemstructural formations. The lines are organized by a general structure; they meet in one point. 


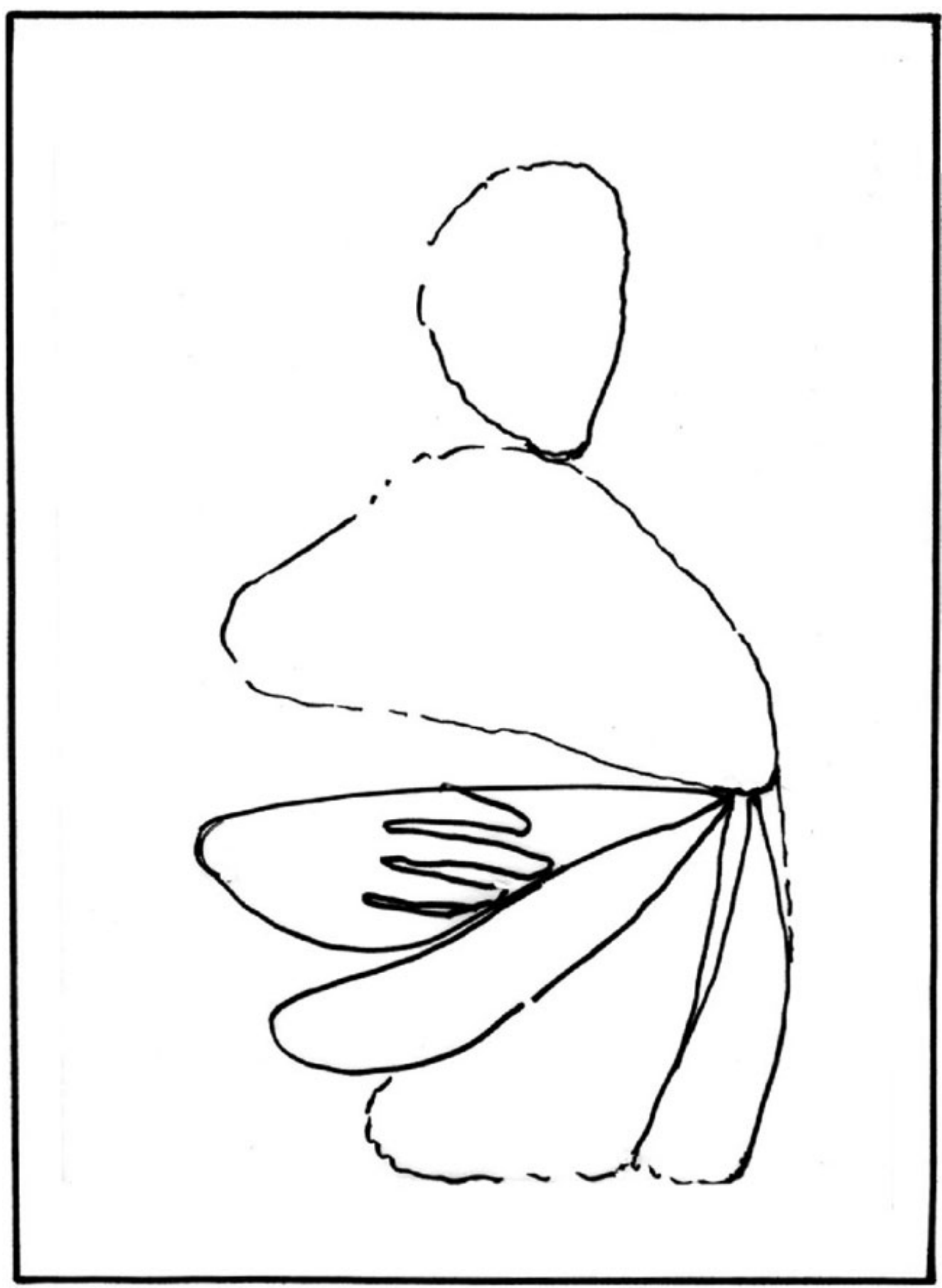

Figure 16. 'Lady with an Ermine.' Representamens of denotations are organized by the systemity of configurations. The configurations are formed among major lines represented by dark shades and boundaries between light and dark areas. These configurations have a general principle of organization, i.e., common structure. They represent the configurations, which are oval on one edge and sharpened on the other. Six of them meet in one point. 


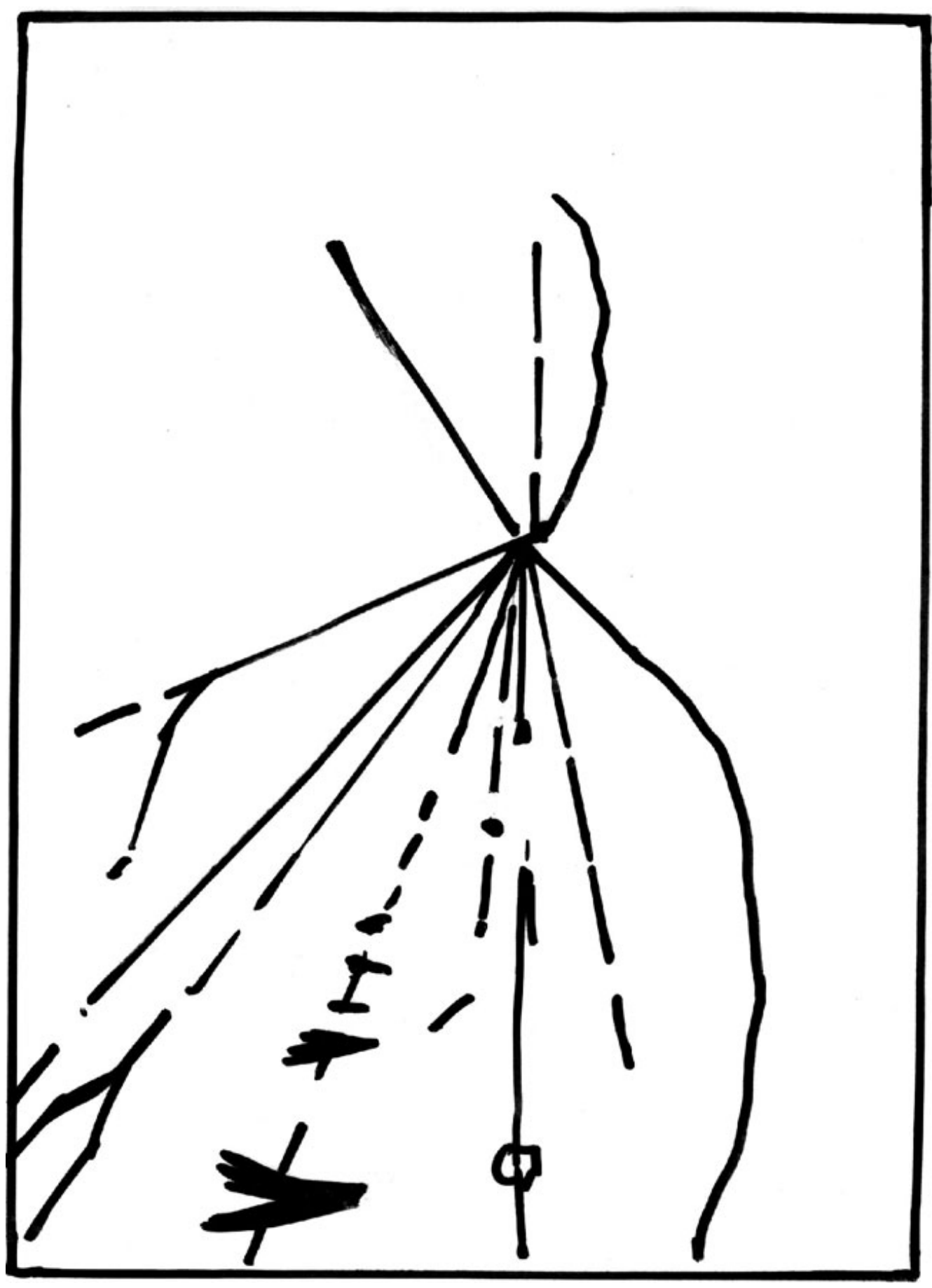

Figure 17. 'Lady with an Ermine.' Representamens of denotations are organized in systemstructural formations of active lines. The lines are organized by a general structure; they all intersect in one point. 


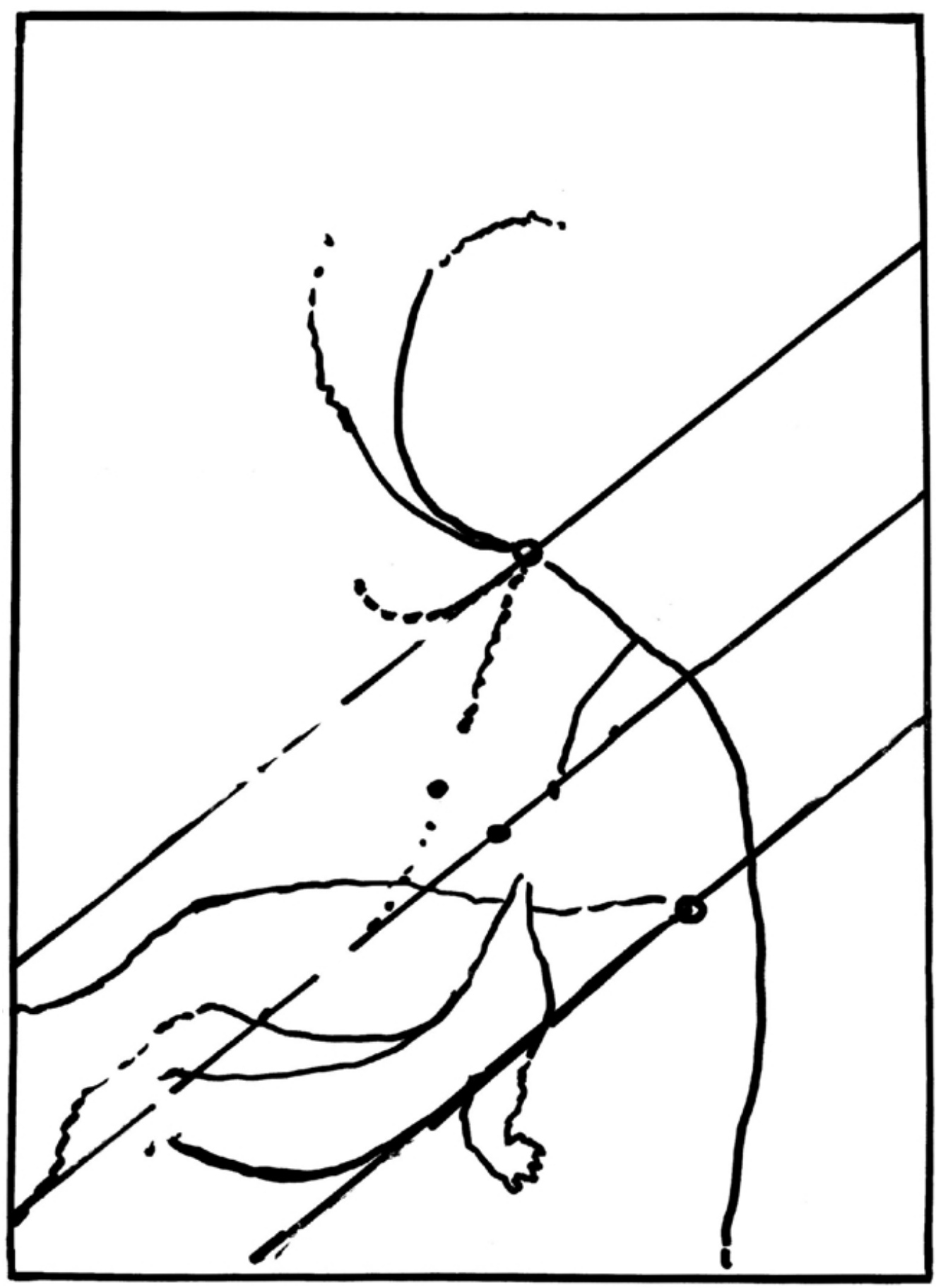

Figure 18. 'Lady with an Ermine.' Representamens of denotations are organized in systemstructural formations. Lines of contours are subordinated to diagonal structures. 
of Cecilia's shoulder and hand (figure 19). This assigns some importance to a small pad with a claw sunk into clothes. The beast denotes the Duchy and his claw symbolizes a tenacious power. The repetition of features strengthens the meanings. This is why unpleasant contours of small claws are repeated across the whole visual field (figure 20). Their sharp tips finish in active points. The connotation of claws is complemented by the analogy of configurations of contours of the animal and Cecilia. In the picture of shoulder folds, the configuration similar to a small lifted pad can be seen. Both of these configurations are expressed by light color (figure 21).

Numeric structures are organizing ones in visual art works (Somov 2007a). In this case, an organizing numeric structure carries some meaning. A small grasping pad with four claws forms a unified quatro-structure of the image. This structure is materialized in basic denotations. In particular, the denotations demonstrated earlier in figures 12 and 13 form the groups of four elements: four eyes, four parts of the polecat's body (head, body, and two pads), four light spots in the lower part (hand, body, and head of the animal, and red-and-white configuration of clothes), four light fields on Cecilia's neck and breast, and four large light flesh-colored configurations, including lady's head, neck, and breast, light group of elements of hand and animal, and red-and-white configuration of clothes. In addition, four zones of composition are formed: (1) Ceci-lia's head, (2) lower part of the image, (3) dark background in the left part, and (4) the background in the right part. The image of lady's head and face also is based on quatro-structures. Four elements outcrop actively on the face: eyes, lower part of the nose, and lips. Cecilia's head (the light part, the face) is divided into four parts. The four-part groups appear to be formed according to various differential characteristics and at different levels of composition (signals, representamens of denotations, denotations, signs, and sems). The materialization of quatro-structure (polecat's pad with four spread claws actively marked by the background) forms an active sign.

The binary structure complements the quatro-structure. Two eyes of Cecilia and two eyes of the animal continued by the line of nose are developed in other active elements. This is why two fingers (forefinger and middle finger) and two strong shades under them are marked out on the hand, as well as two light configurations: the hand and the body of the animal, two arrow-shaped configurations of cloth folds in the right part.

The configurations of rapacious eyes are visually and semantically similar to the signs of claws (figure 22). The sharpened contour of Cecilia's eyes is analogous to the configuration of claws. The configurations of eyes-claws seem to point at an mportant object. This produces the 


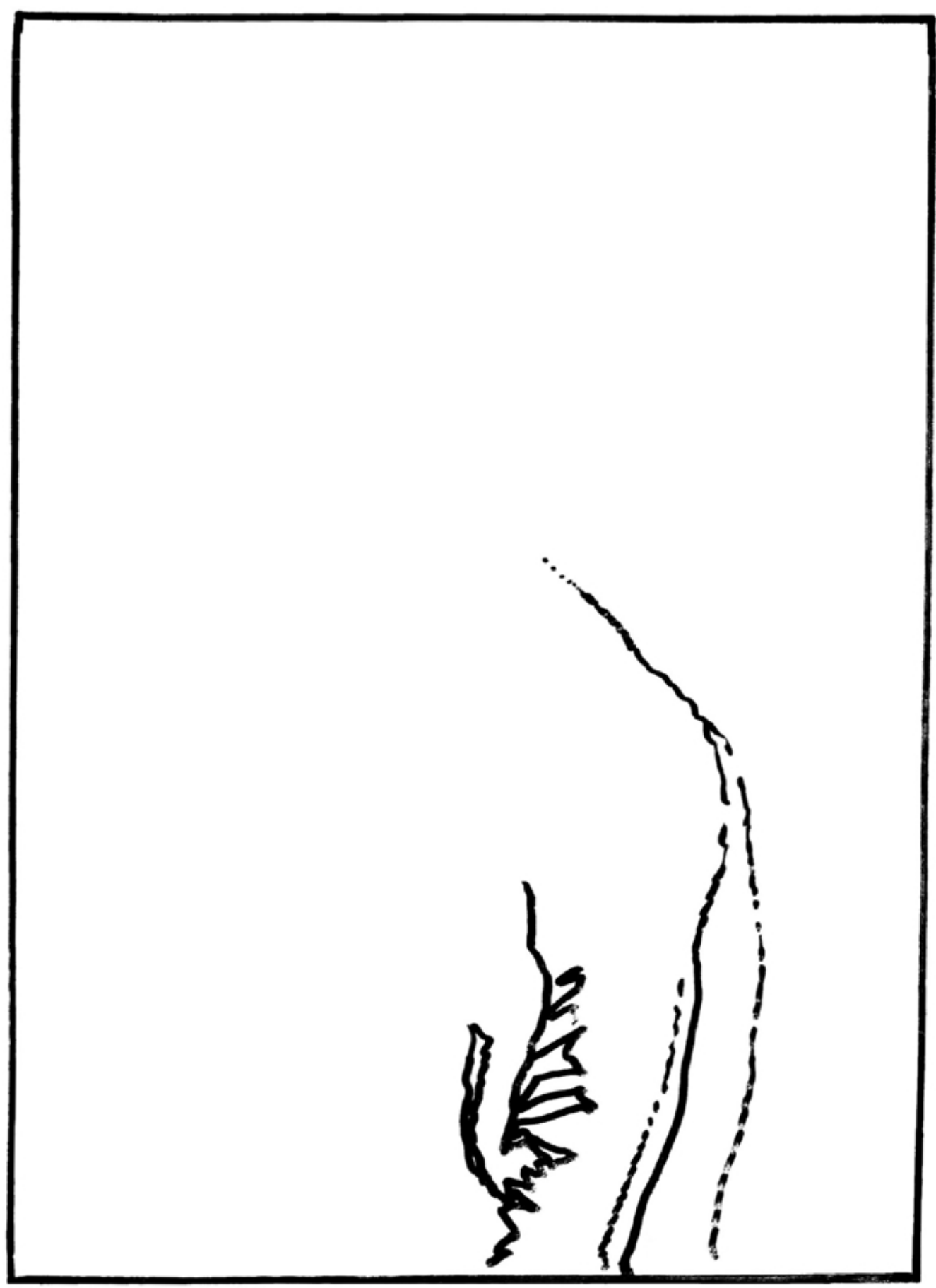

Figure 19. 'Lady with an Ermine.' The organization of signals contributes to the formation of connotations. The analogy of animal pad is created in the lines of contour of the lady's figure. This analogy underlines the significance of this pad and its claws. 


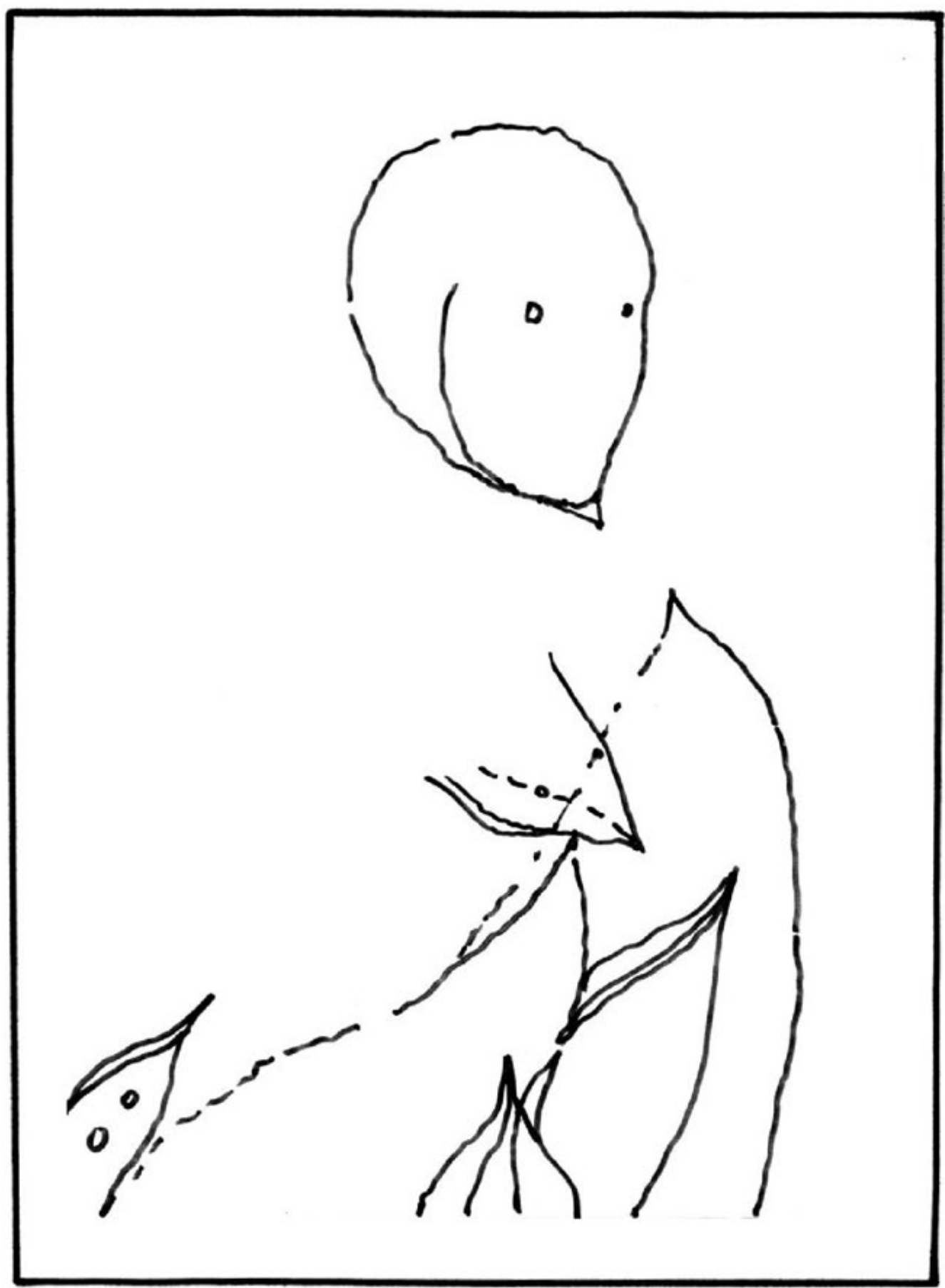

Figure 20. 'Lady with an Ermine.' Sharp contours of small snouts form a unified characteristic of sharp claws and eyes. 


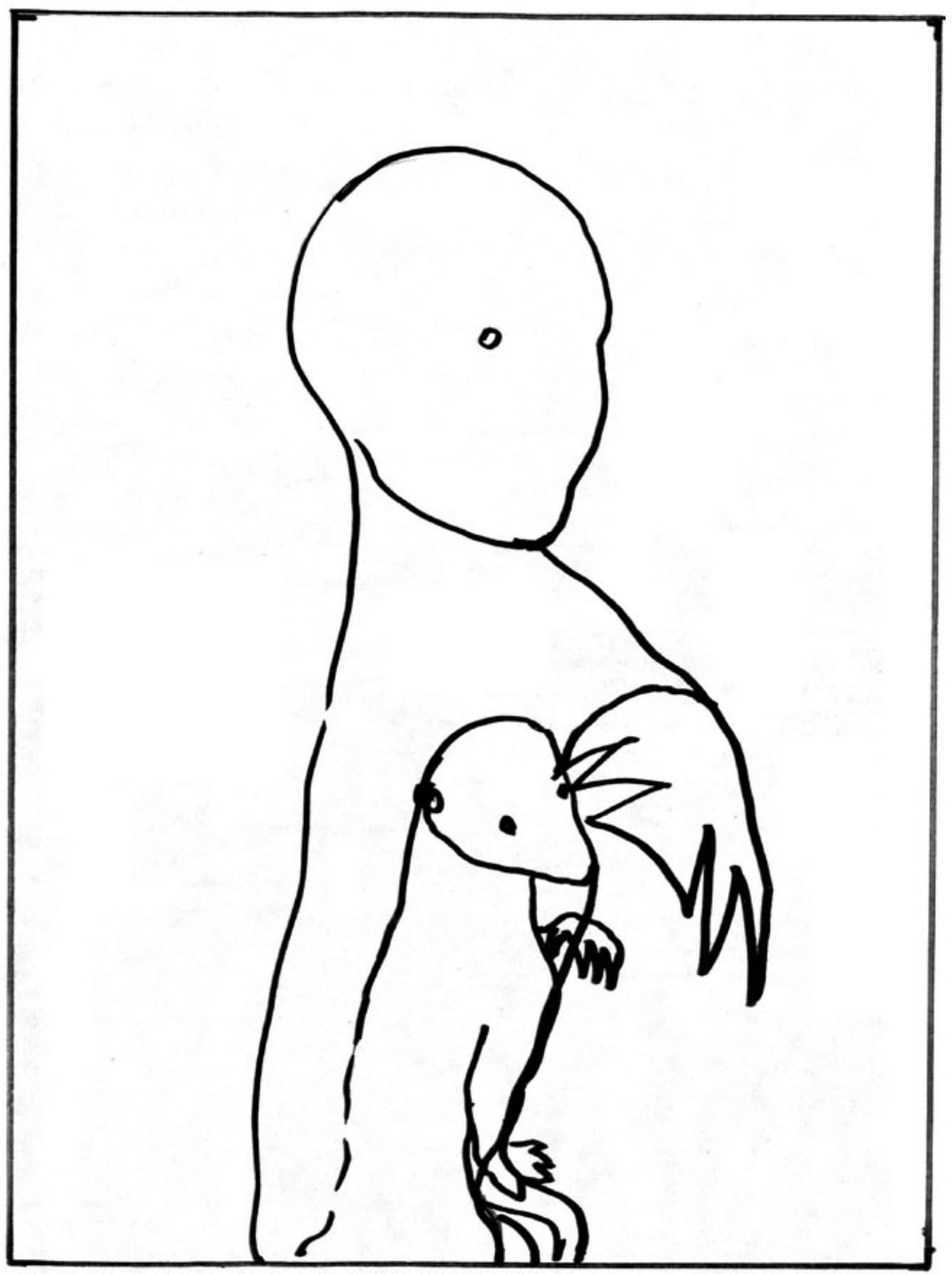

Figure 21. 'Lady with an Ermine.' Configurations, which are analogous to the figure of the animal with a pending pad. Color and light-and-shade pattern of the shoulder strengthens the analogy. 


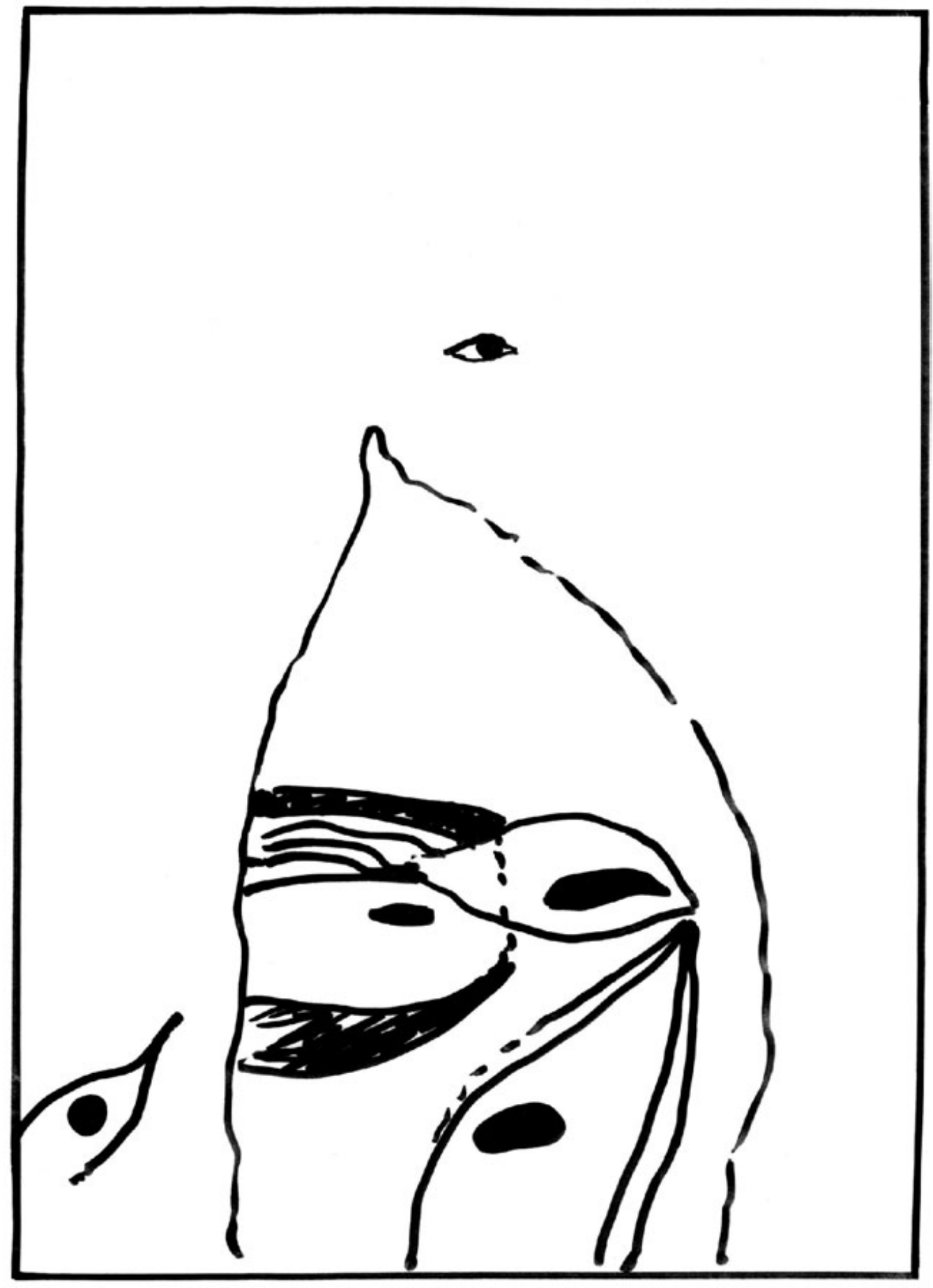

Figure 22. 'Lady with an Ermine.' Eyes-claws. Configurations are formed by lines and points. 
impression of a sharp penetrating look. Together with figure motions, the meaning of purposefulness, vigilance, and tenacity, which was intrinsic to the authorities of Milan, is formed. The configurations resembling climbing claws appear (figures 23 and 24). In this system, the sharp nod of clothes on the shoulder is important. It brings together the dynamic forms of clothes and becomes a focus point of sharpened configurations (figure 25). This point is materialized actively by color and represents a beam of differential characteristics. It is here where dark and light bluish green and red cloth folds meet. Therefore, this nod is important as both an organizing signal and an element in the sign system of eyes and claws.

Configurations resembling claws and eyes also are developed in the shades of cloth folds (figure 26). The characteristics of active configurations (arrow-, claw-, and eye-shaped) are built in organizing configurations and contours and many times reinforced by identities. This promotes the identification of these characteristics in visual perception. In general, the systemities of characteristics and configurations represented in figures 19-26 enhance the formation of visual meanings. Claw-shaped contours produce the feeling of tenacity. Arrow-shaped configurations similar to eyes produce the feeling of tension and piercing look. The features of ascents and splashes develop the meaning of spiritual ascent.

Signals are organized structurally in visual art works (Somov 1975, 2005). Configurations, lines, and points obtain the character of systemstructural formations (figures 27-30). In particular, the elements of dissection and internal field of configurations, marked in figure 28, form a systemity. The configurations partitioned by dark lines are referred to as active signals (figure 29). Black lines form their own systemity. A thin black line of fillet is continued below in the picture of beads. The beads form the line of black circles, which is thicker than the fillet line. Developing a linear character of the image, they make a contrast with the fillet line. A broad black stripe of dress encounters the breast and neck. The artist did not continue this broad black stripe in the clothes on the right side. There, it would have cut the integer configuration of alight shoulder. He used this stripe as an active frame of breast, neck, and head, organizing them into an integer light configuration. A pronounced contrast of black lines was created. The broad stripe is opposed to the thin fillet and small circles of beads. The broad stripe is linked with the thin fillet by even thinner black lines under the stripe. In general, the system of differences and identities of black lines is formed composing a general ornament. There is a structural transition from broad dispersed and secluded black ornaments of the lower part to black strips of the upper part of the portrait. They represent sign forms. This is illustrated by large configurations partitioned by diagonal lines (figures 31 and 32). This line pulses 


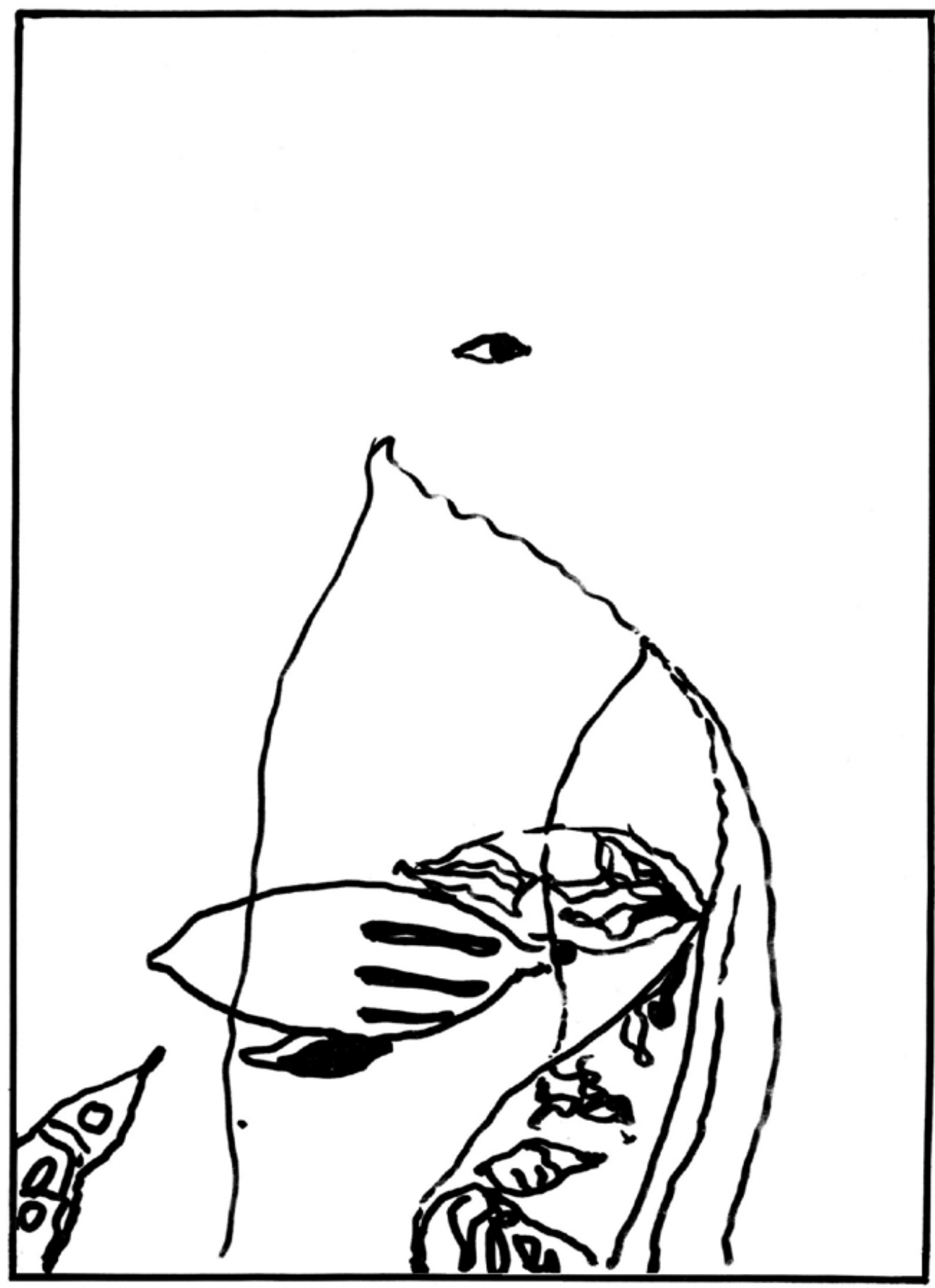

Figure 23. 'Lady with an Ermine.' Partitioning of configurations of eyes-claws. Eye-shaped configuration is partitioned by a complicated pupil-like ornament. 


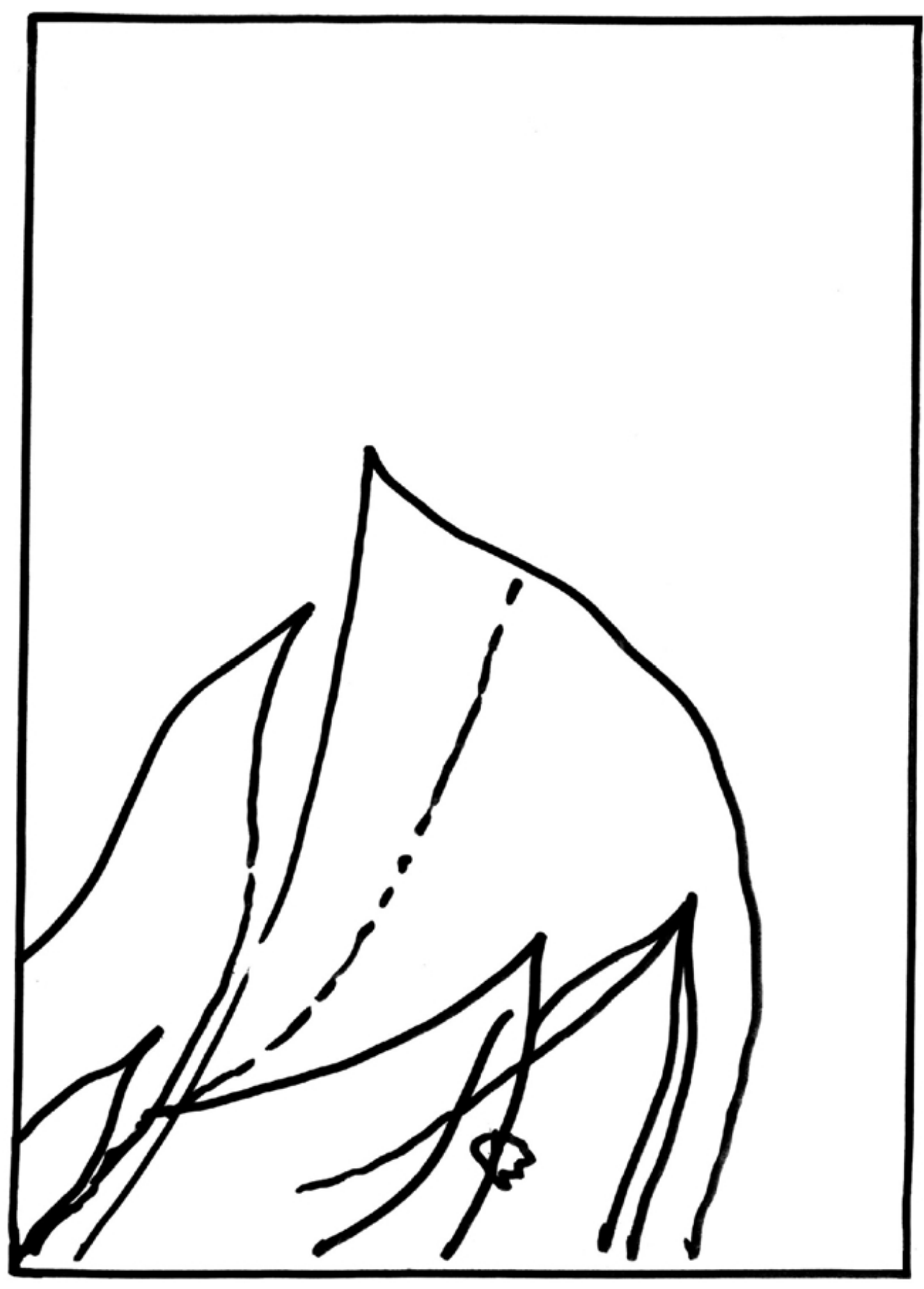

Figure 24. 'Lady with an Ermine.' Claw-like configurations as organizing elements. 


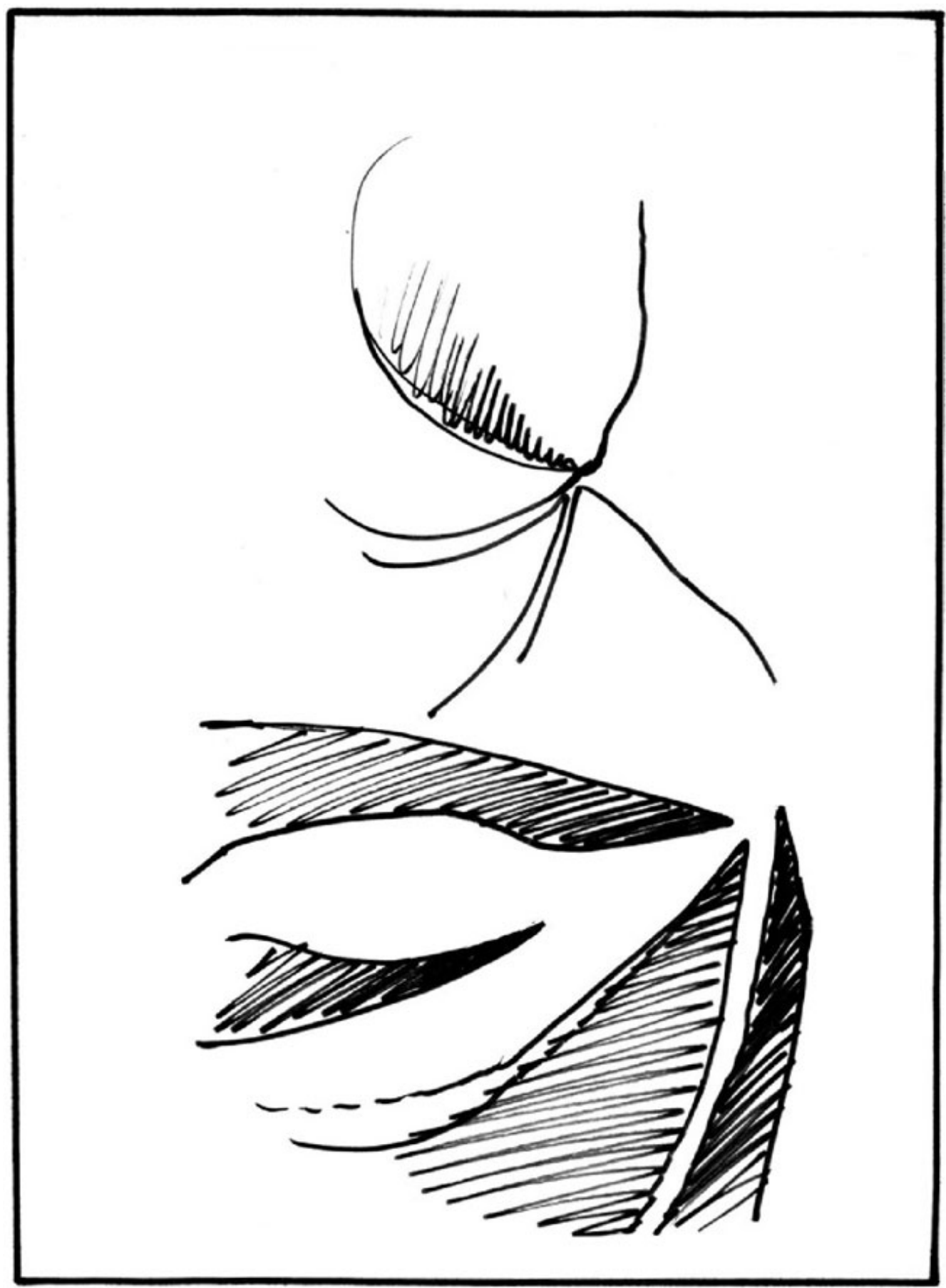

Figure 25. 'Lady with an Ermine.' Claw-like configurations forming dark elements.

generating an ascending rhythm. Like the configurations represented in figures 8-11, this denotes motion and ascent. Each of the parts detached by the line represents a perfect dynamic form. The contour of the lady's head and shoulder, the point of line focus on the edge of the image, and 


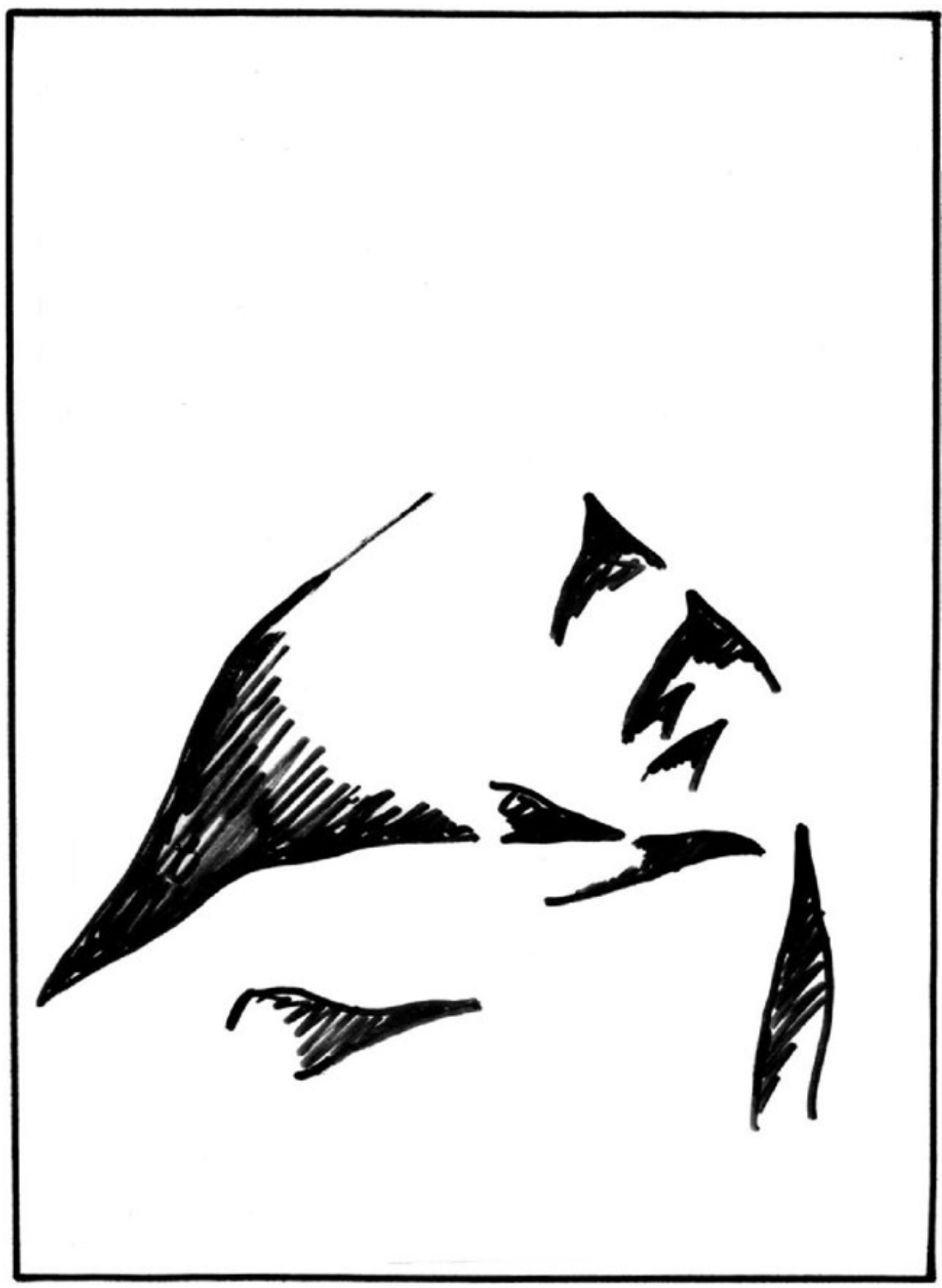

Figure 26. 'Lady with an Ermine.' Organizing shades resembling small claws. 


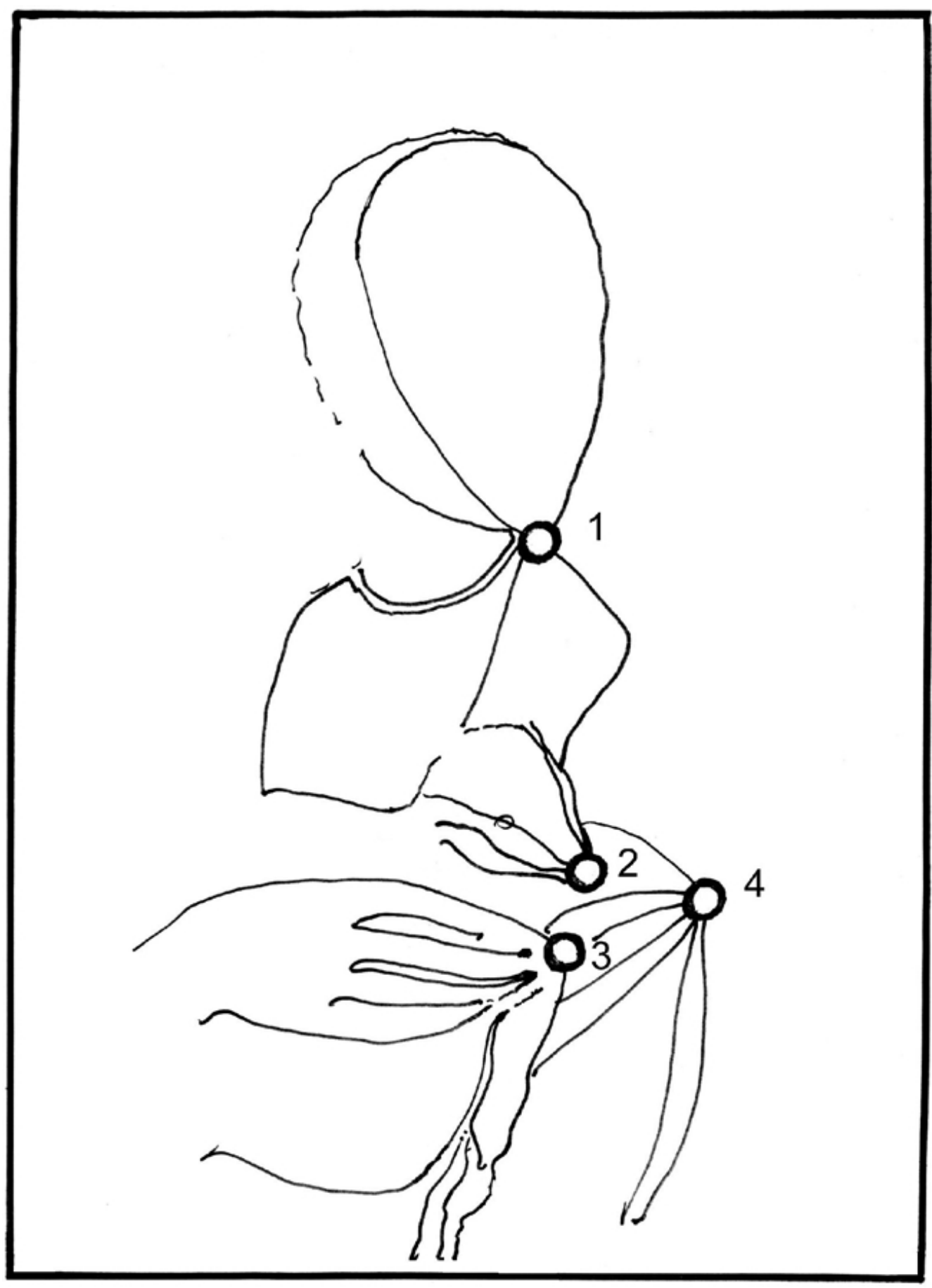

Figure 27. 'Lady with an Ermine.' Configurations formed by dark lines are organized into an integer systemity. 1, 2, 3, 4- centers of convergence of lines of active configurations. These configurations strengthen visual analogy of main elements to the snout of small beast. 


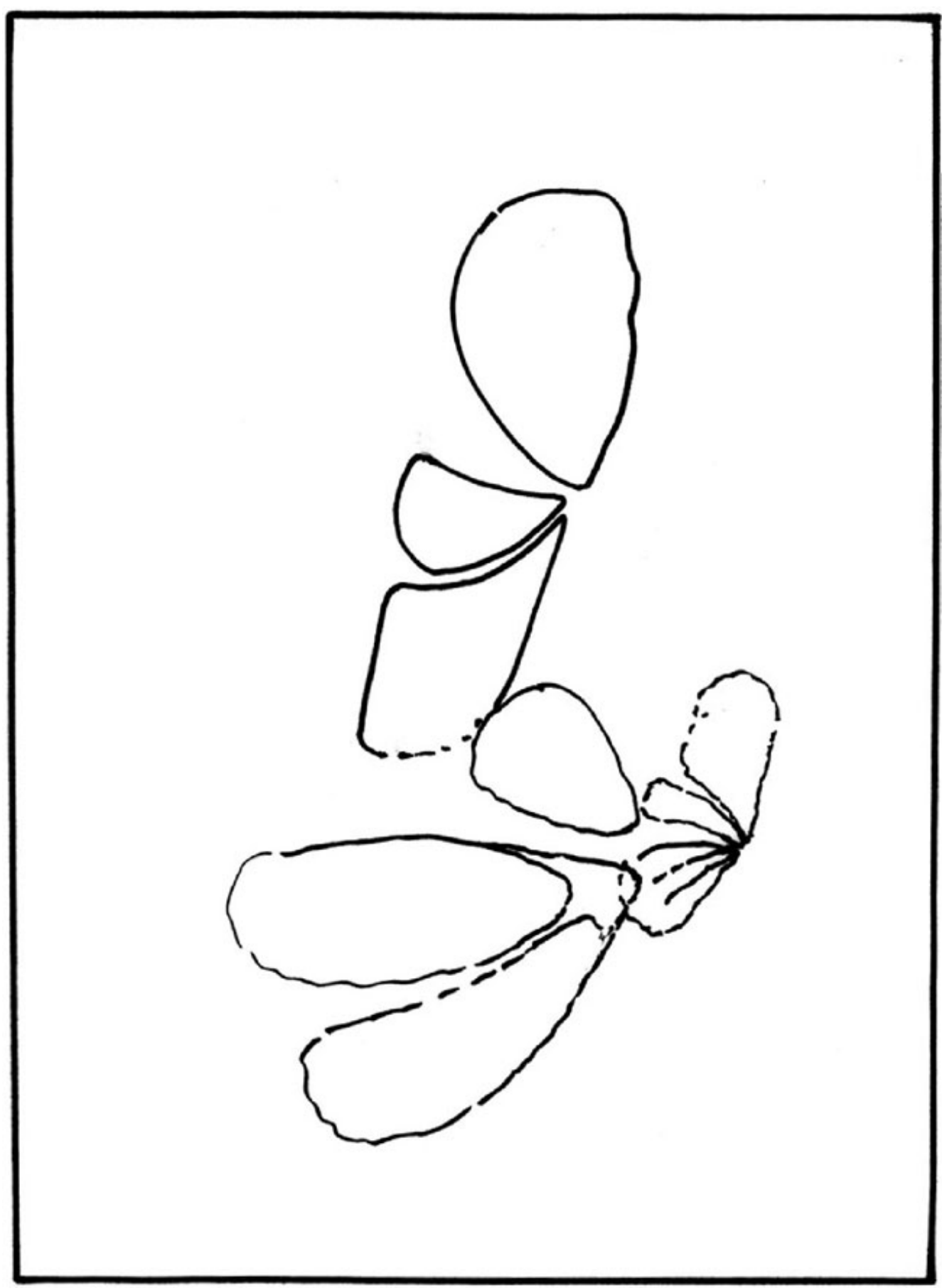

Figure 28. 'Lady with an Ermine.' Light flesh-colored configurations as organized in a systemity. 


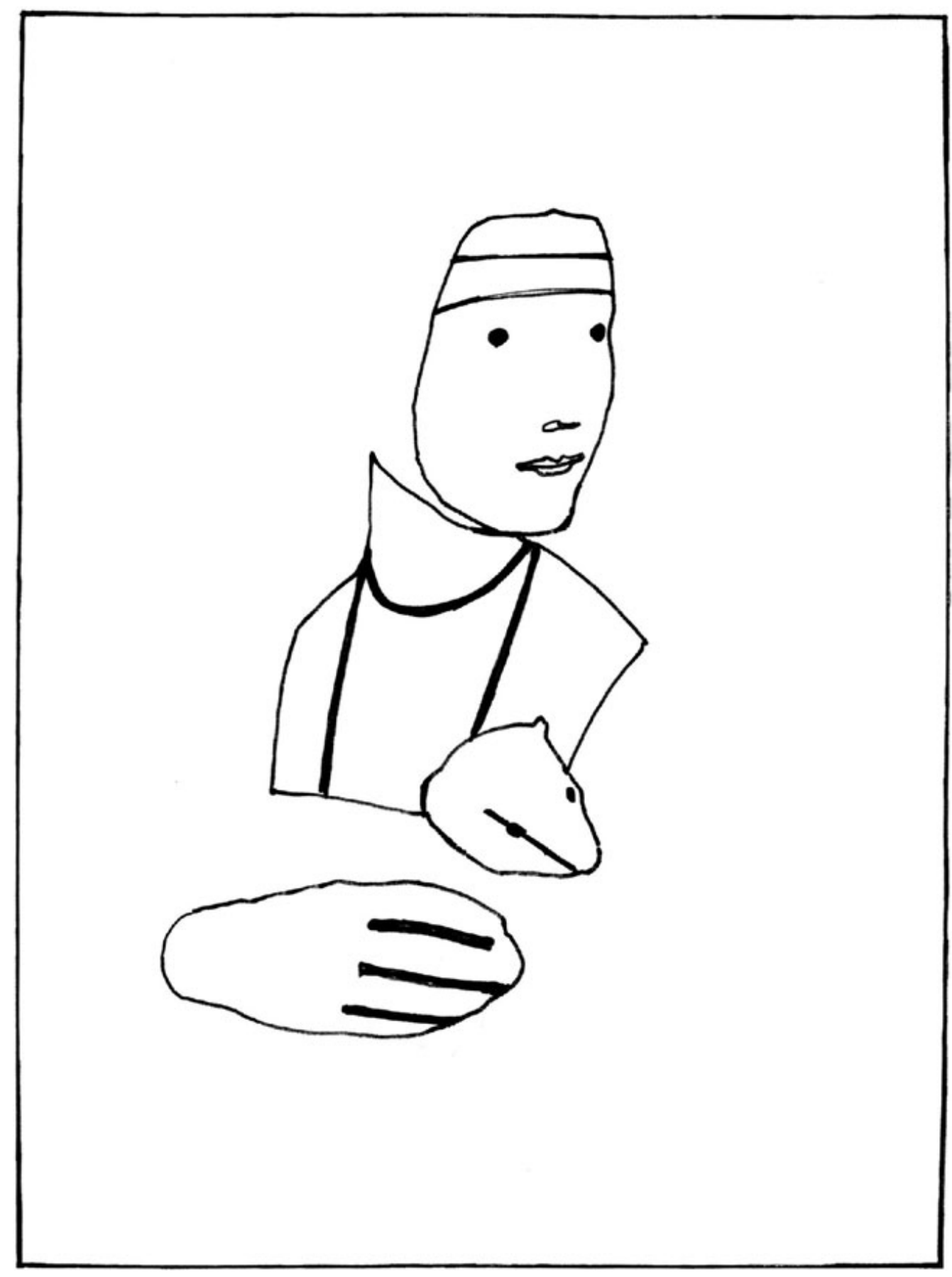

Figure 29. 'Lady with an Ermine.' Organization of signals. Groups of analogous elements. Dark lines and points partitioning major light configurations. 


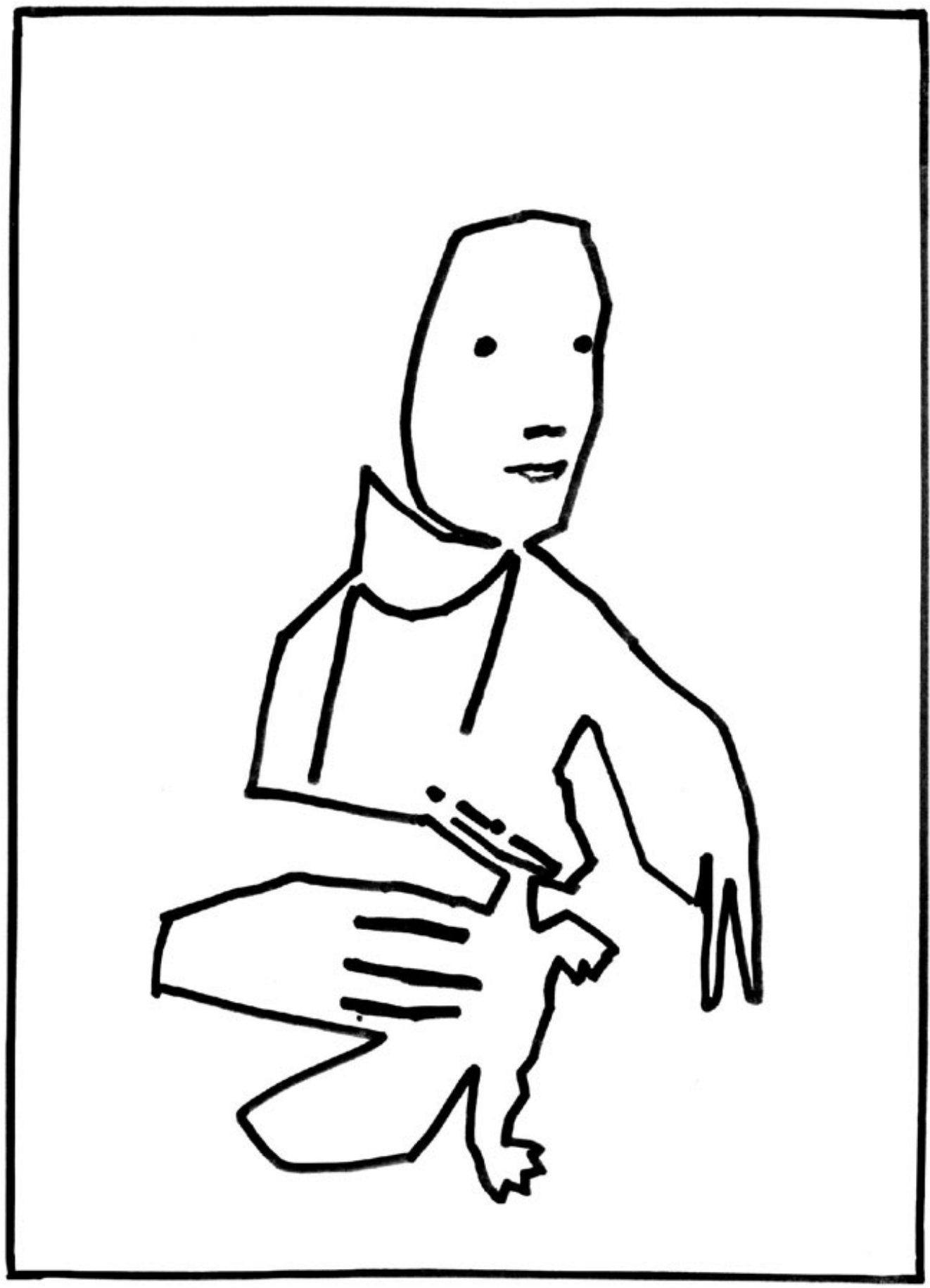

Figure 30. ' 'Lady with an Ermine.' Organization of signals. Configurations of light colors are organized in a general pattern. 


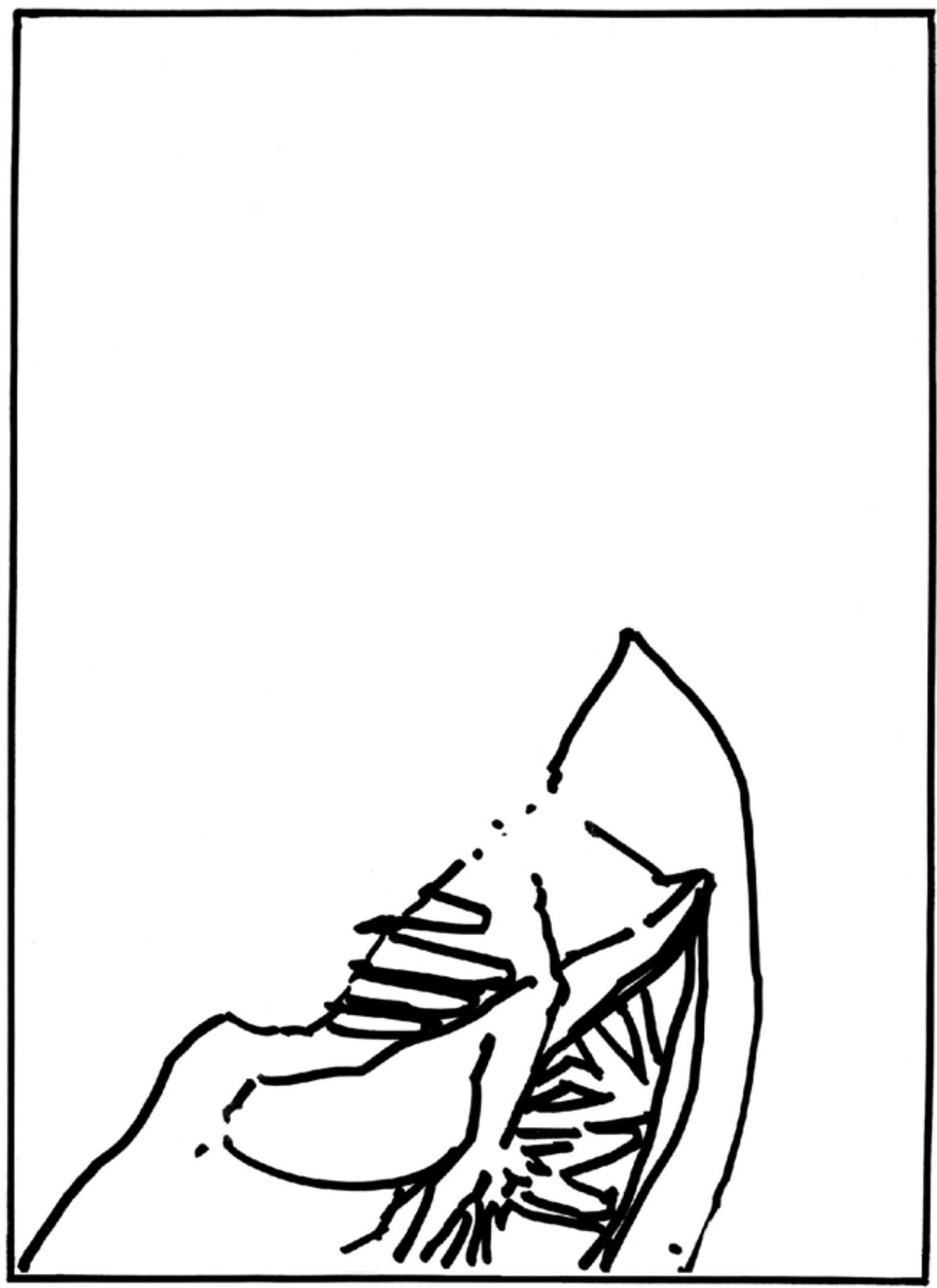

Figure 31. 'Lady with an Ermine.' Organization of signals. 


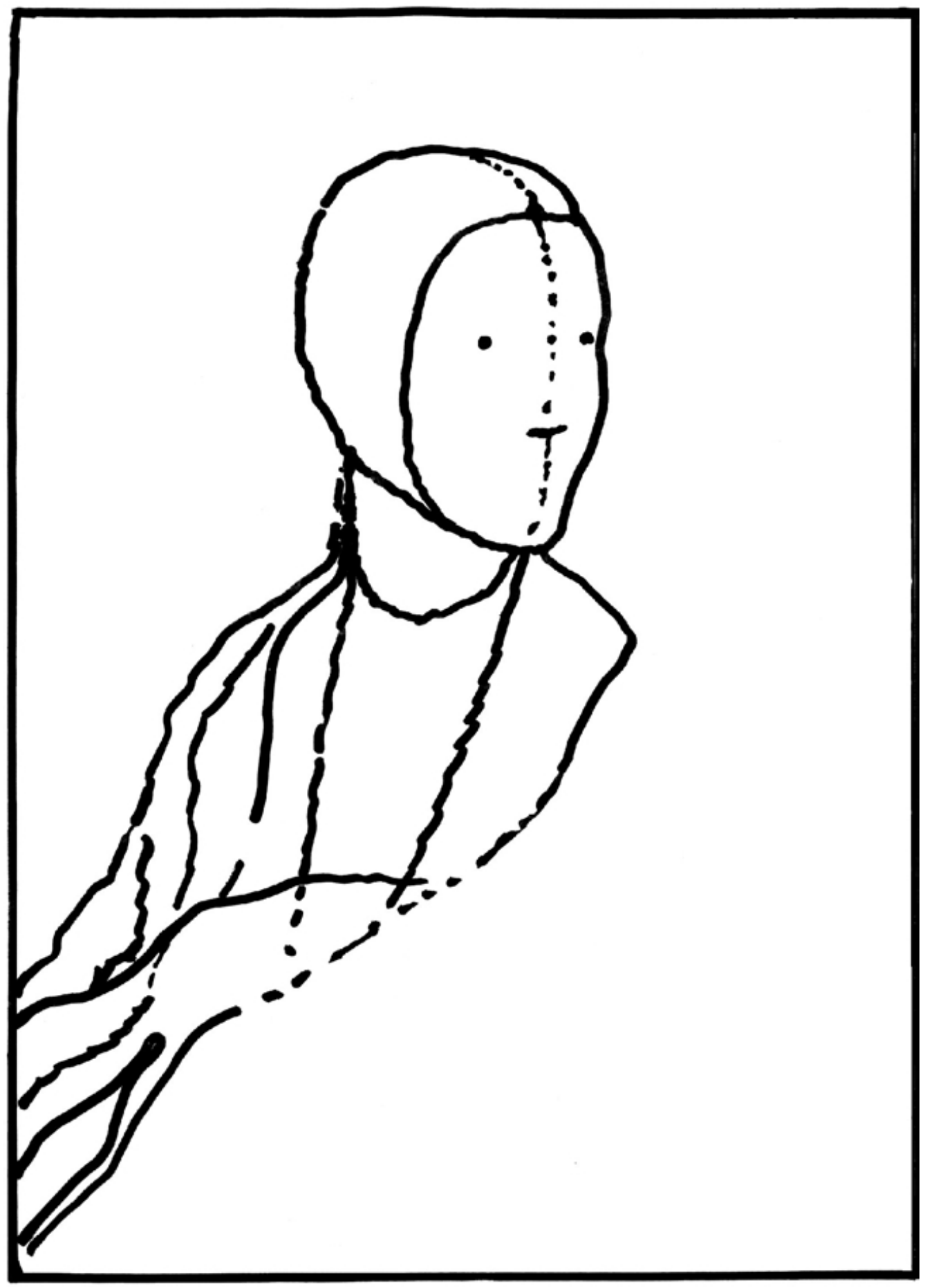

Figure 32. 'Lady with an Ermine.' Upper configuration of dynamic motion. 
some other elements form the system of triangles (figure 33). This assigns an even more organized character to the image.

Earlier, when analyzing visual art works, I have tried to demonstrate that the signs with basic importance and meaning demand the development of visual elements and form systemities (Somov 1986b, 1990). In connection with this, the representamens of the head, face, eyes, and hand of a person in a portrait are supported by the configurations and lines of larger elements of composition. The oval of the lady's face (like any other significant denotation of visual art) demanded a certain development, a creation of a larger analogous configuration. This was achieved by the image of a large oval in the contours of figure (figure 34). In this large oval, one can notice the features of a face with descending locks. An additional connotation is created. This analogy produces an extra, more obscure connotation (figure 35).

In general, when analyzing configurations, lines, and points of the painting, the role of structures and characteristics participating in the organization and mechanisms of identification seems to become more evident. These characteristics are very diverse. They are topological: open or close, convex or concave, symmetrical or asymmetrical; characteristics of contours: straight or curvilinear, broken or smooth, sharp- or obtuseangled, bends or breaks; those of internal partitionings: partitioned by lines or forming convergences (figure 35). These characteristics are the manifestations of structures. On the basis of each characteristic, certain relations emerge. The relations produced on one basis can be identical, while those produced on the other basis can be different. From the viewpoint of image saturation with structures, each image represents a series of tests. When analyzed, the masterpiece can be regarded as a kind of combination of many IQ tests by Eysenck. The structures of repeating Sshaped lines, ascents, and splashes link the characteristics providing the integrity of emotive meanings. The structures of denotative forms (axes and centers) interrelate denotations and its representamens.

The analysis of the portrait demonstrates that the structures are strengthened in characteristics and, in their turn, strengthen the characteristics. In the process of integration of differential characteristics, the integration of representamens and formation of sign integrities proceed (Somov 2001).

Lines usually are organized as independent signals in visual art works. In this portrait, the lines form a specific system-structural formation, which possesses its own dynamics. The motion starts from the left lower part, which supports the general construction of ascents represented in figures 10, 11, 31, and 32. S-shaped lines form a unified ornament (figure $36)$. Due to the analogy, smaller and less active S-shaped lines (2, 4-7) 


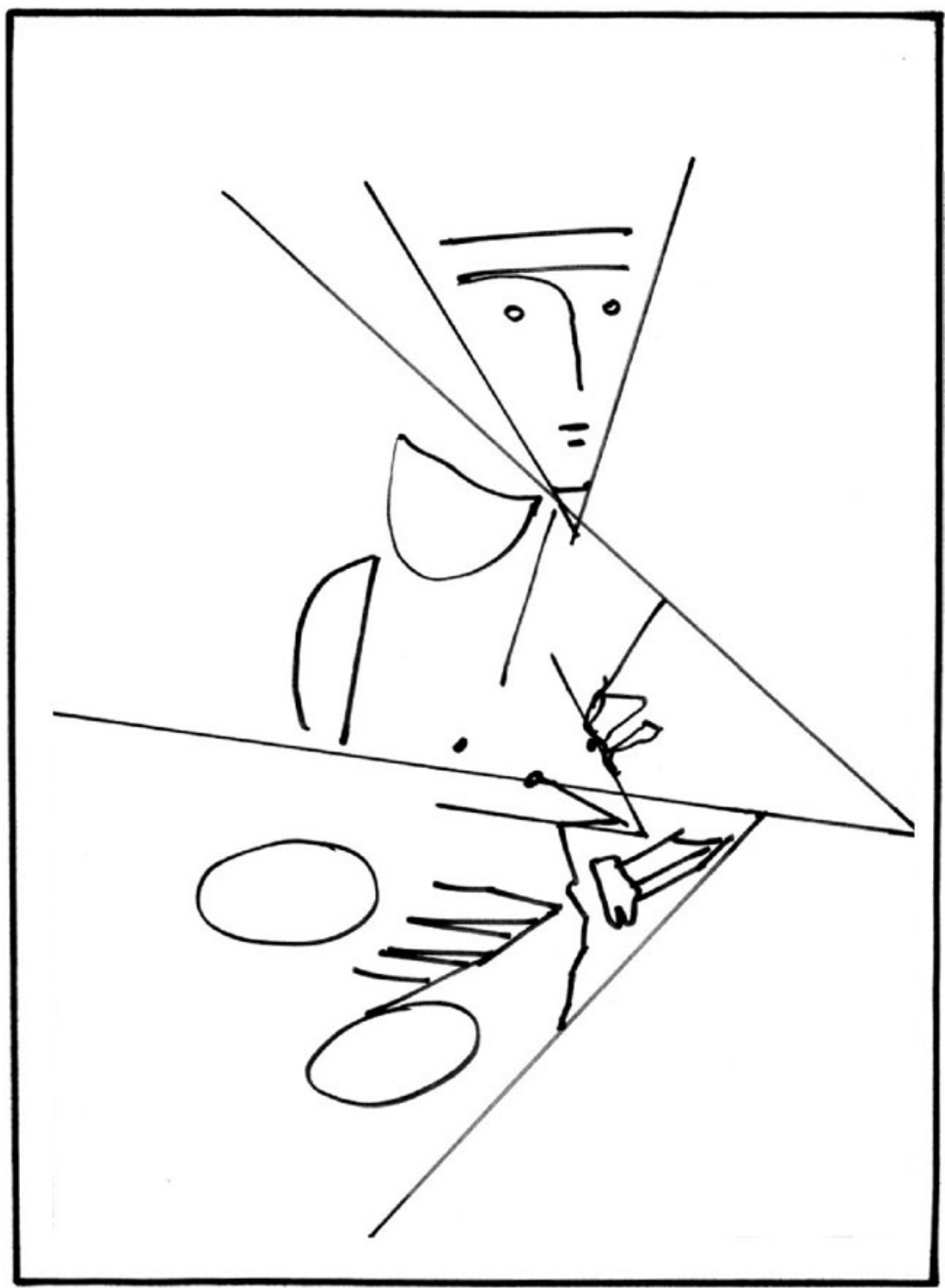

Figure 33. 'Lady with an Ermine.' Boundaries of configurations of triangle type. Basic configurations. 


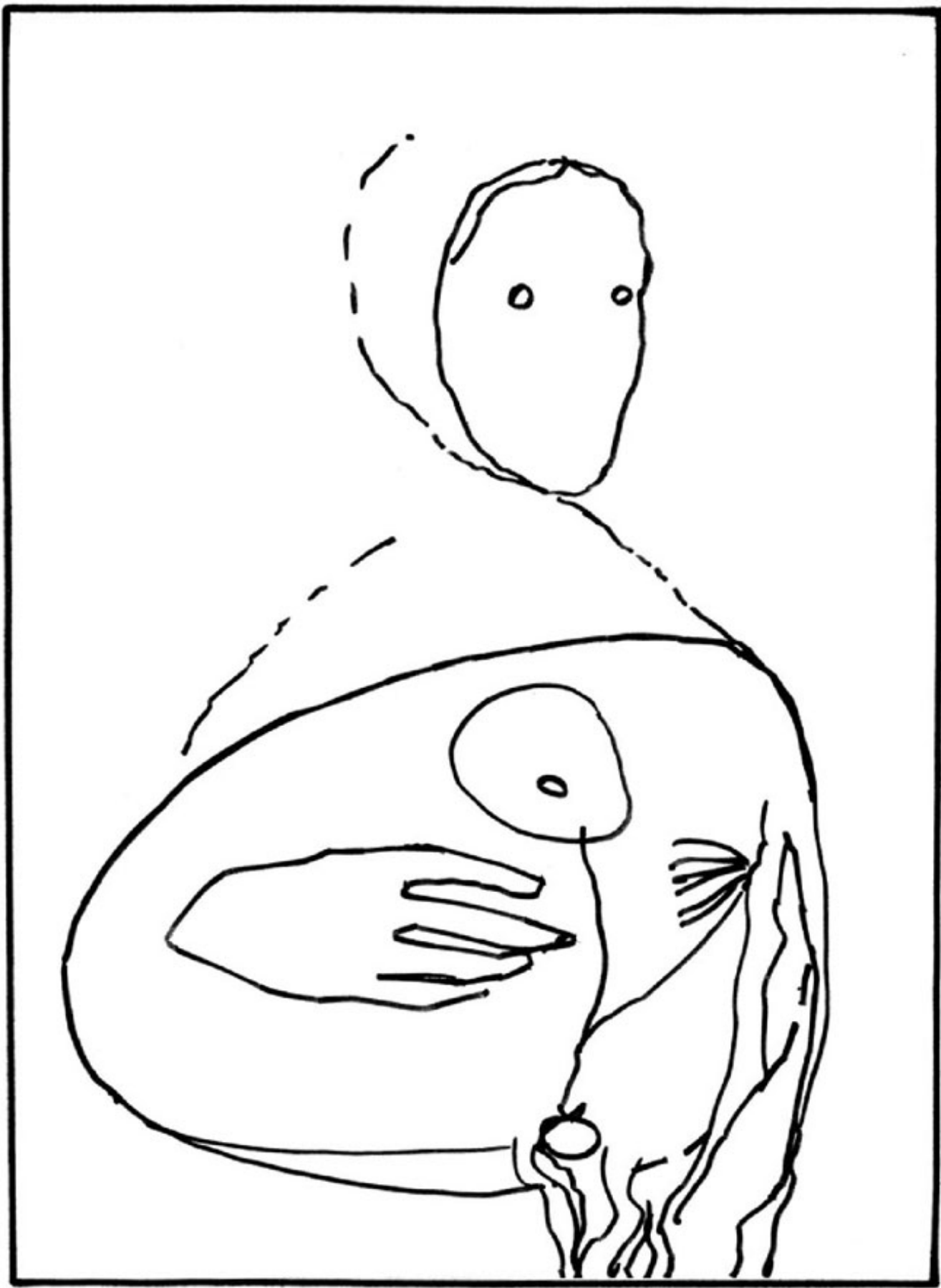

Figure 34. 'Lady with an Ermine.' Organization of signals. Groups of analogous elements. The configuration of the face is developed in a large configuration of the lower part. 


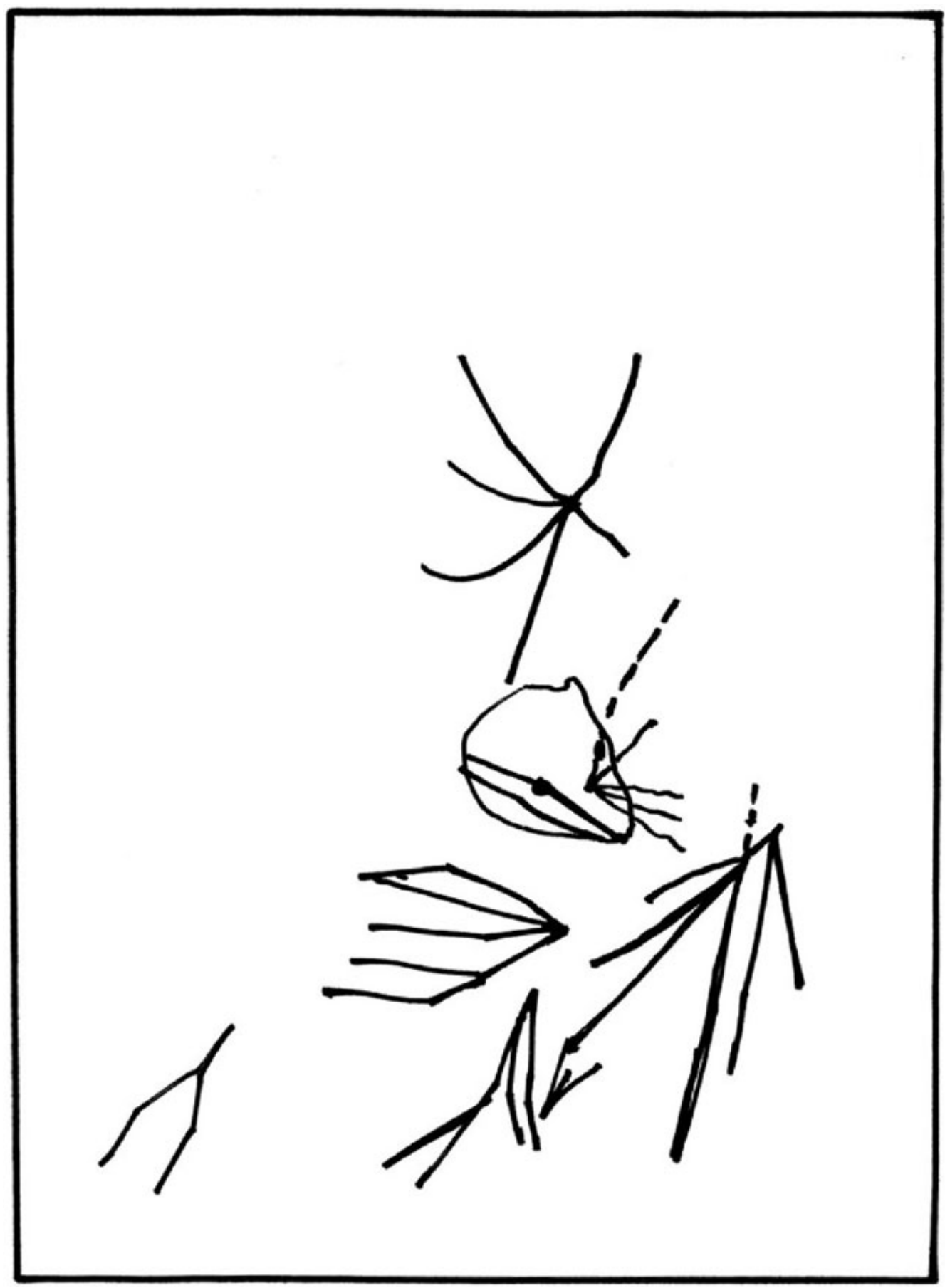

Figure 35. 'Lady with an Ermine.' Organization of signals. Groups of analogous elements. Points are formed on line forks. Line beams organized the image by an integer structure. 


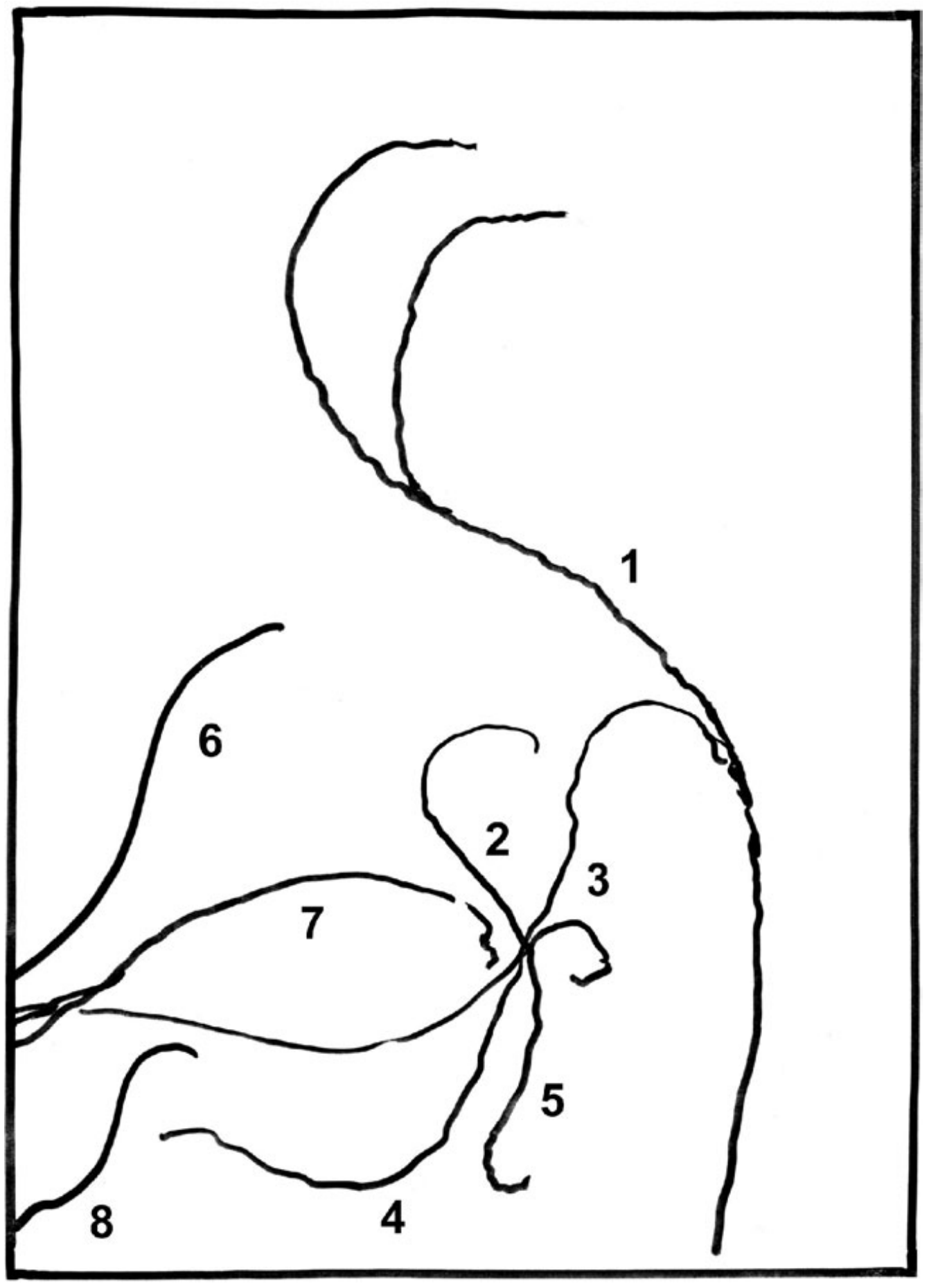

Figure 36. 'Lady with an Ermine.' Organization of signals. Groups of analogous elements. Sshaped lines. System-structural formations. Large S-shaped lines $(1,3,3-4,7)$ are supplemented by smaller lines $(2,5,2-5,6,8)$. 
contribute to the activation of the major line (1). The number of linear elements and other groups of elements equals seven, which corresponds to the regularity of $7+2$ (Miller 1956). In the group of lines, there is a systemity, which relates the major S-shaped line with other lines of the portrait. Two main nods of intersection of active lines with the S-shaped one are organized; they are placed under Cecilia's chin and on the animal snout. These centers increase the activity of representamens of basic denotations: the beauty's face and animal snout. The lines forming these points approach to the major S-shaped line. This principle controls active contours and the lines of the clothes, as well as the less definite borders of light and shade and boundaries of forms dissolving into light and shade. In general, the system-structural formation of active lines, their inter-flows, and interrelations is produced, which complements the systemity of contours represented earlier in figure 15. The forms of denotations and their perception in many respects are subordinated to this systemity.

Organizing straight lines also forms element-organizing structures (figures 37 and 38).

Interrelations between major denotations and image field. Like in other masterpieces of visual art, these are, first of all, interrelations of the proportions of the configurations of basic denotative elements and the rectangle of the image (figures 39 and 40). Earlier, I have tried to demonstrate that the dimensions and allocation of the most important depicted objects are interrelated with the rectangle of the whole composition (Somov 2005, 2006, 2007a). Cecilia's head is inscribed in a rectangle. This rectangle is geometrically similar to the general one and those formed between the axis of head and left edge of the portrait (figure 40).

The regularities of proportions of Cecilia's face and polecat's head can be revealed (figure 41). These internal partitionings with an active pattern form the finest and most active ornaments in the center of the portrait. In general, an integer system-structural combination of dimensional relations is formed. Generally, the structures of dimensional relations identify the most significant elements (Cecilia's face and head and parts of the an-imal body), both mutually and with the main signal — the general field of the image.

Signals and connotations form integer system-structural formations. The pattern of Cecilia's face is developed in the pattern of the lower part of the figure, which makes it possible to organize all the light elements of the portrait. In this case, the connotative function also is fulfilled. Basic contours of light and shade and active lines make it possible to see a large face with overhanging elements of fool's cap on the right side (figure 42). This merry grinning mask resembles a mummer. The lines of this connotation are clearly materialized by the boundaries of light and shade and 


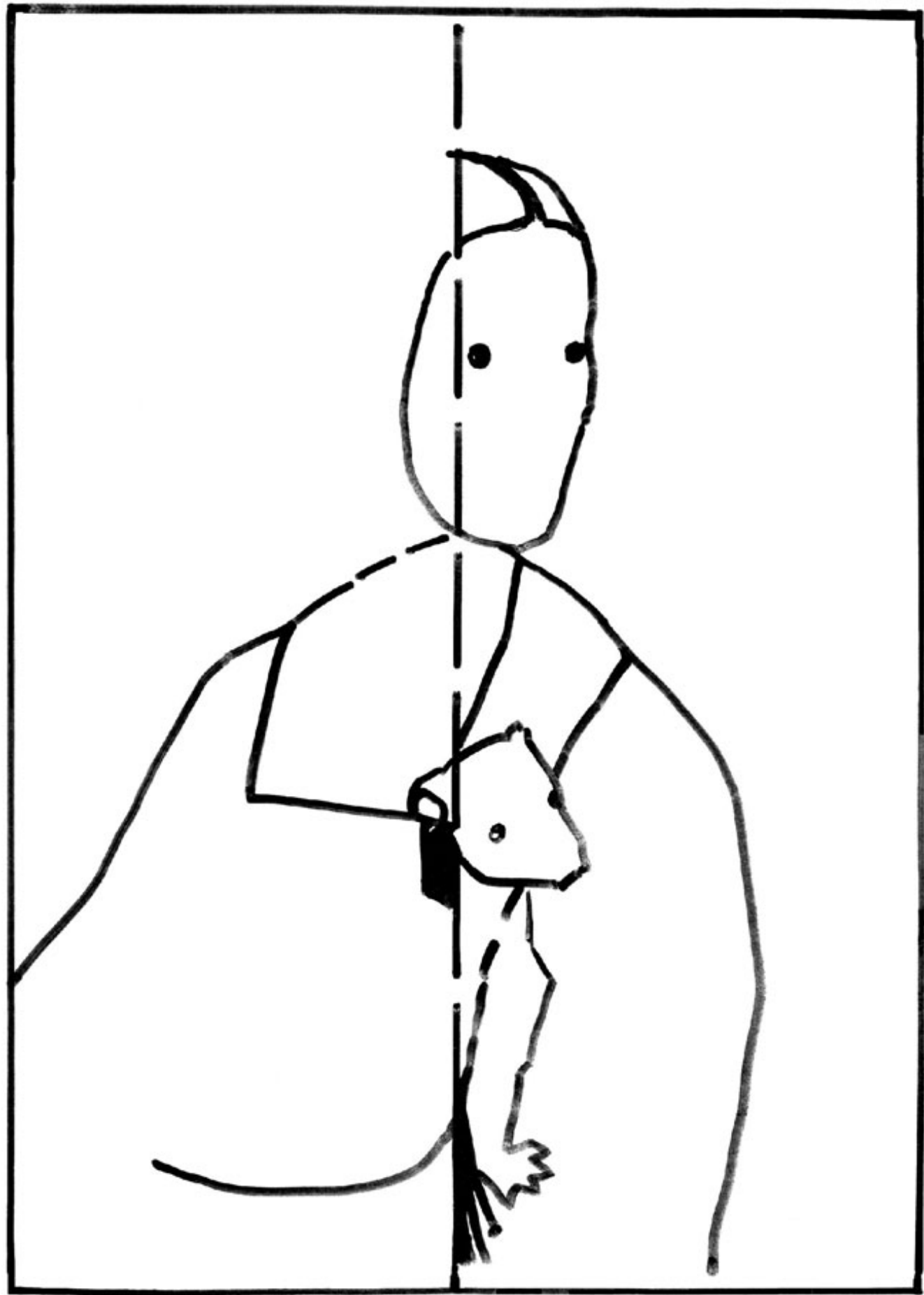

Figure 37. 'Lady with an Ermine.' Organization of the image field on the basis of symmetry. The axis of symmetry separates basic elements of the right part. 


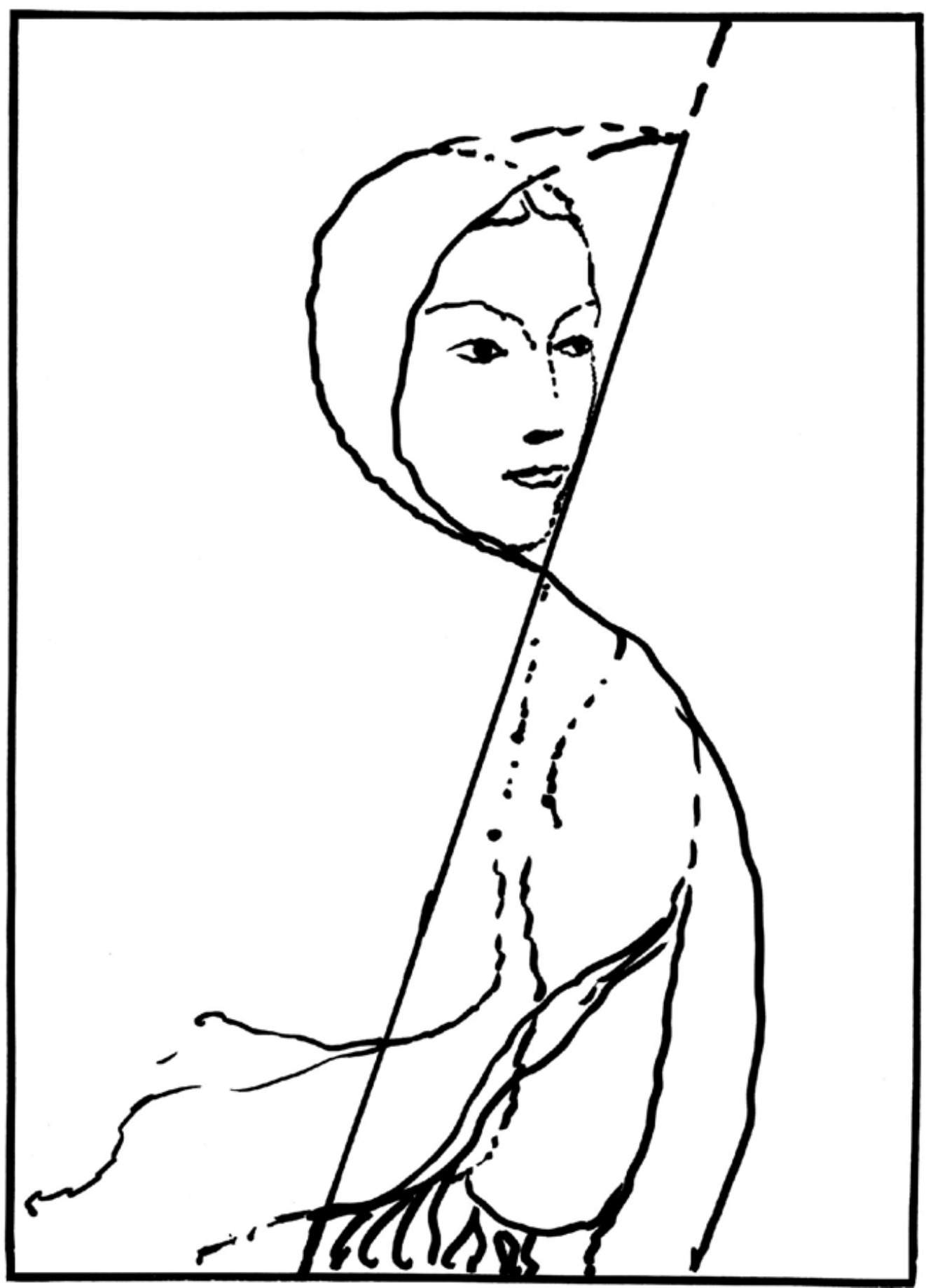

Figure 38. ' 'Lady with an Ermine.' Organizing elements on the basis of symmetry of the axis. 


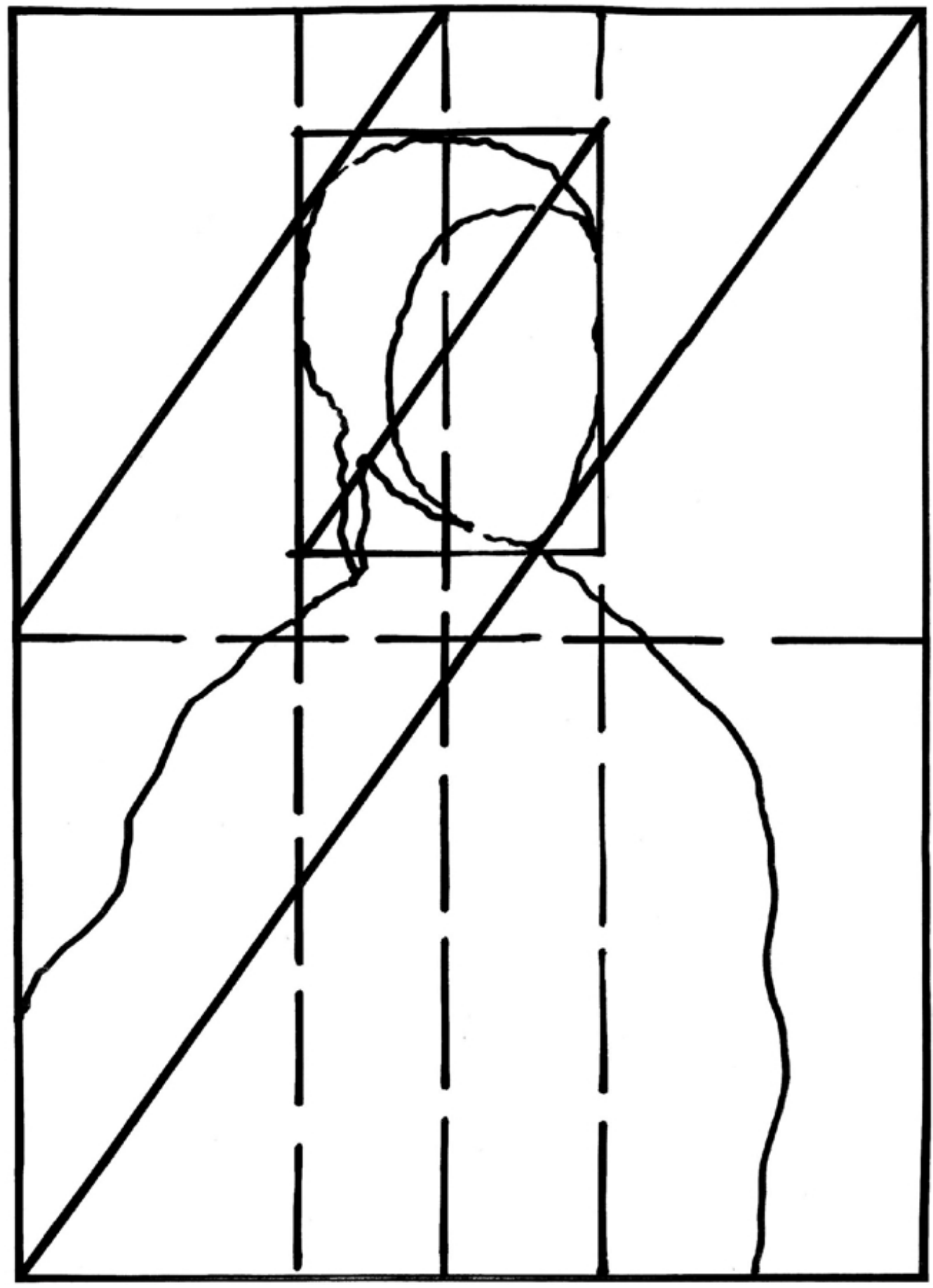

Figure 39. 'Lady with an Ermine.' Interrelations of denotations and the image field. Basic proportions. 


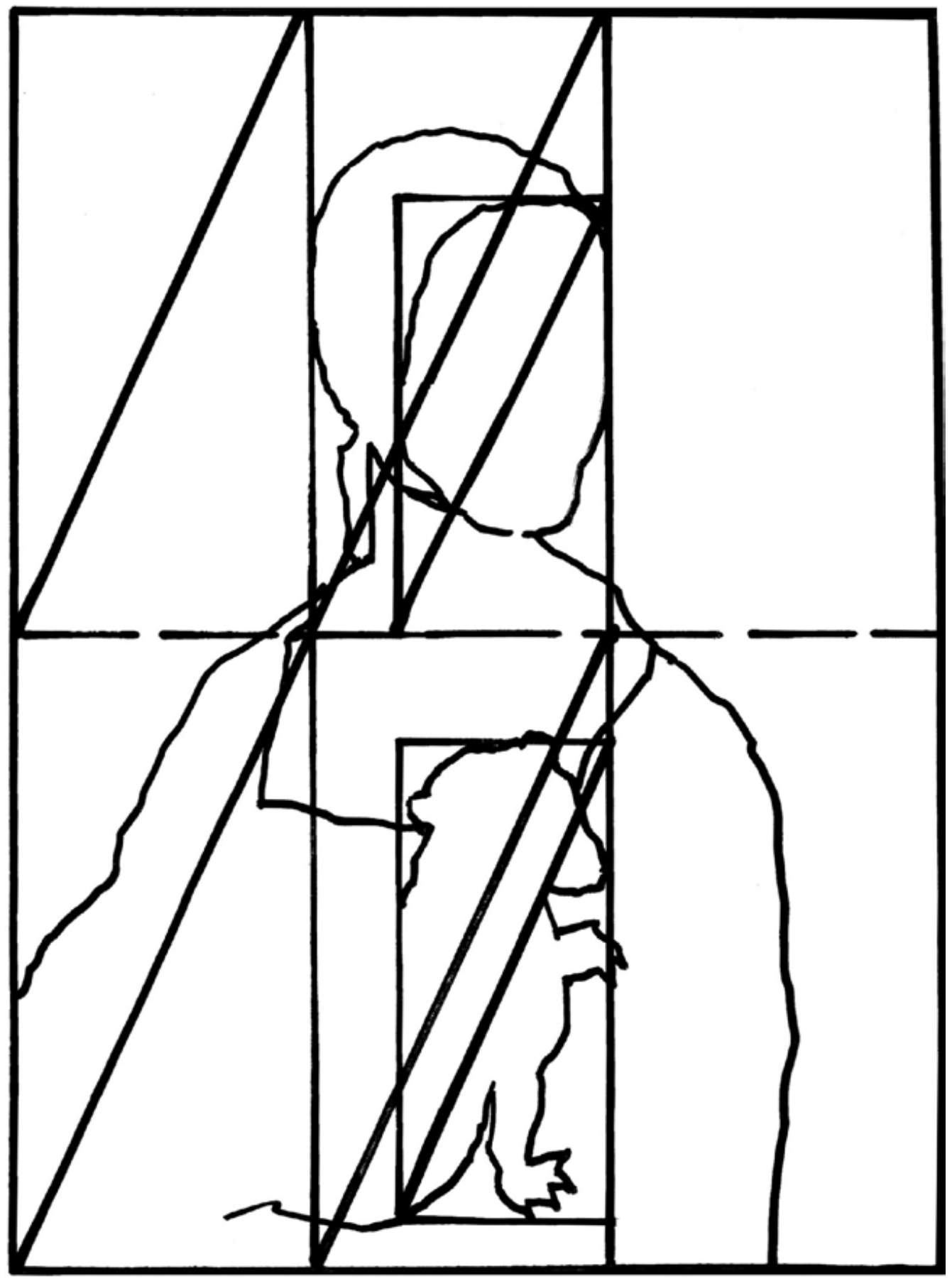

Figure 40. 'Lady with an Ermine.' Interrelations of denotations and the image field. Proportions of elements. 


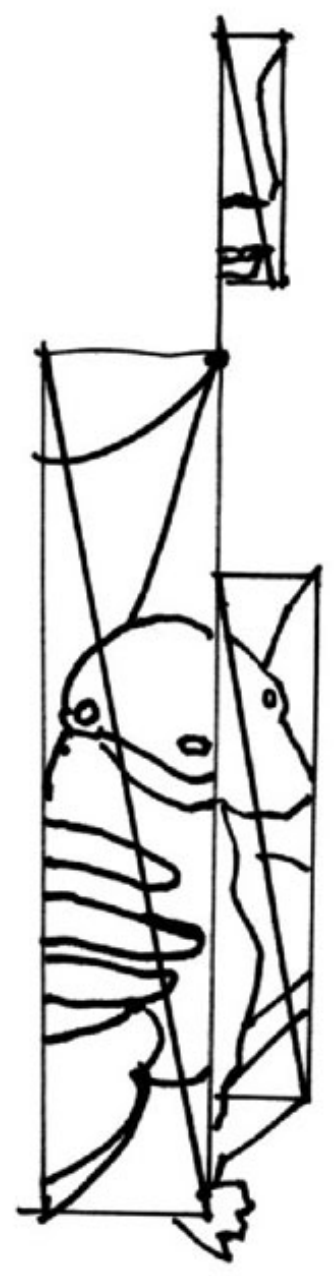

Figure 41. 'Lady with an Ermine.' Structure of dimensional relations. An aristocratic pattern of rectangles is formed, with inscribed major icons. 


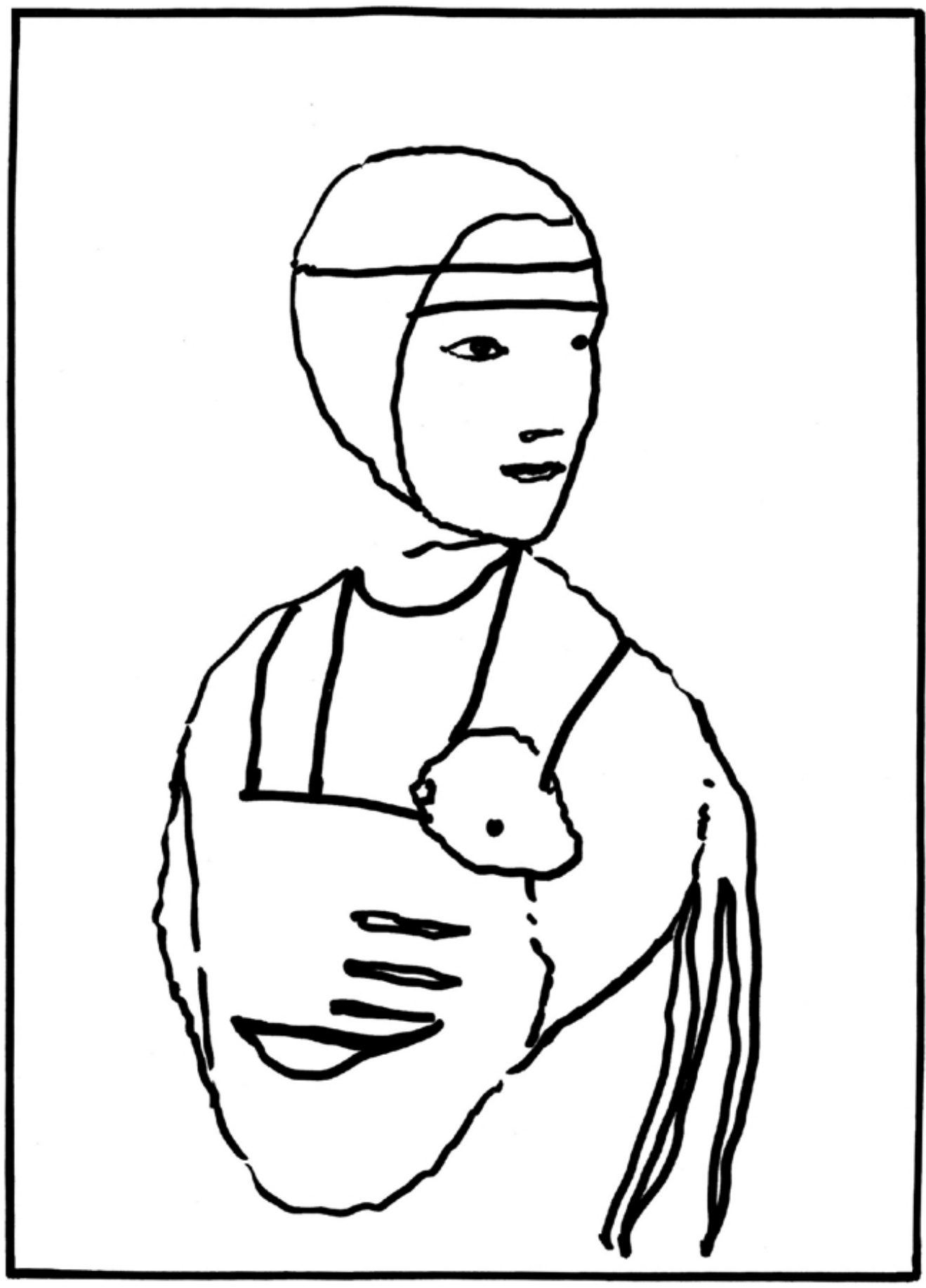

Figure 42. ' 'Lady with an Ermine.' Organizing configurations obtain the character of connotation; the pattern resembles a head. 


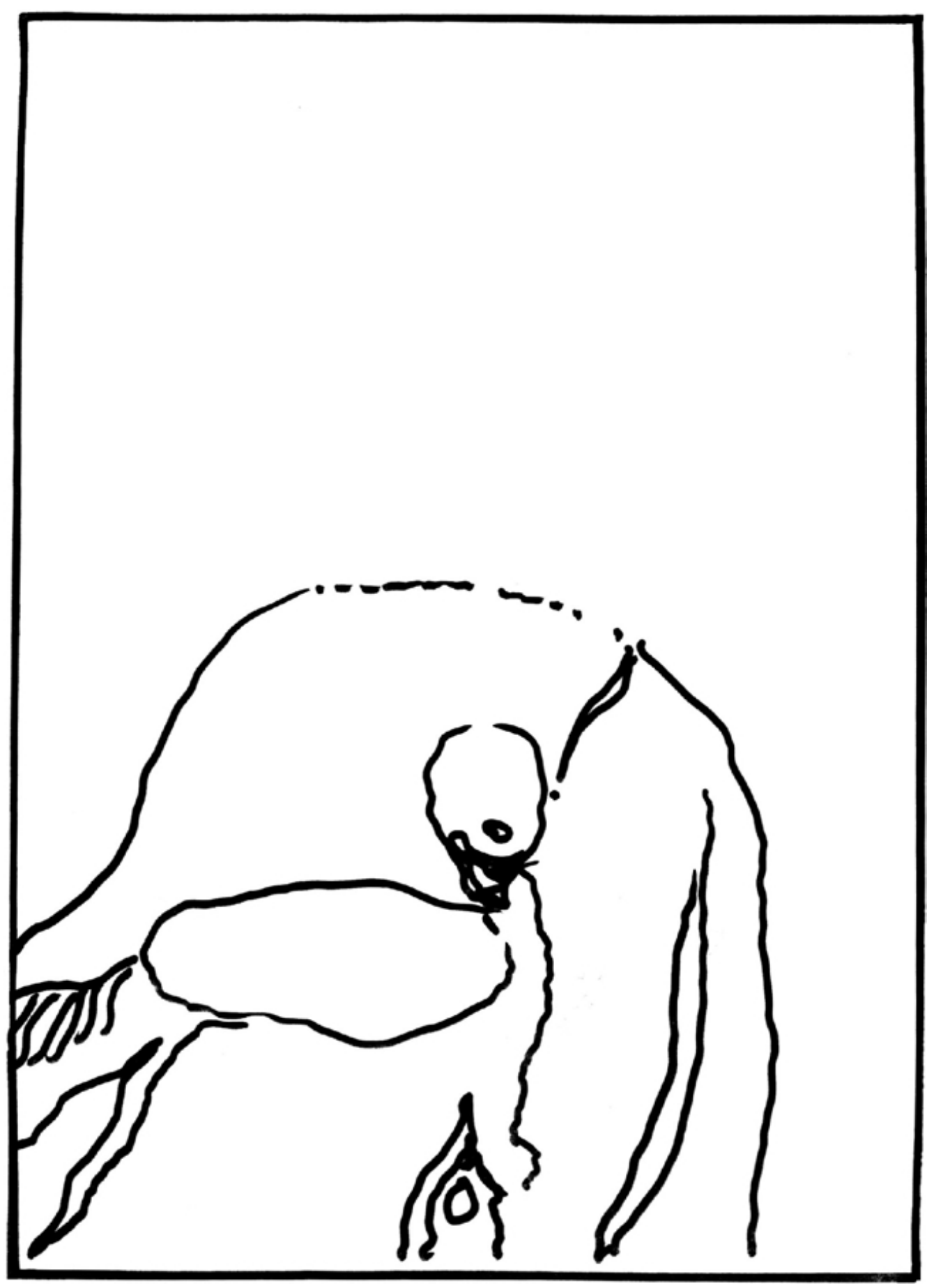

Figure 43. ' 'Lady with an Ermine.' Organizing connotation of the head. 


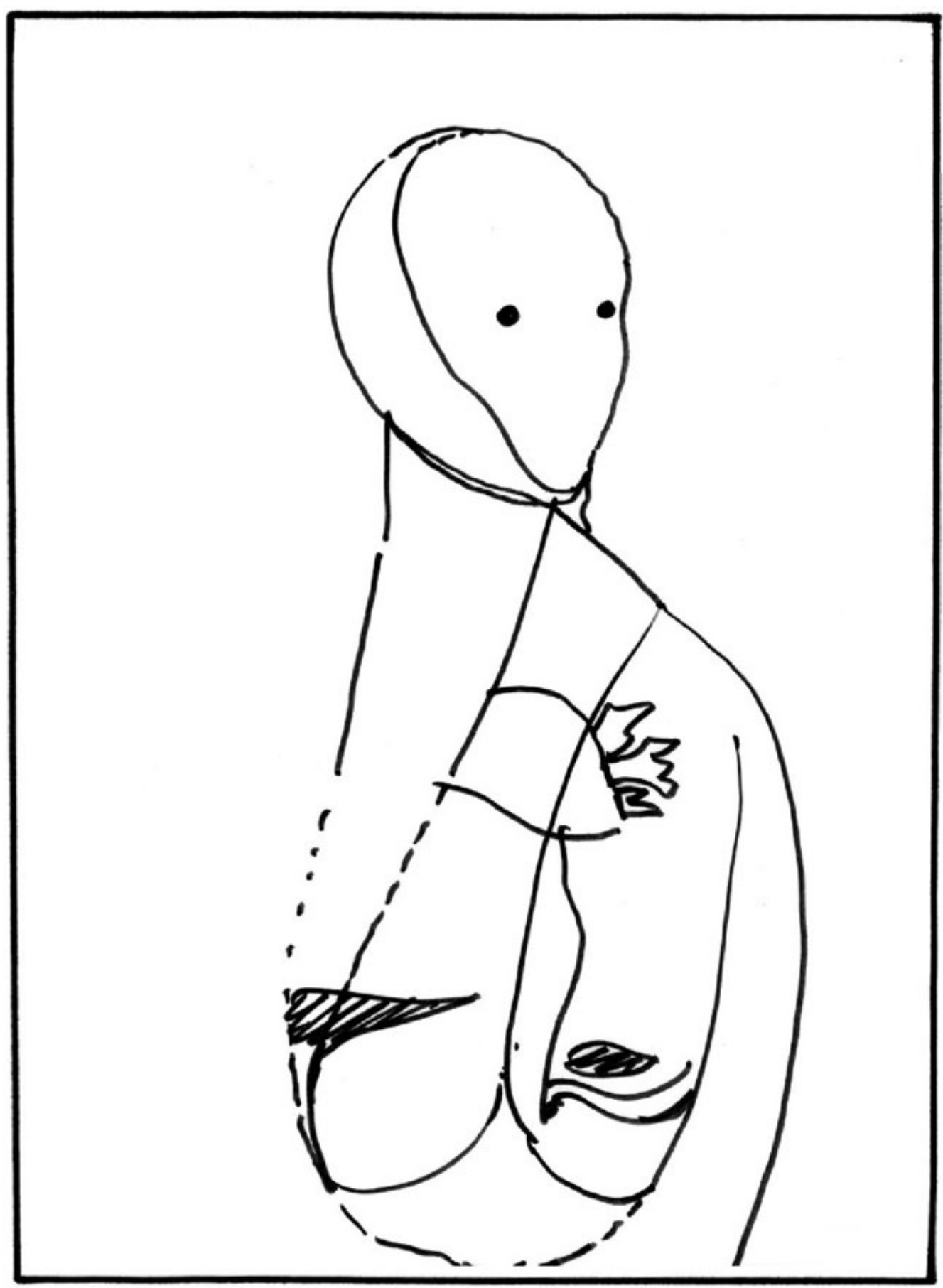

Figure 44. 'Lady with an Ermine.' Connotation: an upturned face.

differences between light and dark elements. In addition, the connotations of a serious and frightful face, similar to Cecilia's face, can be seen (figure 43), as well as smiling women's faces (figures 44 and 45). These faces look as if they were copied from the pictures by Picasso. They produce an 


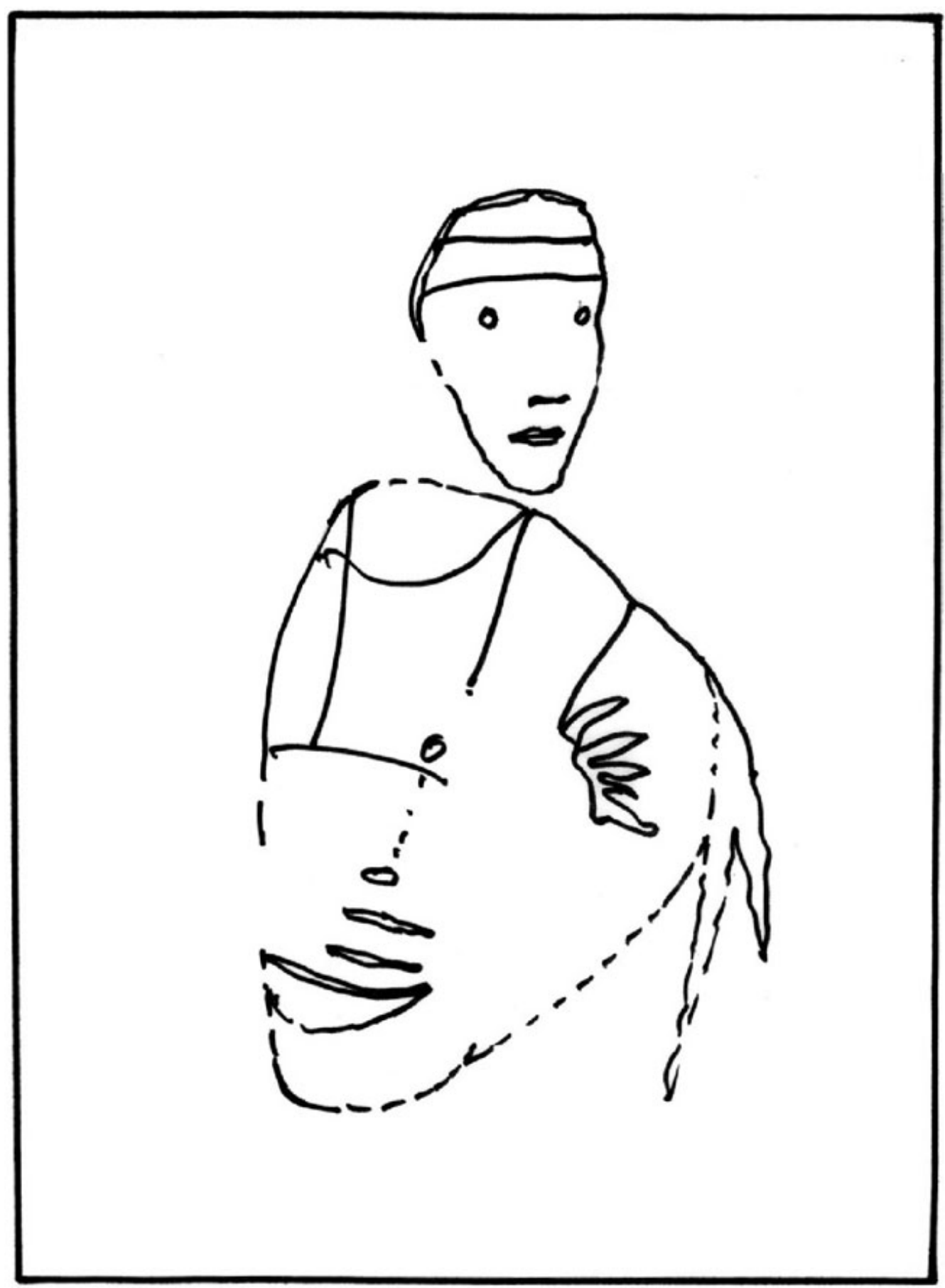

Figure 45. 'Lady with an Ermine.'Connotation: an upturned face.

impression of refined smiles. The atmosphere of celebration and refined aristocraticism is supported by the pattern of the whole lower part of the image (figure 46). By its complexity, this ornament equilibrates the head and face of Cecilia (in rotary s ymmetry). This assigns them a special 


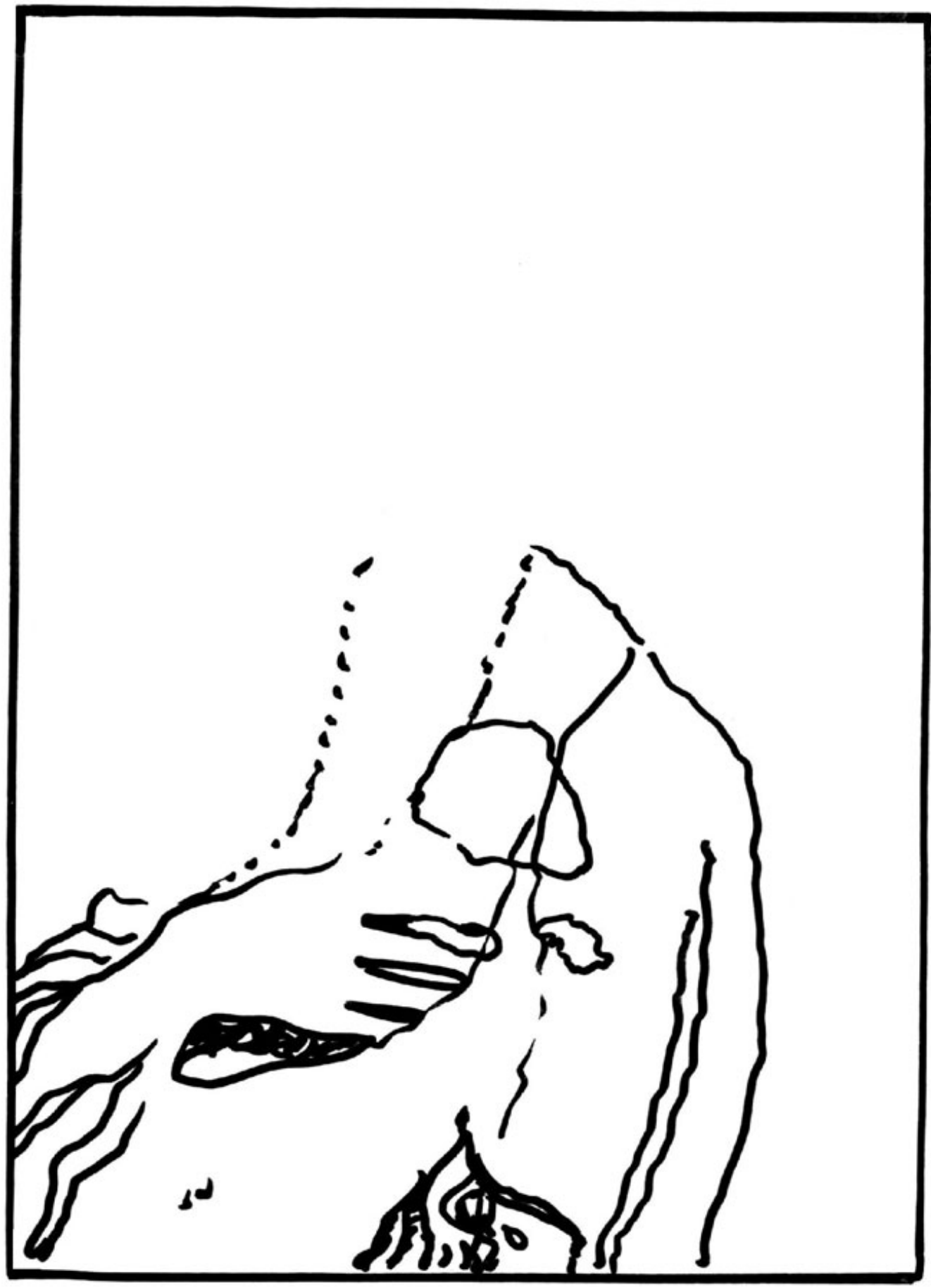

Figure 46. 'Lady with an Ermine.' Organizing configurations form a connotation. 


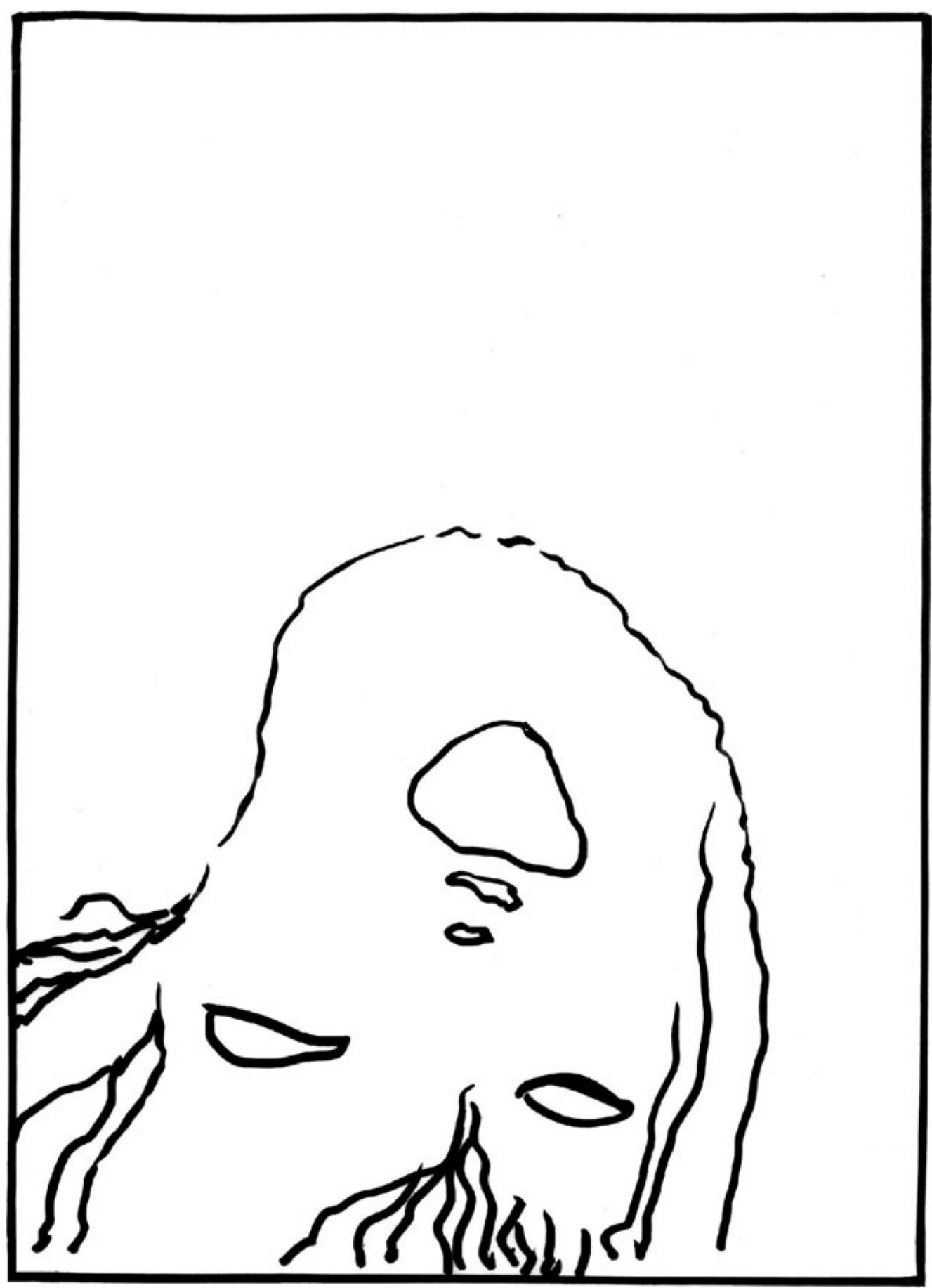

Figure 47. 'Lady with an Ermine.' The configuration of the lower part of the portrait resembles a woman lying head-on to a spectator. 
importance. Freely painted black lines of sleeves are contrasted to the lines of the upper part. They form exquisite ornaments. In these ornaments, an upturned head of a fervent woman with flowing hear appears, reminding of a nuptial bed (figure 47). This seems to be the main connotation of the portrait, because the liaison is its main context.

\section{Notes}

1. New Time is the period since the epoch of the Renaissance in Europe and before our time.

2. Leonardo’s ‘Codex Atlanticus’ (1480-1518, Biblioteca Ambrosiana, Milan, Italy).

3. Leonardo's ‘Treatise on painting' in 'Codex Vaticanus Urb. Lat. 1270' (Biblioteca

Apostolica Vaticana, Rim, Italy).

\section{References}

Alberti, Leon Battista (1935). Desyat knig o zodchestve [The ten books about architecture] architecture],Leon Battista Alberti. Matsa I. (ed.), Feodor A. Petrovskiy (trans.). Moscow: Academy of Architecture of USSR.

Ashby, Ross William (1956). Introduction to Cybernetics. London: Chapman and Hall.

Barbyshev, Eugeny N. and Somov, Georgij Yu. (1990). Formoobrazuyushie struktury I arkhitekturnaya forma [The form-making structures and the architectural form]. Architecture of USSA 2, 8-14.

Bongard, Mikhail M. (1967). Problema uznavaniya [The problem of recognition]. Moscow: Nauka.

Chandler, Daniel (1994). Semiotics for Beginners. Available online at http://visualmemory. co.uk/daniel/Documents/S4B/

Chomsky, Noam (1972). Language and Mind. New York: Harcourt, Brace, and Jovanovich.

Danesi, Marcel (1999). The interconnectedness principle and the semiotic Analysis of discourse. Applied Semiotics/Se miotique Applique e 6 (7), 394-401.

Deacon, David, Pickering, Mike, Golding, Peter, and Murdock, Graham (1999). Researching Communications: A Practical Guide to Methods in Media and Cultural Analysis. London: Arnold.

Dilthey, Wilhelm (1905) 1958. Der psychische Strukturzusammenhang. In Dilthey, W., Gesammelte Schriften, vol. 7, pp. 3-23. Gottingen: Vandenhoeck \& Ruprecht.

Eco, Umberto (1968). La strutture assente [The absent structure]. Milan: Bompiani.

Eco, Umberto (1973) 1977. Zeichen: Einfuhrung in einen Begriff und seine Geschichte. Frankfurt: Suhrkamp.

Eco, Umberto (1976) A theory of Semiotics. Bloomington:Indiana Univ. Press.

Greimas, Algerdas J. and Courtes, Joseph (1979). Se miotique, dictionnaire raisonne de la the orie du langage, vol. 1. Paris: Hachette.

Hjelmslev, Louis (1948) 1959. Structural analysis of language. In Hjelmslev, L., Essais linguistiques, pp. 27 -35. Copenhagen: Nordisk Sprogog Kulturforlag.

Il'in, Victor V. (1972). Ontologicheskie i gnoseologicheskie funktsii kategorii kachestva $i$ kolichestva [Ontological and gnoseological functions of catrgories of quality and quantity]. Moscow: Vysshaya shkola 
Ivanov, Vyacheslav V. (1978). Chet i nechet. Assimetriya mozga i znakovih system [Couples and uncouples. Asymmetry of a brain and sign systems]. Moscow: Sovetskoe Radio.

Ivanov, Vyacheslav V. (2008). Dualnye strukturi v antropologii: kurs lektsii, April-May 2005. [Double-natured structures in anthropology: course of lectures, April-May 2005]. Moscow: Russian State University for the Humanities.

Klaus, Georg (1973). Semiotik und Erkenntnistheorie. Munchen: Fink.

Kröber, Günter (1968). Die Kategorie "Struktur" und der kategorische Strukturalismus. Deutsche Zeitschrift fur Philosophie 16: 1310-25.

Leonardo da Vinci (1999). Selected works. A. A. Guber et al. (trans. and ed.), vol. 2. St. Petersburg: Neva; Moscow: OLMA-PRESS.

Levi-Strauss, Claude (1970). Anthropologie Structurale. Paris: Deux Plon.

Martinet, Andre (1962). A Functional View of Language. Oxford: Oxford University Press.

Martynov, Victor V. (1966). Kibernetika, semiotika, lingvistika [Cybernetics, semiotics, linguistics]. Minsk: Nauka Tehnika.

Miller, George A. (1956). The magical number seven, plus or minus two: Some limits on our capacity for processing information. Psychological Review 63, 81-97.

Moles, Abraham A. (1966). Teoriya informacii i esteticheskoe vospriyatie [The theory of information and the aesthetics perception]. Moscow: Mir.

Morris, Charles W. (1971). Writings on the General Theory of Signs. Paris: Mouton.

Nöth, Winfried (1998). Handbook of semiotics, Thomas A. Sebeok (ed.). Bloomington, IN: Indiana University Press.

Petitot-Cocorda, Jean (1985). Morphogenese du sense. Paris: Presses Univ. de France.

Piaget, Jean (1979). Theore du langage. Theorie de l'apprentissage. In Le debat entre Jean Piaget et Noam Chomsky, Massimo Piatelli (ed.), 53-64. Paris: Parmarim.

Quine, Willard Van Orman (1973). The Roots of Reference. LaSalle, IL: Open Court.

Rosenfeld, Azriel (1969). Picture Processing by Computer. New York/London: Academic Press.

Russell, Bertrand (2000 [1948]). Human Knowledge: Its Scope and Limits. Moscow: Terra. Saussure, Ferdinand de (1959). Course in general linguistics. New York: Philosophical library.

Shekhter, Mark S. (1967). Psihologicheskie problemy uznavaniya [Psychological problems of recognition]. Moscow: Prosveshenie.

Somov, Georgij Yu. (1975). Vizual'naya organizatsiya ob'ekta proektirovaniya. Problemy formoobrazovaniya i kompozitsii promishlennyh izdeliy [Visual organization of designed objects. Problems of form design and compositions of industrial products]. In Trudy instituta tekhnicheskoi estetiki [Works of the institute of technical aesthetics], Erik G. Yudin (ed.), 164-177. Moscow: ITA Press.

Somov, Georgij Yu. (1986a). Priroda razlichiy i tozhdestv v arkchitekturnoy kompozitsii [Nature of distinctions and identities in architectural composition]. In Teoriya kompozitcii $v$ sovetskoy arkhitekture [The theory of composition in the soviet architecture], Ludmila I. Kirillova (ed.), 32-41. Moscow: Stroiizdat.

Somov, Georgij Yu. (1986b). Plastika arkhitekturnoi formy v massovom stroitel'stve [Plastics of architectural form in mass design]. Moscow: Stroiizdat.

Somov, Georgij Yu. (1990). Problemy teorii arkhitekturnoy formy [Problems of the theory of architectural form]. In Forma $v$ arkhitekture [Form in architecture], Alexander G.

Rappaport and Georgij Yu. Somov (eds.), 164-334. Moscow: Stroiizdat.

Somov, Georgij Yu. (2001). Semiotics of architecture and architecture of semiotics. Semiotiche Berichte 1-4, 339-352.

Somov, Georgij Yu. (2003). Conviviality problem in the structure of semiotic objects. TRANS 15. Available online at http://www.inst.at/trans/15Nr/01_2/somov15.htm. 
Somov, Georgij Yu. (2005). Semiotic systems of works of visual art: Signs, connotations, signals. Semiotica 157 (1/4), 1-34.

Somov, Georgij Yu. (2006). Connotations in semiotic systems of visual art (by the example of works by M. A. Vrubel). Semiotica 158 (1/4), 147-212.

Somov, Georgij Yu. (2007a). Semiotic systemity of visual art works (case study of The Holy Trinity by A. Rublev). Semiotica 166 (1/4), 1-79.

Somov, Georgij Yu. (2007b). Structures and semiotic systems. Semiotica 167 (1/4), 1-35.

Tyukhtin, Victor S. (1977). Otrazhenie, sistemy, kibernetika [Reflections, systems, and cybernetics]. Moscow: Nauka.

Ursul, Arcadij D. (1971). Informatsiya [Information]. Moscow: Nauka.

Vitruvius, Marcus Pollio (2004). The Ten Books on Architecture. Boston: Elibron Classics.

Voronin, Leonid G., Napalkov, Anatolij V., and Tselkova, Nina V. (1982). Algoritmicheskiy analiz raboty mozga [Algorithmic analysis of brain work]. Moscow: Moscow State University.

Wallace, Robert (1975). The World of Leonardo, 1452-1519. Alexandria, VA: Time-Life. Witcombe, Christopher L. C. E. (2007). Water in art. Magister Botanicus (Sept.), 85-94. Witcombe, Christopher L. C. E. (n.d.). Leonardo da Vinci and water. Available online at http://witcombe.sbc.edu/water/artleonardo.html.

Zöllner, Frank (1991). Rubens reworks Leonardo: 'The fight for the standard.' Achademia Leonardi Vinci 4, 177-190.

Georgij Yu. Somov (b. 1946) is an associate professor at Moscow State Building University <georgij.somov@gmail.com>, home page: gsomov.com. His research interests include theory of architecture and urban design, semiotics of architecture and visual art, and theoretical semiotics. His recent publications include 'Semiotic systems of works of visual art: Signs, connotations, signals' (2005); 'Connotations in semiotic systems of visual art (by the example of Works by M. A. Vrubel)' (2006); 'Semiotic systemity of visual artworks: Case study of The Holy Trinity by Rublev' (2007); and ‘Structures and semiotic systems’ (2007). 